Andrews University

Digital Commons @ Andrews University

1998

\title{
Analysis of University Personnel's Perception of Institutional Factors Impacting Student Persistence/Retention
}

Jose Melendez

Andrews University

Follow this and additional works at: https://digitalcommons.andrews.edu/dissertations

Part of the Educational Leadership Commons, and the Higher Education Commons

\section{Recommended Citation}

Melendez, Jose, "Analysis of University Personnel's Perception of Institutional Factors Impacting Student Persistence/Retention" (1998). Dissertations. 570.

https://digitalcommons.andrews.edu/dissertations/570

https://dx.doi.org/10.32597/dissertations/570

This Dissertation is brought to you for free and open access by the Graduate Research at Digital Commons @ Andrews University. It has been accepted for inclusion in Dissertations by an authorized administrator of Digital Commons@ Andrews University. For more information, please contact repository@andrews.edu. 


\section{Andrews \$university}

Seek Knowledge. Affirm Faith. Change the World.

Thank you for your interest in the

\section{Andrews University Digital Library of Dissertations and Theses.}

Please honor the copyright of this document by not duplicating or distributing additional copies in any form without the author's express written permission. Thanks for your cooperation. 


\section{INFORMATION TO USERS}

This manuscript has been reproduced from the microfilm master. UMI films the text directly from the original or copy submitted. Thus, some thesis and dissertation copies are in typewriter face, while others may be from any type of computer printer.

The quality of this reproduction is dependent upon the quality of the copy submitted. Broken or indistinct print, colored or poor quality illustrations and photographs, print bleedthrough, substandard margins, and improper alignment can adversely affect reproduction.

In the unlikely event that the author did not send UMI a complete manuscript and there are missing pages, these will be noted. Also, if unauthorized copyright material had to be removed, a note will indicate the deletion.

Oversize materials (e.g., maps, drawings, charts) are reproduced by sectioning the original, beginning at the upper left-hand comer and continuing from left to right in equal sections with small overlaps. Each original is also photographed in one exposure and is included in reduced form at the back of the book.

Photographs included in the original manuscript have been reproduced xerographically in this copy. Higher quality 6" 69 "black and white photographic prints are available for any photographs or illustrations appearing in this copy for an additional charge. Contact UMI directly to order.

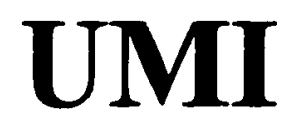

A Bell \& Howell Information Company

300 North Zeeb Road, Ann Arbor MI 48106-1346 USA

$313 / 761-4700 \quad 800 / 521-0600$ 
Andrews University

School of Education

\title{
ANALYSIS OF UNIVERSITY PERSONNEL'S PERCEPTION \\ OF INSTITUTIONAL FACTORS IMPACTING STUDENT PERSISTENCE/RETENTION
}

\author{
A Dissertation \\ Presented in Partial Fulfillment \\ of the Requirements for the Degree \\ Doctor of Philosophy
}

by

Jose Melendez

October 1997 
UMI Number: 9834278

Copyright 1997 by

Melendez, Jose

All rights reserved.

UMI Microform 9834278

Copyright 1998, by UMI Company. All rights reserved.

This microform edition is protected against unauthorized copying under Title 17, United States Code.

\section{UMI \\ 300 North Zeeb Road \\ Ann Arbor, MI 48103}


Copyright by Jose Melendez 1997

All Rights Reserved 


\title{
ANAL YSIS OF UNIVERSITY PERSONNEL'S PERCEPTION \\ OF INSTITUTIONAL FACTORS IMPACTING STUDENT PERSISTENCE/RETENTION
}

\author{
A dissertation \\ presented in partial fulfillment \\ of the requirements for the degree \\ Doctor of Philosophy
}

by

Jose Melendez

APPROVAL BY THE COMMITTEE:
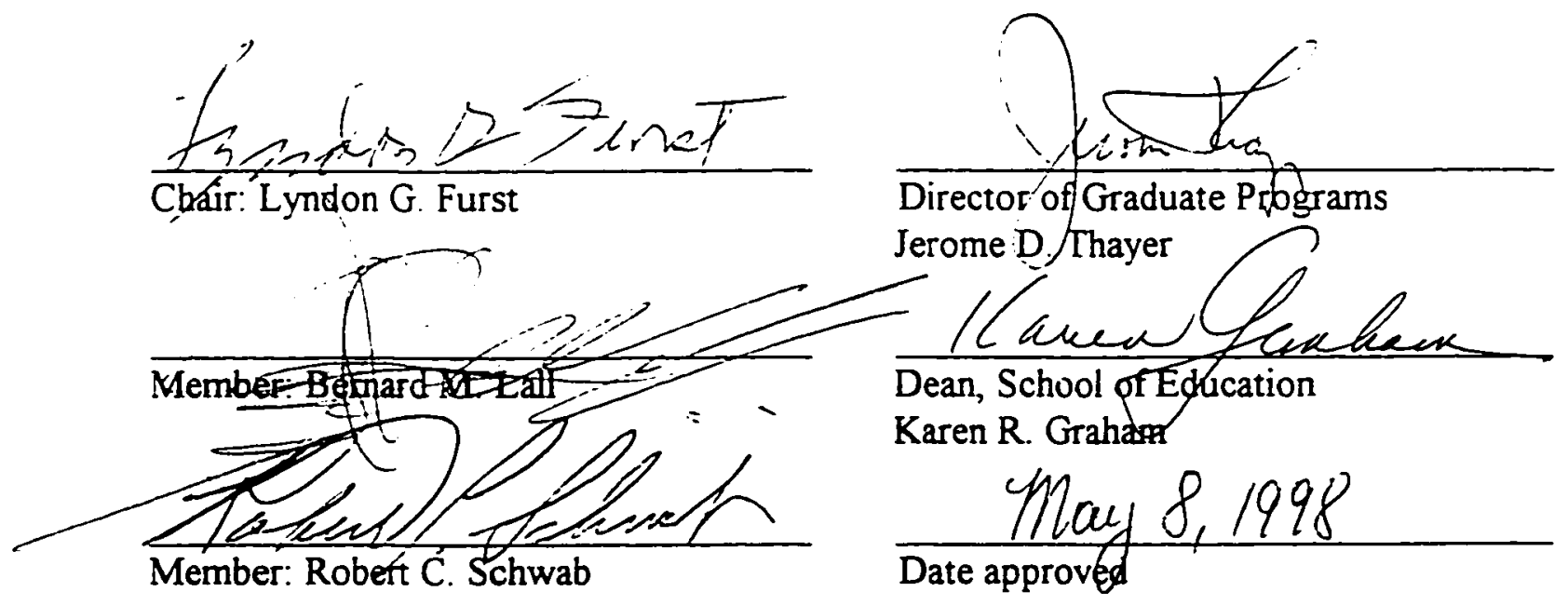


\section{ABSTRACT}

\section{ANALYSIS OF UNIVERSITY PERSONNEL'S PERCEPTION OF INSTITUTIONAL FACTORS IMPACTING STUDENT \\ PERSISTENCE/RETENTION}

by

Jose Melendez

Chair: Lyndon G. Furst 


\title{
ABSTRACT OF GRADUATE STUDENT RESEARCH
}

Dissertation

\author{
Andrews University \\ School of Education \\ Title: ANALYSIS OF UNIVERSITY PERSONNEL'S PERCEPTION OF \\ INSTITUTIONAL FACTORS IMPACTING STUDENT PERSISTENCE/ \\ RETENTION \\ Name of researcher: Jose Melendez \\ Name and degree of faculty chair: Lyndon G. Furst, Ed.D. \\ Date completed: October 1997
}

Problem

Universities are assessing which institutional efforts are most directly impacting student attrition. This study identified important institutional factors impacting student attrition/retention using university personnel. It also measured personnel perception of how satisfactorily addressed were institutional factors impacting student persistence.

\section{Methods}

A quantitative survey methodology was used, and a survey instrument was developed and validated in the study. Tinto's 1987 model of Student Departure and the Melendez model of Transaction Satisfaction toward Student Persistence were used to 
guide the development of the instrument. The Melendez model was formulated as a rival hypothesis and an alternative tool for the study of student attrition. It posited that institutional efforts toward students' academic and personal satisfaction have a direct impact on student persistence.

The new model was used to interpret the results. The subjects were administrators, faculty, and professional staff and clerical/technical staff from a Midwestern public university. The data were analyzed using factor and reliability analyses, analysis of variance, $t$-tests, multivariate and discriminant analyses.

\section{Results}

Overall, the university personnel perceived the instrument items as important institutional factors impacting student retention. Conversely, they generally did not perceive the university's efforts as highly satisfactorily address factors.

The seven most important factors impacting student retention are academic advising, financial aid services, students' commitment to their education, instructor's effectiveness, students' attitude toward education, administrators/faculty/staff caring about students' progress, and students' class attendance. The four most satisfactorily addressed institutional factors impacting student persistence were library services, registration services, campus safety and security services, and instructor effectiveness.

\section{Conclusions}

Based on this study ( 1 ) the new instrument yielded adequate statistical results, (2) in general, university personnel perceived institutional factors impacting student retention as important and were generally not highly satisfied with the university's efforts in 
addressing factors impacting student retention, (3) the data were adequately interpreted by the Melendez model, and (4) a similar study should be conducted to refine the instrument and to examine student retention from the perspective a customer/service transactional satisfaction relationship using both students and university personnel 
To my fantastic and wonderful wife, Carmen L. Melendez, our loving mother, Vicky Melendez, and father, Jose

Melendez, also to our marvelous children: Alfonso

David, Yderlin, Jose F., Jenny Y., and M. Alberto and my darling sisters: Veronica and Margarita 


\section{TABLE OF CONTENTS}

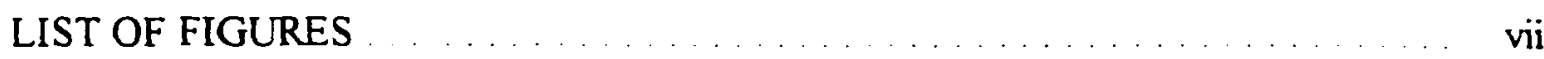

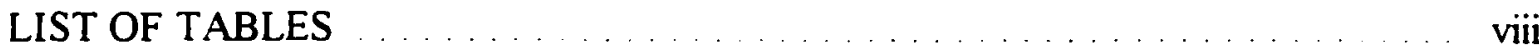

ACKNOWLEDGMENTS .......................

Chapter

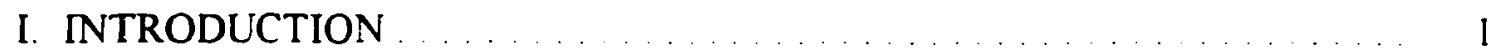

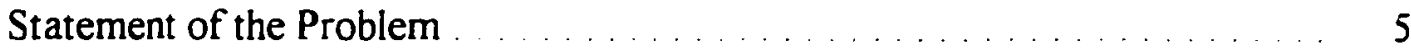

Purpose of the Study . . . $\ldots \ldots \ldots \ldots \ldots \ldots \ldots$

Theoretical Framework ........................ 7

Research Questions and Null Hypotheses . . . . . . . . . . . . . . . 12

Research Questions . . . . . . . . . . . . . . . . . . . . . 12

Null Hypotheses $\ldots \ldots \ldots \ldots \ldots$

Significance of the Study $\ldots \ldots \ldots \ldots \ldots \ldots \ldots \ldots \ldots \ldots$

Definition of Terms .............................. 14

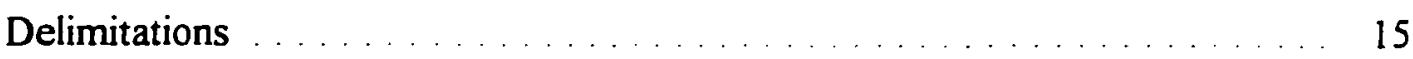

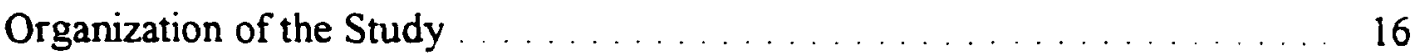

II. REVIEW OF RELATED LITERATURE $\ldots \ldots \ldots \ldots \ldots \ldots \ldots \ldots \ldots$

Theoreticians and Models . . . . . . . . . . . . . . . . . . . . . . . 20

Atheoretical Studies . . . . . . . . . . . . . . . . . . . . . . 20

Major Theorists, Models, and Researchers . . . . . . . . . . . . 22

Pascarella and Terenzini's Institutional Integration Scale . . . . . . . . . 33

Tinto's Revised Model . . . . . . . . . . . . . . . . . . . . . . . . . . 33

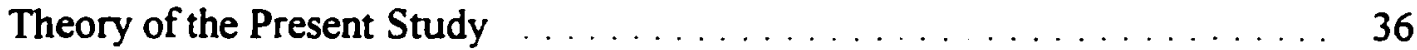

Related Studies $\ldots \ldots \ldots \ldots \ldots \ldots \ldots \ldots \ldots \ldots \ldots \ldots \ldots \ldots$

Summary . . . . . . . . . . . . . . . . . . . . . . . 46

III. RESEARCH METHODOLOGY AND DESIGN $\ldots \ldots \ldots \ldots \ldots \ldots \ldots \ldots \ldots .49$

Population . . . . . . . . . . . . . . . . . . . . . 49 


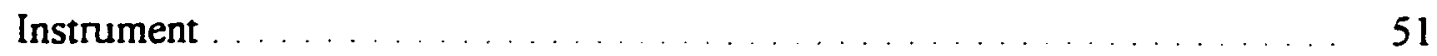

Instrument Development $\ldots \ldots \ldots \ldots \ldots \ldots \ldots \ldots \ldots \ldots$

Research Questions . . . . . . . . . . . . . . . . . . . 54

Null Hypotheses . . . . . . . . . . . . . . . . . . . . . . . . . . . 54

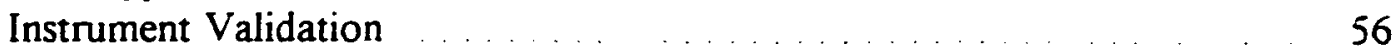

Importance Scale . . . . . . . . . . . . . . . . . . . . . . 59

Satisfaction Scale . . . . . . . . . . . . . . . . . . . . . . 62

Summary ................................ 82

Collection of Data . . . . . . . . . . . . . . . . . . . . . . . 84

Research Questions and Null Hypotheses . . . . . . . . . . . . . . . 87

Research Questions ............................. 87

Null Hypotheses . . . . . . . . . . . . . . . . . . . . . . . . 87

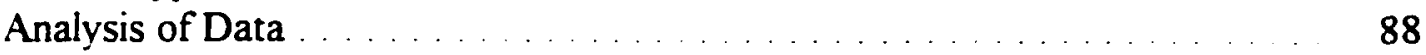

Limitations . . . . . . . . . . . . . . . . . . . . . . . . 91

Assumptions . . . . . . . . . . . . . . . . . . . . . . .

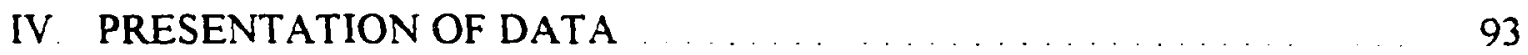

Demographic $\operatorname{Results~.~.~.~.~.~.~.~.~.~.~.~.~.~.~.~.~.~.~.~.~.~.~.~.~.~} 93$

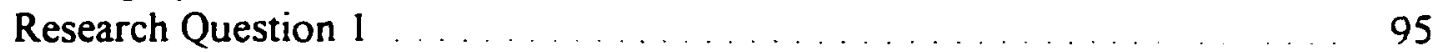

Research Question $2 \ldots \ldots \ldots \ldots \ldots \ldots$

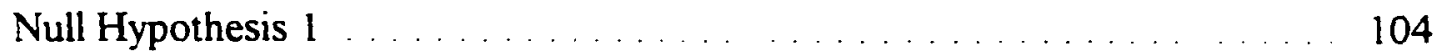

Null Hypothesis $\mathbf{2} \ldots \ldots \ldots \ldots$

University Status Group . . . . . . . . . . . . . . . . . . . . . 111

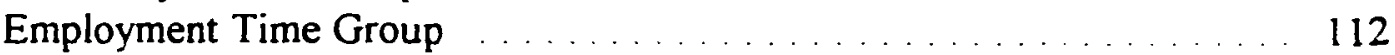

Gender Group . . . . . . . . . . . . . . . . . . . . . . . . . . 116

Divisions, Schools, and Programs Group ... . . . . . . . . . . 117

Teach Introductory Level Course(s) Group . . . . . . . . . . . . . . . . . 126

Null Hypothesis 3 . . . . . . . . . . . . . . . . . . . . . . . . . . . . . . . . . 129

University Status Group . . . . . . . . . . . . . . . . . . . 131

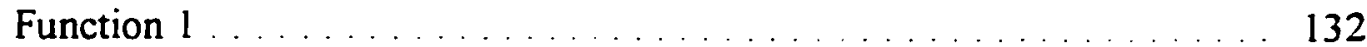

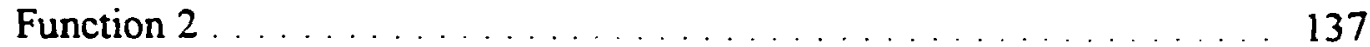

Employment Time Group $\ldots \ldots \ldots \ldots \ldots \ldots \ldots \ldots \ldots \ldots$

Gender Group . . . . . . . . . . . . . . . . . . . . . . . . . . . . . . . . 144

Divisions, Schools, and Programs Group . . . . . . . . . . . . . . . . . . . 144

Teach Introductory Level Course(s) Group . . . . . . . . . . . . . . . . . . . . . 149

Summary of Findings $\ldots \ldots \ldots \ldots \ldots \ldots \ldots \ldots$

V. SUMMARY, CONCLUSIONS, AND RECOMMENDATIONS ...... 158

Methodology . . . . . . . . . . . . . . . . . . . . . . . . . . 162

Instrument . . . . . . . . . . . . . . . . . . . . . . 163

Research Question $1 \ldots \ldots \ldots \ldots \ldots \ldots \ldots \ldots \ldots \ldots$ 


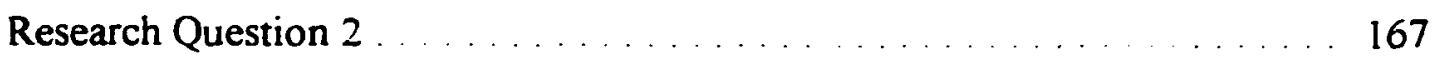

Null Hypothesis 1 . . . . . . . . . . . . . . . . . . . . . . . . . . . . 169

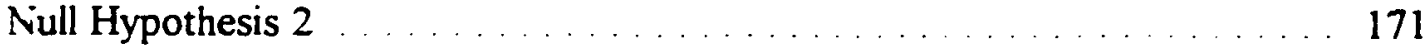

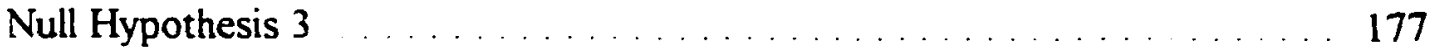

Conclusions . . . . . . . . . . . . . . . . . . . . . 183

Recommendations . . . . . . . . . . . . . . . . . . . . . . . 184

Recommendations for Administrative Practice . . . . . . . . . . . . . . . 184

Recommendations for Further Research . . . . . . . . . . . . . . . . . . 186

Appendix

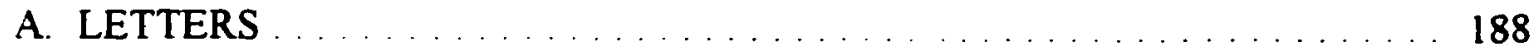

B. SURVEY . . . . . . . . . . . . . . . . . . . . . . . . . 194

C. COMPUTER PRINTOUTS . . . . . . . . . . . . . . . . . . . . . . . 199

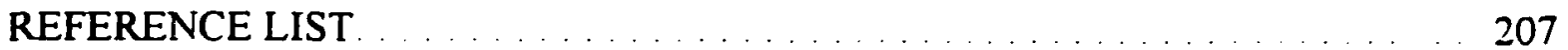

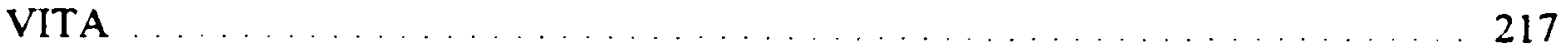




\section{LIST OF FIGURES}

1. Tinto's Model of Institutional Departure . . . . . . . . . . . . . . . . 9

2. Melendez's Model of Transactional Satisfaction toward Student

Persistence . . . . . . . . . . . . . . . . . . . . . . . . . . . . 11

vii 


\section{LIST OF TABLES}

1. Reliability Analysis: Importance--Total . . . . . . . . . . . . . . . . 61

2. Reliability Analysis: Importance--Institutional Subscale . . . . . . . . . . . 63

3. Reliability Analysis: Importance--Student Subscale. . . . . . . . . . . . . . . 64

4. Reliability Analysis: Satisfaction--Total. . . . . . . . . . . . . . . . . 66

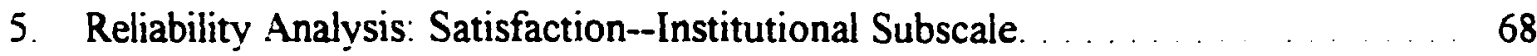

6. Reliability Analysis: Satisfaction--Student Subscale. . . . . . . . . . . . . . 69

7. Factor Analysis: Importance-41 Items . . . . . . . . . . . .

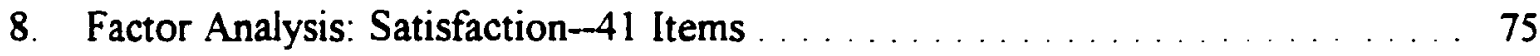

9. Factor Loading: Importance--Eight Factors $\ldots \ldots \ldots \ldots \ldots \ldots \ldots$

10. Factor Loading: Satisfaction--Eight Factors $\ldots \ldots \ldots \ldots \ldots \ldots \ldots \ldots$

11. Factor Loading: Importance--Two Factors. . . . . . . . . . . . . . . . 83

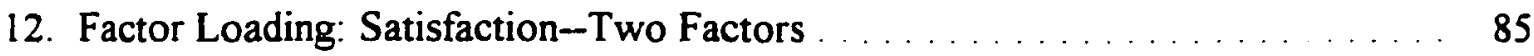

13. Demographic Groups of the Subject Population . . . . . . . . . . . . . . 96

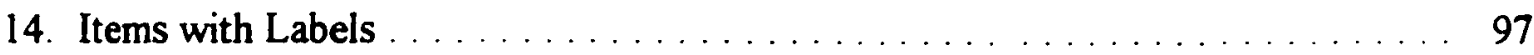

15. Rank Descending Means: Importance $\ldots \ldots \ldots \ldots \ldots \ldots \ldots \ldots \ldots \ldots$

16. Rank Descending Means: Satisfaction $\ldots \ldots \ldots \ldots \ldots \ldots \ldots \ldots$

17. Rank Descending Means: Importance/Satisfaction . . . . . . . . . . . . 107

18. Rank Descending Means: Satisfaction/Importance . . . . . . . . . . . . . . 109 
19. MANOVA $\mathrm{t}-$ Test (Wilks): Importance Total Scale

20. One-way ANOVA: Importance--WKR 41 Items.

21. One-way ANOVA: Importance-YRS 41 Items

22. I-Test: Importance--Gender 41 Items

23. Discriminant Analysis: Importance Cases-- DEPT

24. Discriminant Functions: Importance--DEPT

25. Discriminant Function Coefficients: Importance--DEPT

26. Discriminant Functions Group Means (Centroids): Importance--DEPT

27. One-way ANOVA: Importance--DEPT 41 Items

28. I-Test: Importance--Teach Introductory Level Course(s) 41 Items

29. MANOVA 1 -Test (Wilks): Satisfaction Total Scale

30. Discriminant Analysis: Satisfaction Cases--WKR

31. Discriminant Functions: Satisfaction--WKR

32. Discriminant Function Coefficients: Satisfaction--WKR.

33. Discriminant Functions Group Means (Centroids): Satisfaction--WKR

34. One-way ANOVA: Satisfaction-WKR 41 Items

35. One-way ANOVA: Satisfaction--YRS 41 Items

36. 1-Test: Satisfaction-Gender 41 Items

37. One-way ANOVA: Satisfaction-DEPT 41 Items . 150

38 t-Test: Satisfaction-Teach Introductory Course(s) 41 Items 


\section{ACKNOWLEDGMENTS}

I will be eternally grateful to the many people who believed in me to foresee the day of this completion. I would like to give thanks to my committee: Dr Lyndon G. Furst, Dr. Bernard M. Lall, and Dr. Robert C. Schwab for their encouragement, patience, and scholastic expertise in this study

A special thanks goes to "The Conductor," Dr. Furst, my chair and adviser, who ensured the timely completion of this dissertation. I am especially indebted to Karen White and her staff in having the vision to parent this project.

On a more personal level, I wish to thank my wife, Carmen, whose encouragement has inspired me to reach a new heights in professional development. It was only because of her personal sacrifice and assistance that this dream came true. I want to thank my parents for the solid family foundation and love that gave me the stamina to endure until the end. For you mom and dad, "I did it."

However, the height and depth and breath of my gratitude goes to our Heavenly Father and our Lord Jesus Christ who created us with such marvelous minds and makes a way when there is no way, praise be to God, Lord Almighty. 


\section{CHAPTER I}

\section{INTRODUCTION}

The need to increase student persistence in institutions of higher education has become a growing concern for educational administrators. With the increased competition for post-secondary students and the increasing demand for financial accountability from funding sources of higher education, student attrition/retention research has become a necessity (Matthew, 1993). McJamerson (1991) reported a need for institutions to assess their campuses concerning the problem of student attrition. He suggested that retention research should include surveying institutional personnel as well as students before developing student persistence strategies and policies (p. 36). Lall and Lall (1994) stated that leadership's function is to send up 'trial balloons" to identify workers' positions on specific issues before developing organizational strategies and plans (pp. 76-78).

In many public institutions of higher education, budgets and appropriations are formulae driven according to student head count (White \& Mosely, 1995, p. 400). Therefore, colleges and universities that reduce student attrition maintain larger portions of their revenue for their efforts since monies are distributed in accordance with the number of students attending. This challenges institutions of higher education with open admissions, minimal admission criteria, and first-year attrition rates of $30 \%$ to $60 \%$ to 
assess their present status and develop efficient student retention programs and recruitment practices.

Terenzini (1982) stated that the development of effective student retention programs in institutions of higher education is the most efficient way to manage financially the institutional budget. Retaining enrolled students is less costly than finding and enrolling new or transfer students (p. 55).

Since obtaining a college degree has become an increasing demand on American workers, "a college degree is coming to have much the same status as a high school diploma had earlier in the century" (Nehila, 1996, p. 3). A college degree may be important during periods of high unemployment. In 1992, about $3.2 \%$ of people with college degrees were unemployed compared with $6.2 \%$ of those with only high school diplomas (Nehila. 1996). With the changes in the labor market and the political demands to employ people who were formerly excluded from higher education, a greater portion of the population is seeking advanced degrees in institutions of higher education (Collis, 1991; Nehila, 1996; Tinto, 1987).

The issue of attrition/retention of students in higher education goes back to the later part of the 1800 s. Thomas Jefferson advocated that democracy needs an educated citizenry to flourish (White, 1993, pp. 1-5). The Morril Land Grant Act of 1862 created opportunities for many people to attend colleges who were previously excluded from attending institutions of higher learning.

The land grant act allowed states to develop local public institutions of higher education. With this opportunity came the problem that many individuals enrolled in 
college without the necessary academic and social preparations or resources to succeed academically.

During the 1960s and 1970s, retention was not a major issue since enrollment grew rapidly as many postwar baby boomers sought admission into institutions of higher education (Nehila, 1996, p. 3). The major administrative thrust was recruitment. When students dropped out, the institution quickly replaced them with another student (White, 1993, p. 2)

However, in the early 1980s, the student population of higher education began to shrink as the large baby boomer population was getting beyond traditional college-age students (Nehila, 1996). Moreover, the succeeding generations of college students were even smaller (Keller \& McKeown, 1984; White, 1993, pp. 3-5). Along with a reduced student population, the national student departure percentages for first-year students ranged from $34 \%$ to $60 \%$. To complicate the issue, many federally funded training and educational programs were and are competing for post-secondary students (Beal \& Noel, 1980; Nehila, 1996)

In response to student attrition, institutions began to develop elaborate and expensive marketing strategies to obtain a competitive advantage over other institutions. Some institutions focused on accommodating more non-traditional students in the hope of replacing the loss of traditional-age students. However, non-traditional students have a higher dropout rate than traditional students (DeVaugh, 1995). Eventually, the efforts to recruit new students while losing $30 \%$ to $60 \%$ of the first-year student body became financially inefficient. As a result, institutions began to look at the problem of student 
attrition more closely with the hope of developing effective strategies for retaining enrolled students (Nehila. 1996).

With the increasing high costs of higher education being underwritten by the federal government, federal funding sources also began to monitor closely how many students were persisting until degree completion. Presently, national legislation requires institutions of higher education to conduct statistical studies on the rates of student graduation (White, 1993). Hence, administrators and researchers of higher education began to examine seriously the causes of and solutions to student attrition (Beal \& Noel, 1980; Tinto, 1975).

The following are four benefits for investigating and addressing the student attrition/retention issue:

1. Economic factors: Administrative, recruiting, and admission officials realized that all the time, money, and effort put into recruiting were not producing the desired goal of increasing student persistence. Administrators found that retaining currently matriculated students was more cost effective than recruiting new students. Maintaining current students also provided a more stable funding base.

2. Institutional climate factors: Administrators believed that retaining students improved the institution's climate and faculty morale.

3. Student factors: Students would feel a great sense of achievement and loyalty toward the institution as they fulfilled their educational goals (Nehila, 1996; Tinto, 1987).

4. Societal factors: With more educated citizens, society would experience greater growth and more positive economic and social benefits (White, 1993). 


\section{Statement of the Problem}

Researchers have expressed the need for institutions to provide quality institutional programs by critically examining the extent to which the institutions were contributing to the students' intellectual and personal development (Astin et al., 1980, p. 132; Spanbauer, 1996). Past student retention research has almost exclusively focused on the students as subjects. The vast majority of related literature on retention implied that the students' academic and social characteristics were the primary factors directly impacting student attrition (Boyle, 1988; Lagowski, 1992; Noel, Levitz, Saluri, \& Associates, 1985; Tinto, 1993; Wyatt, 1987).

However, according to Roueche and Baker (1987), leadership is the key in the development and implementation of institutional programs that enhance student success Astin et al. (1980) recommended the need to study the effects of the relationship between leadership in institutions of higher learning and student success since only a few studies used administrators, faculty, or support staff as research subjects. Nanus (1992) advocated that all the stakeholders in an enterprise should be included when a new vision, institutional endeavor, or problem is to be undertaken (p. 64).

Bean (1982a) suggested the necessity for researchers to link student persistence with the institutional environment by identifying institutional factors (efforts or services) that directly enhanced student success and contributed to student persistence. Thus, when student satisfaction and success are achieved, greater student persistence is the outcome (Noel et al., 1985). Therefore, providers of higher education in public institutions must 
continually reevaluate and improve all aspects of the institutional environment in order to increase student persistence and retention significantly.

The latest undergraduate retention reports from a Midwestern public commuter university showed a slow and continued decline in student retention percentages of firstyear students from one year to the next: Fall 1993, 57.6\%; Fall 1994, 56.7\%; and Fall $1995,54.2 \%$. To reduce student attrition, administrators sought to first understand why students drop out or stop out of institutions of higher education (Stodt \& Klepper, 1987). Although most studies on student persistence/attrition have focused on students as their research subjects, some researchers have emphasized the need to study the perception of institutional personnel (i.e., administrators, faculty, or staff) as it relates to institutional factors impacting student persistence before drafting strategic institutional plans (Noel, 1978; Noel et al., 1985)

\section{Purpose of the Study}

The purpose of this study was to identify the least and most important institutional factors impacting student attrition/retention, and to identify the least and most satisfactorily addressed factors impacting student persistence at this university. Also, the study sought to determine if there were significant differences between the importance scores and the satisfaction scores, and if there were significant differences among the subgroups of five demographic groups for the Importance and Satisfaction Scales.

To conduct this research, a survey instrument was developed and validated in the study. The subjects for the study were personnel from a Midwestern university, which 
consisted of the entire population of administrators, faculty, professional staff. and clerical/technical staff.

Moreover, this was an exploratory study in which a new synthesized student persistence/departure model was created. Also, since no instrument was available to measure university personnel's perception of retention factors, an extensive process of instrument development and validation was performed in order to give greater reliability and validity for the generalization of the results. Some of the findings were the foundations for recommendations for further research.

The validation process of the instrument confirmed the identity of a comprehensive judgmental list of salient institutional factors impacting student attrition. Also, the data were analyzed to determine the relationship of the importance scores and the satisfaction scores to student persistence. The results can provide administrators of higher education with greater insight as to what particular personnel development training, institutional programs, or activities will produce the most significant improvement in student retention.

\section{Theoretical Framework}

Tinto (1975) posited the first widely accepted theory and model on student departure. He developed his model by synthesizing the current theories and models into one comprehensive model (Bean, 1980). The model was largely posited on Durkheim's (1961) studies on suicide and Spady's (1970) sociological theory that shared group values and friendship relationships were synonymous with student dropout decisions (Bean, 1982a, p. 21) 
Fishbein and Ajzen (1975) and Bean (1983) later modified Tinto's (1975) model to include other specific factors that impacted student academic and social integration (Hossler, Bean, \& Associates, 1990, p. 151). Later, Tinto (1987) revised his 1975 model of institutional departure by using Van Gennep's (1960) studies on students' rites of passage as the locus of control for student departure/persistence decisions. Again, Tinto (1987) synthesized other attrition/retention studies to come up with his 1987 longitudinal Model of Institutional Departure (p. 114). (See Figure 1.)

This model claimed that student attrition in higher education was an outcome of a longitudinal interactive process between the students' pre-entry attributes, intentions, educational goals and commitments, and their level of institutional academic and social integration. The individual's interactive institutional experiences and external commitment would modify students' initial intentions and commitments, at which time they again would decide to continue or depart from institutions of higher education. Thus, Tinto's (1987) model posited that the higher the degrees of student academic and social integration, the lower would be the likelihood of student departure (pp. 112-116)

Tinto (1987) commented on the tendency of attrition/retention researchers to "overlook the role the institution plays in the withdrawal process" (p. 86). Similarly, Noel (1978) advocated that a concerted effort to increase student retention should force "an institution to examine itself closely, and what it observes will not always be pleasant or easy to accept" (p. 87). Jose (1978) reported 'that the attitude of faculty, administrators, and staff toward students is a significant factor in student retention" (p. 57). Hossier et al. (1990) emphasized that "retention is everyone's business" and that "fitting in depends 


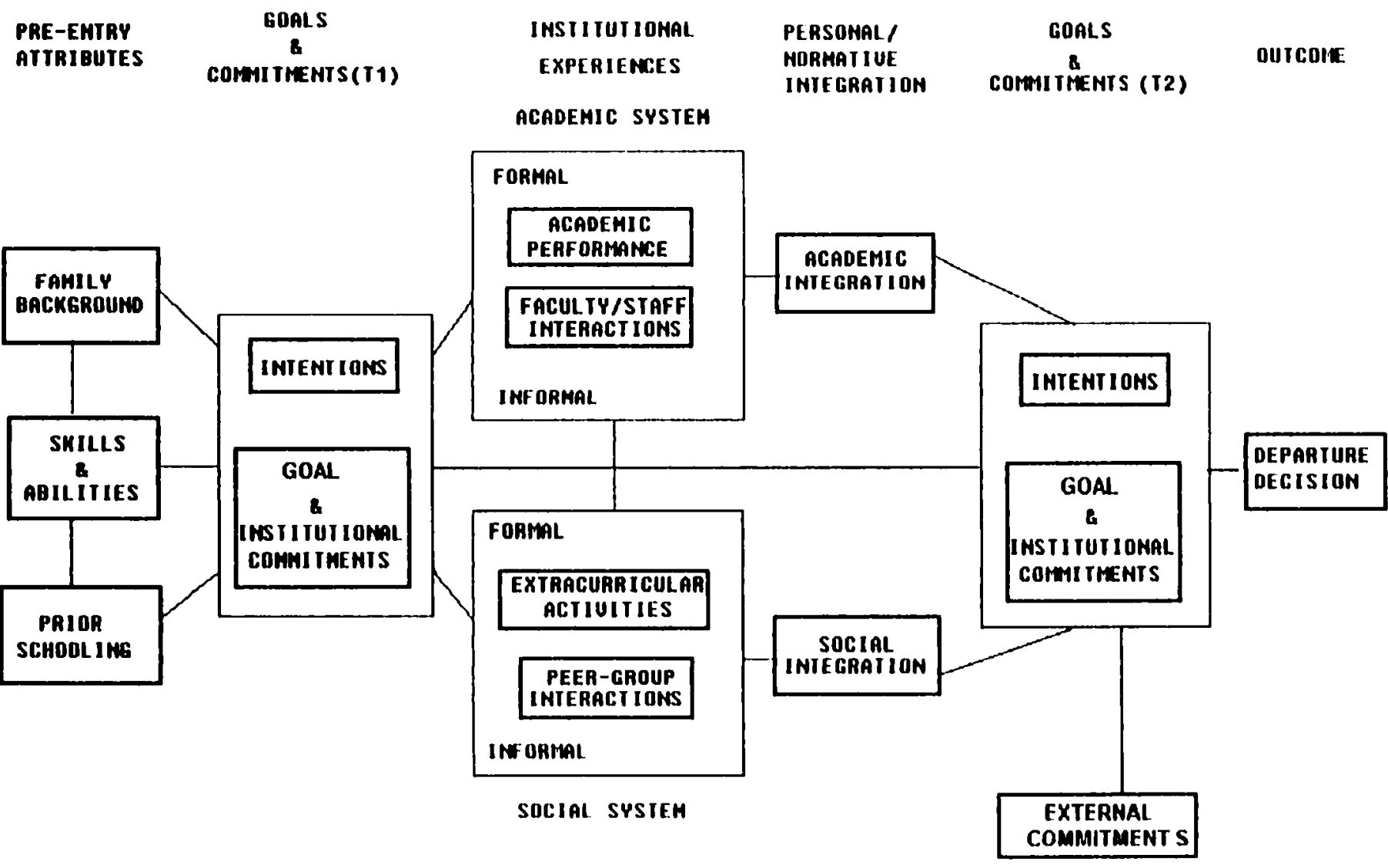

TIME (I)

Figure 1. Tinto's (1987) Model of Institutional Departure. 
on the student on one hand and the institution on the other" (p. 147). Stodt and Klepper (1987) advocated that academic and student affairs administrators should work in partnership to increase retention. Lagowski (1973) acknowledged that faculty members with caring attitudes toward students can significantly influence students' decisions to continue their studies. Cabrera (1992) reported student persistence as the result of student and institutional environmental interaction. White and Mosely (1995) stated, "A large percentage of drop outs occur in the first eight weeks of college" (p. 402). This implied that administrators should identify what the institution can do to identify institutional factors that highly influence attrition during the first 8 weeks of class.

Stiefelmeyer (1993), who conducted research on retention using presidents, deans, faculty, and counselors in Alabama's 2-year colleges to test their perception of student persistence efforts, recommended that further research on student attrition should be conducted using administrators, faculty, and academic counselors. Thus, the present study used administrators, faculty, clerical/technical staff, and professional staff to identify, measure, and analyze data concerning the institutional efforts impacting student persistence. Bean (1982a) suggested that variables in retention/attrition models can be added or deleted from other retention models to fit the situational needs of different institutional studies (p. 25). Consequently, I modified Tinto's (1987) interactive model by deleting, rearranging, and adding variables to propose a new model of student persistence. I posited student persistence as directly and indirectly influenced by the institution's efforts to provide students' with academic and personal satisfaction. (See Figure 2.)

Thus, in this study a new model was developed and a new student persistence 


\begin{tabular}{|c|c|c|c|c|}
\hline $\begin{array}{l}\text { PRE-ENTRY } \\
\text { ATTRIBUTES }\end{array}$ & DISPOSIMON & DECISION & $\begin{array}{l}\text { TRANSACTIONAL } \\
\text { INSTITUTIONAL } \\
\text { EXPERIIINCE }\end{array}$ & DISPOSITION \\
\hline
\end{tabular}

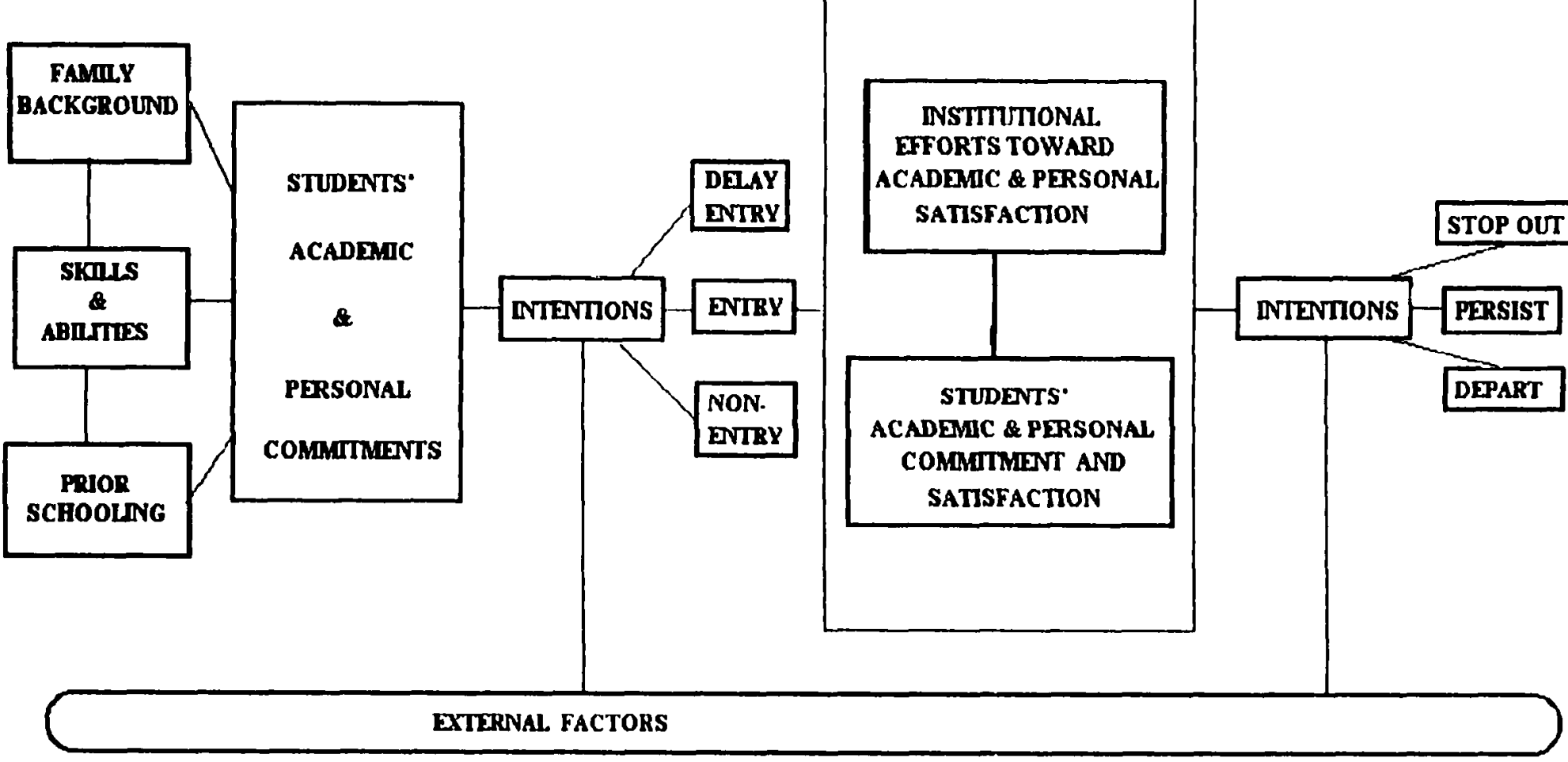

$\operatorname{TMNE}(\mathrm{T})$

Melendez's 1997 Model of Transactional Satisfaction Toward Student Persistence. 
instrument was created to identify salient institutional factors and to measure personnel's perception on how satisfactorily these factors are addressed. The Melendez (1997) Model of Transactional Satisfaction Toward Student Persistence proposes a time-sensitive longitudinal process. The premise of the model is that students and the institution interact within a transactional relationship experience between the student as a customer and the university as the service provider.

The students' pre-entry attributes and external factors continually influence their academic and personal commitments, which impact on their disposition of intentions toward delay entry, entry, or non-entry into an institution of higher education. After entry into the university, students have positive or negative transactional institutional experiences that are contingent upon the quality of their academic and personal commitment and the quality of the institution's efforts toward students' academic and personal satisfaction. This transactional institutional experience influences the students' satisfaction with the institution and thus influences their disposition of intention to persist, stop out, or depart. High levels of institutional commitment toward students' academic and personal satisfaction produce higher levels of student persistence.

\section{Research Questions and Null Hypotheses}

This study sought to address two research questions and three null hypotheses. They are as follows:

\section{Research Questions}

1. What university efforts are perceived by personnel as the least and the most 
important institutional factors impacting student retention/attrition?

2. What university efforts are perceived by personnel as the least and the most satisfactorily addressed institutional factors impacting student retention/attrition?

\section{Null Hypotheses}

1. There is no significant difference between the Importance Scale scores and the Satisfaction Scale scores of university personnel.

2. There are no significant differences among university personnel in their perception of the importance of institutional factors impacting student retention/attrition.

3. There are no significant differences among university personnel in their satisfaction with the university efforts to address institutional factors impacting student retention/attrition effectively.

\section{Significance of the Study}

Stiefelmeyer (1993) in her recommendation for further research stated that a comparative perception study on student persistence should be conducted among administrators, faculty, counselors, and students. Schein (1985) supported the practice of understanding the priority issues among organizational members as an administrative necessity for leaders (p. 2).

Thus, I used university personnel as the subject population for this study. Also, this study focused on personnel since another research study was simultaneously being conducted using the university students. The two studies are to be merged at a later time.

Another significance of this study was the introduction of an exploratory model 
and the development and validation of a new survey instrument that posed a more pragmatic approach to the study of student persistence/departure. I contended that student persistence/departure is a transactional relationship between the students as consumers and the institution as the service provider. The Melendez model posited that the institution's instructional or non-instructional efforts/services impact students' academic and personal commitment and satisfaction, which directly influence student persistence/departure.

The instrument provides a way to identify salient factors and to measure personnel's satisfaction level with the university's efforts impacting student attrition/ retention. The data were tested for congruity among personnel within the diverse demographic groups and subgroups.

Also, this study provided information to university administrators for the development of strategic plans to address student attrition. The results of this study will enhance the visionary planning of university officials to efficiently address concerns about student attrition. Thus, administrators are encouraged to consider student attrition/retention as more an issue of client/service relationships than of psychological or sociological integration (fit).

\section{Definition of Terms}

The following terms are defined for the use in this study:

Attrition: The loss of matriculated students from institutions of higher education by transfer or departure from an educational program before degree completion. 
Departure: Students who transfer or depart from institutions of higher education before the fulfillment of their educational goals.

Drop out: The act of permanently discontinuing or departing from a degree course of study.

Institutional Factors: Proactive institutional factors, activities, efforts, commitments, or attitudes that influence or support student satisfaction and continued enrollment until the completion of an educational goal.

Persistence: Students who continue matriculating in the university until their educational goals or degrees are completed.

Retention: Students who are successfully encouraged to remain in the university system until their educational goals or degrees are completed.

Stop out: The act of a student discontinuing from a degree course of study for an unspecified amount of time.

Transaction relationship: The exchange of resources between students and an institution of higher education for the satisfactory fulfillment of students' academic and personal expectations.

\section{Delimitations}

The delimitations are as follows:

1. Only administrators, faculty, professional staff, and clerical/technical staff members were used in the study.

2. No students were surveyed in this study since a separate student retention study 
was being conducted by another researcher. which surveyed only students.

3. The literature review focused on related research studies from the 1960 s to 1996

4. Only institutional commitments, activities, or efforts impacting student retention within the transactional institutional experiences were tested in this study.

5. This was not a study on attrition, persistence, or retention of university personnel.

Since the study was conducted in a non-residential, public university, the results may be generalized to similar universities with comparable research variables. Also, the results may be generalizable to similar institutional personnel but not to university students.

\section{Organization of the Study}

The dissertation has five chapters. Chapter 1 contains the introduction, statement of the problem, purpose of the study, theoretical framework, research questions and null hypotheses, significance of the study, definition of terms, delimitations, and organization of the study

Chapter 2 presents the review of related literature by documenting the historical development of student attrition. It also includes the theoreticians and models, theory of the present study, and related studies.

Chapter 3 describes the research methodology and design, population, instrument, collection of data, analysis of data, research questions and null hypotheses, limitations, and 
assumptions.

Chapter 4 presents the findings of the demographic information, research questions, and hypotheses.

Chapter 5 provides a summary of the study, methodology, instrument, summary of findings, conclusions, and recommendations for administrative practice and further research. 


\section{CHAPTER II}

\section{REVIEW OF RELATED LITERATURE}

Concern over student attrition in higher education has produced a large body of literature that utilized various forms of research methodologies (Bangura, 1992, pp. 8-12). Understanding why students depart or persist in institutions of higher education has been a growing interest for university administrators, students, funding sources, parents, and the business community.

However, many of the conclusions drawn from the results of attrition/retention research are contested by other researchers (Nehila, 1996, p. 4). There has been disagreement among researchers concerning student attrition/retention research results, definitions, the appropriateness of theories, models, methods of study, and the data analysis processes (Bangura, 1992).

Bangura (1992) attributed the disagreements in retention research to the different research methodology, construct factors, subjects selection, research sites, and the models or theories used to interpret the results. Retention research was most significant when it was conducted with the specific subjects or in the context of interest instead of generalizing the results on another population than the one studied.

This chapter provides a report of literature of the research, concepts, models, and 
theories that were used to explain student persistence or attrition within a public university setting. The study focused on the concepts and models of student departure from the early 1960s and through 1996. The literature review was intended to do the following:

1. Provide a familiarization with existing studies

2. Reaffirm the need for the study

3. Provide a theoretical background on student persistence

4. Establish the theoretical framework for a new model and a new instrument.

The focus in the literature search was on statistical research studies of student persistence, especially as they pertained to using university personnel as research subjects. This review of literature on student persistence presents a description of the historical development, major theoreticians and models, the theoretical framework of this study, and a summary of related studies.

The study of student retention in higher education has been noted as complex and with conflicting results. This review of literature on retention theories and models begins by defining "theory" and "model." Hossler et al. (1990) suggested that theories are statements that facilitate the search for why things happen. Theories also guide the selection or elimination of constructs (variables) in the development of new instruments to measure the concepts in question.

Kerlinger (1973) defined "theory" as interrelated constructs (concepts) that present a systematic view of the phenomena being studied by specifying the relationships among the studied variables (p. 9). Thus, student attrition theories are to provide plausible reasons why students drop out and which students are most likely to depart. 
Models, on the other hand, tie theory to specific situations by simplifying perceived reality Minute details are omitted from a model in order to reveal the assumed important factors and their sequenced relationships (Hossler et al., 1990, p. 150).

Retention models bridge the gap between the abstract and the pragmatic. The model structure is deduced from theory, and the content is derived and validated from expert judges in the field, from the literature on the topic, or from inductive empirical study. However, theory construction, model building, and conceptual testing are reciprocal and circular processes, each feeding on the other.

In student attrition models, the factors are presumed to identify interrelationships between various factors and the decision to drop out (Bean, 1982a, pp. 17, 18). The following synthesis of the literature demonstrates the evolving nature of attrition research from the atheoretical period to the theoretical and model development epoch. The final section of this chapter presents related research studies of the variables and subject population.

\section{Theoreticians and Models}

\section{Atheoretical Studies}

Retention research before 1960 was atheoretical (non-theory driven). During the 1960s, educational researchers began to develop models and theories that were exclusively applicable and adaptive to studying, defining, testing, and understanding student attrition (Hossler et al., 1990; Summerskill, 1961). Initially, student departure research was mostly atheoretical studies and descriptive analyses of observed facts (Pascarella, 1982a, p. 89). 
College student dropouts were classified as "any student who leaves college . . and does not obtain his degree at the same time as the class with which he originally enrolled" (Pervin, Reik, \& Dalrymple, 1966, p. 7). With this definition, 60\% of the students were classified as college dropouts. Pervin et al. (1966) reaffirmed that student attrition was considered a social problem and stated, "Dropouts are referred to in academic circles as casualties or non-survivors" (p. 37). Thus, dropping out of school was considered as sociological phenomena akin to a mental disease.

Cope (as cited in Noel, 1978) wrote that the fundamental question of retention/attrition research was "what appears to make the difference between students who leave and those who stay?" (p. 1). Years ago, colleges would classify the reason for student dropout as financial, academic, personal, or simply unknown. Personal and unknown reasons were the largest categories for departure. Knoell (cited in Pervin et al., 1966) reported that Summerskill's (1961) review of college dropout research showed that the studies were exclusively related to students' performance in college and divided the studies into four major types as follows:

1. Census studies to establish baseline data

2. Autopsy studies to identify reasons for attrition from students who dropped out

3. Case studies to facilitate administrative decision making

4. Prediction studies to identify admission variables related to the success or failure of students (pp. 64-66).

The descriptive studies consisted mostly of analyses of observed facts or factual statements from which empirical generalizations were reported. Factorial relationships 
were assumed to exist from the measured characteristics of dropout students, and correlations among variables were considered to be without causation. These studies described the extent of attrition and the time students were most likely to depart. They did not focus on the causation or the predictability of the factors nor did they identify why students departed. The results of the studies were used mainly to design strategies for admission or recruitment but not to increase retention. However, the studies served to generate propositions for further studies (Bean, 1982a, p. 18).

Pervin et al. (1966) noted that the major research factors were biological, social, academic, motivation, adjustment, illness, injury, and finances. After reviewing dropout factors of the 1960s, Lenning, Beal, and Sauer (1980) classified them into three types: academic, demographic, and financial. These studies involved the collection and correlation of demographic data: age, sex, or hometowns. Pre-entry characteristics were high-school grades, standardized test scores, and majors. Although, students with high class ranking were more likely to stay in institutions of higher education, studies did not identify why some high-ranking students also dropped out (Lenning et al., 1980). Summerskill (1961) began to focus on the intellectual or academic attributes of students in his studies of student retention (Tinto, 1987, pp. 86-87). These studies were also descriptive in nature.

\section{Major Theorists, Models, and Researchers}

Many research models and theories on student retention were proposed, modified, synthesized, or applied to different demographic, social, or institutional settings. Various 
retention factors were eventually identified and proposed as causes for student attrition. Demographic research subjects included traditional. nontraditional, or minority students. Student retention studies were conducted in 2-year, 4-year, public, private, single- or multi-institutions of higher education. Retention factors contained pre-matriculation characteristics, programs, activities within the institutional environment, external environment influences, and attitudinal or cognitive outcomes.

Student departure was said to involve an interactive relationship between an individual and the institution. Some of the reported causes for student dropout were difficulty of course work, boredom with academics, sense of wasting time in college, financial hardship, lack of motivation, and psychiatric problems (Astin, 1975; Tinto, 1975). Eventually, institutional researchers arrived at a consensus that the following independent factors were necessary before initiating retention research:

1. Rates of retention/attrition

2. Individual characteristics (family background, intelligence, sex, goal commitment)

3. Characteristics of the college (quality, size, distance from home, place of residence, or amount of financial aid)

4. Interaction with the college environment (social and academic integration) (Tinto, 1987).

From here, various theories and models were developed from existing psychological (Spady, 1970), social (Tinto, 1975, 1987), or business (Bean, 1980) theories. These theories, models, and researchers were to provide suggestions or 
information as to what entry-level characteristics or institutional characteristics were more important in influencing student departure decisions and which academic or social factors contributed most to students' leaving (Bean, 1982b).

Festinger's (1962) theory of cognitive dissonance asserted that students who do not comfortably fit within the social educational environment will eventually experience emotional dissonance. As students feel they do not fit into the norms of their new environment, they experience emotional discomfort that compels them to reduce or eliminate the dissonant feeling. They then either can change their behavior or depart from the environment. By association, Festinger proposed that students may choose to drop out when they feel emotional dissonance in their college environment (Lenning et al., 1980).

Chickering (1974) advocated a psychological theory to explain student attrition. He posited that students with low academic and social developmental skills have higher tendencies to drop out of institutions of higher education. He conducted research using traditional college students of ages 17-25. Chickering claimed that most first-year college students were confronted with the need to resolve immediately and control three important vectors in life: developing competence, emerging emotions, and developing autonomy.

Thus, research studies based on Chickering's (1974) theory were conducted to identify developmental tasks that impact student attrition. Recent research studies have validated Chickering's theory (Butler \& Markley, 1993; Coplen, 1994; Thiede, 1994). The findings indicated that the following factors produced significant student development 
changes and thus student retention: faculty and student interactions, participation in campus activities, and peer interactions.

In the 1970s, there was a heavy reliance on psychological theories and models to explain student departure. Consequently, Spady (1970) developed the first longitudinal theoretical model of the dropout process using Durkheim's (1961) suicide theory, which proposed that shared group values and friendship relationships helped to explain suicide as a form of societal departure (Tinto, 1987).

Spady regarded student dropouts as those who withdrew from a social system, and he associated this behavior to suicide--a permanent withdrawal from a social system. Spady postulated that students withdraw from college because of lack of shared values or normative support. Shared values between the student and the institution were asymmetric in accountability. Students were expected to accept the institution's advocacy of student success by achieving academic excellence and normative congruity, and by establishing an effective emotional, financial, or social support system (Bean, 1982a). In Spady's model of shared group values, grade performance, normative congruence, and a friendship support system were expected to increase student satisfaction and institutional commitment. These were to reduce the likelihood of student departure (Bean, 1982a, p. 21).

Rootman's (1972) Person-Role Fit model was derived from the work of Biddle and Thomas (1966) on the theory of person-role fit. The model focused on the relationship between the individual's characteristics and the role requirements of the student. This theory was complementary to Spady (1970) and Tinto (1975) in that it used 
the academic and social integration concepts. Students with high levels of person-role fit were most likely to have high levels of academic and social integration.

Rootman (1972) studied freshman attrition at the U. S. Coast Guard Academy He used wide ranges of factors to synthesize a causal model of voluntary withdrawal from adult social organizations. Rootman's model proposed that the two independent variables of student attrition were discussing leaving with a friend or discussing leaving with someone outside their social system. These were to have a positive and direct effect on voluntary withdrawal. However, two other variables have a negative effect on voluntary withdrawal. These were having a successful interpersonal fit and person-role fit within an organization. To conduct studies with Rootman's model, the researcher needed to obtain psychological characteristics and a personal profile of the student's role in the institution before and after matriculation. The higher the level of similarity between student characteristics and students' roles in the institution, the more likely it would be that the student would persist (Bean, 1982a, p. 20). Bean (1982a) stated that the model was not considered very useful in that institutional researchers had little control over the personality types of the students enrolled and the logistic problem of a pre- and post-test data collection process. Though the theory was simple, it could lack accuracy.

Astin's $(1975,1984)$ theory of student involvement stated that the more involved students were in college, the greater will be the amount of student learning, personal development, and persistence. The student involvement theory was operationalized by identifying factors that indicated active participation in the learning process.

Astin based his theory on Freudian's concept of cathexis where individuals are 
most likely to invest energies in activities and objects outside of themselves that they liked. In DeVaugh's (1995) literature review, research studies on Astin's theory were reported as demonstrating strong relationships between student involvement and student achievement (Astin. 1985, 1993; Friedlander \& MacDougall, 1991). However, the theory was used as a basis for further model building than for conducting retention research.

Tinto (1975) formalized a synthetic theory and model from other theories to explain the student attrition phenomena of higher education students. His model was considered the most widely tested and cited model of all the empirical retention studies (Bean, 1982a, pp. 21-22). Tinto (1975) developed his theory by combining Durkheim's (1961) theory on suicide and Spady's (1970) theory of social values to explain student dropout. Pascarella (1982a) mentioned that numerous research studies showed Tinto's (1975) model as highly congruent with Durkheim's (1961) and Spady's (1970) work. Tinto proposed that normative congruence and friendship support were factors influencing students' decisions to drop out of institutions of higher education.

Tinto's (1975) theory was the first to emphasize the longitudinal nature of the student attribution process as a time-sensitive interactive process of students' background attributes, academic outcome, and social factors (Hossler et al., 1990, p. 150). The theory proposed that institutional student persistence efforts have a measurable impact on the academic and social development of the students. It also implied the existence of an accountable relationship between students and institutions (Hossler et al., 1990, p. 86).

Tinto's (1975) model noted the students' background characteristics, such as family presupposition, individual attributes, and pre-college schooling. All interact and influence 
the students' commitment to enhance their educational goals toward graduation. Academically, educational goal commitments provided incentives toward higher grade point averages and more intellectual development. This was to increase the students' academic integration with the institution and to produce a higher level of educational goal commitment. High levels of goal commitment purported to reduce the likelihood of student dropout.

For Tinto, social integration was enhanced when students had high levels of peer group and faculty interaction. This increased the students' institutional commitment and thus reduced the likelihood of departure (Bean, 1982a. pp. 21-22). Tinto's (1975) model was more linear than Spady's (1970). Although it has similar factors, Bean (1982a) contended that the main problem with Tinto's (1975) model was the placement of goal commitment and institutional commitment twice in the model (p. 21).

DeVaugh (1995) claimed that Tinto's (1975) model of student departure asserts that the student's level of integration with the academic and social systems of an educational institution was the key contributor to students' decision to withdraw or remain in college (p. 30). Moreover, he stated that despite extensive research studies supporting Tinto's (1975) model the results were inconclusive as to whether academic or social integration was more important.

Pascarella and Terenzini (1980) developed and later duplicated an instrument to evaluate the validity of Tinto's fundamental constructs of social and academic integration and its impact on student persistence (Terenzini, Lorang, \& Pascarella, 1981). Both works supported the integration constructs as relatively stable predictors of student 
persistence. However, Pascarella and Terenzini (1983) found that the ability of Tinto's (1975) model to predict attrition is small. For public resident universities, they said it explained only $19 \%$ or $21.7 \%$ of the total variance. Bean (1982a) contended that Tinto's model was complex and gave up simplicity for accuracy and generalizability.

Fishbein and Ajzen (1975) developed a student attrition model based on how intentions to act influenced behavior. Their psychological model asserted that a person's behavior is preceded by the intention to perform the behavior.

According to this retention model, dropping out of institutions of higher education was the result of past behavior, attitudes, and norms that influence the intended behavior. In this model, intent replaced institutional commitment as the immediate precursor of departure decisions. Thus, intent to leave institutions of higher education was the best predictor and the primary variable of student attrition. Both Fishbein and Ajzen (1975) and Bean (1983) modified Tinto's model to include effective factors that impacted on the academic and social integration of students (Bean, 1982a, pp. 24, 25). The model was later modified by Bentler and Speckart (1979) and synthesized by Bean (1982a). Bean (1980) later produced his own attrition model.

Bean $(1980,1983,1985)$ developed three models of student attrition. In the first two models, he synthesized work from other existing models into his own model of student attrition. Bean's (1980) model was comparative with the Spady (1970) and Tinto (1975) conceptual approach, but it owed no intellectual debt to Durkheim (1961).

The underlying assumption for this student attrition model was analogous to employee turnover in the corporate workplace. Bean's model borrowed from Price's 
(1977) work on organizational employee management (Hossler et al., 1990, p. 151). The model identified four categories of variables: students' background characteristics. organizational activities, attitudirial mind-set. and environmental influences. All of these were to have direct or indirect effects on the students' intent to depart from institutions of higher education. Bean (1980) suggested that intent to depart from institutions of higher education was the immediate precursor to dropping out. Researchers used Bean's models to identify types of variables leading to causal sequences that explained student attrition (Bean. 1982a, p. 25)

Bean (1983) modified his 1980 model to reflect Bentler and Speckart's (1979) psychological models and Price and Mueller (1981) on student attrition. The model proposed that people's behavior is the result of a cyclical psychological process where their beliefs influence their attitude. This in turn influences the person's intentions to act. Then, the behavior in question was performed. Similarly, students' beliefs about their experience in institutions of higher education led them to develop attitudes that influenced whether they would stay or depart from college.

This affects the students' intent to stay (or leave) followed by actual departure or persistence. Bean's (1980) model contained 10 variables, which reflected the students' interaction with the institution--such as grades, practical value of the education received, the sense of self-development due to schooling, the repetitiveness of school life, information related to the student role within the school, participation in decision making, having close friends, having the courses one wants to take, being treated fairly, and memberships in campus organizations. These variables were to influence the students' 
satisfaction with the institution and impact the students' intent to leave or stay.

Thus, intent to leave institutions of higher education was noted as positively related to departure. In addition, the environmental external variables--opportunity to transfer to another institution of higher education and the likelihood to marry--were directly and positively related to student departure. Bean`s 1980 model contained similar variables to academic and social integration as Tinto's (1975) and Spady's (1970) models (Pascarella, 1982b).

Bean recognized that factors external to the institutions of higher education might affect retention, and thus included environmental variables as causal factors in the attrition model. However, institutions have little control over environmental factors that contribute to decisions to remain or depart from institutions of higher education (Hossler et al., 1990. p. 151). The model contributed to operationalizing the concepts of the person-fit and the social integration that were in Rootman and Spady's attrition/retention models (Bean, 1982a, p. 24).

Later, Bean and Metzner (1985) proposed a model of attrition/retention for the nontraditional student. They classified nontraditional students as those who have limited interaction with other members of the college community. The difference between this model and earlier ones was that this model considered the students' social support systems as environmental factors of attrition/retention. The social support variables were from the students' family (spouse, children, or parents), friends outside institutions of higher education, or people at work.

This model was in contrast to traditional (residential) students where the faculty 
and the student peers formed the most important support groups. Thus, social integration was expected to be less important for nontraditional students. Environmental variables were more influential in decisions to persist or depart from institutions of higher education for nontraditional students (Hossler et al., 1990, pp. 151, 165).

Pascarella's (1980) attrition/retention study proposed that the quality and quantity of the informal interaction between students and faculty had a direct impact on students' decision to withdraw or persist. This was a conceptual model of student dropout that emphasized the importance of informal student-faculty contact (Bean, 1982a. p. 23). In his model, background characteristics interacted within the institution's image, policies, size, admission criteria, the academic standards, and the amount of student/faculty contact.

The institutional activities were to influence the extent and quality of students' informal involvement with the faculty members, the campus's peer culture, and extracurricular activities. This was to produce the following educational outcomes: academic performance, intellectual development, personal development, educational and career aspirations, college satisfaction, and institutional integration. Educational outcomes were expected to influence student persistence or withdrawal decisions directly (Pascarella, 1982b).

In summary, the three main models--Bean (1980), Pascarella (1980), and Tinto (1975)-had many similarity in their approach to student retention studies. They described attrition as a longitudinal process, considered student background characteristics as directly influencing student retention, used the theoretical base of student social and academic integration, and proposed complex models in order to gain accuracy and 
generalizability (Bean, 1982a, p. 23).

\section{Pascarella and Terenzini's Institutional Integration Scale}

Pascarella and Terenzini (1980) developed the Institutional Integration Scale to measure the effect of values congruence among student peers using Tinto's (1975) student departure model (p. 648). They found that the more qualitative the central role of other people in students' lives and the higher the level of the students' efforts and involvement in their academic and personal investment, the greater was the likelihood of higher educational and personal returns

Pascarella (1980) and Terenzini (1982) later became the two leading researchers of student retention. They have done extensive research on modified adaptations of Tinto's (1975) student academic and social integration variables.

\section{Tinto's Revised Model}

Hossler et al. (1990) stated that Tinto's revised (1987) model was the last reported retention model. (See Figure 1.) Tinto's 1987 model was also a synthesis of other models that best explained student departure from institutions of higher education. Tinto's 1987 model was a modification of his initial 1975 model. He incorporated several new features that were used from Bean's (1980) intention to leave or stay in institutions of higher education and Pascarella's (1980) emphasis on the importance of student interactions with faculty and staff.

However, Tinto's revised (1987) model was theoretically based on Van Gennep's 
(1960) theory of students' rites of passage. Van Gennep (1960) concluded that the rites of passage for students occurred in three stages: separation (from family and childhood support), transition (adaption to new ordeals, training, values, and activities), and incorporation (adopting a new set of values and behaviors). Similarly, Tinto proposed that attrition occurred when a student's rites of passage were incomplete (Hossler et al., 1990, p. 154)

Tinto's 1987 model was similar to the 1975 model with the exception of the addition of the environmental influences, students' intentions, and external commitments. The model sought to explain attrition in terms of an individual's academic and social integration within the educational environment. It maintained that attrition was a complex, longitudinal process (Nehila, 1996, p. 24).

Nevertheless, Tinto recognized the influence of students' changing attitudes and emphasized a second set of intentions and commitments as directly impacting the decision to depart or continue enrollment. He acknowledged the interactive nature of different factors in the retention phenomena. Thus, students were acted upon by the environment, which affected future interactions. These interactions caused students to reassess their intentions and decisions to leave or persist (Nehila, 1996, pp. 24, 27).

As students interact with the organization academically and socially, they develop attitudes toward the institutions of higher education. These interactions affect the students' attitudes toward their fit with and loyalty toward an institution. Thus, the levels of student interaction within the institutional environment are potent predictors of continued enrollment (Hossler et al., 1990, pp. 152-153). 
In Tinto's 1987 model, students enter institutions of higher education with varying pre-entry family and community background attributes. The students differ in personal attributes (e.g., sex, race, and physical disabilities), levels of intellectual and social skills or abilities, diverse values orientation in intellectual and political preferences, and prior educational experiences and achievement (e.g., high-school grade point average and SAT/ACT scores). These pre-entry attributes are posited as having a direct impact upon student departure from college and are affected by the students' intentions and commitments toward future educational activities. The students' educational intentions and goals concur with the level and type of education or occupation they desired. Students enter an educational institution with preset affective mind-sets concerning their level of commitment to their educational goals and institutional fit. This, along with external student commitments, sets the conditions for subsequent environmental interactions between the students and the institution (p. 115).

Interactive experiences within the institutional academic and social environmental systems influenced students' scholastic or occupation intentions, educational goals, and institutional commitments. All of these were centrally related to the outcome of continuance or departure from the institution before degree completion. Thus, Tinto (1987) posited that the greater the students' integration within the institutional environment, the greater the likelihood of persistence until degree completion (pp. 115116).

His model explained how environmental difficulty, values incongruence, and student isolation experiences influenced student departure. It addressed the longitudinal 
multi-interactive nature of the process of student attrition/retention and explained how and why some students voluntarily departed or disassociated themselves from institutions of higher education before degree completion. The model did not concentrate on dismissal. It was not a descriptive model of the degree of departure, nor did it deny that individuals have much to do with their own leaving. The model's aim was to be administratively policy relevant where institutional officials can modify activities to retain more students until degree completion. It intended to provide a structure for planners to identify institutional factors that may interfere with the progression of student scholastic development. Thus. the institution can alter those factors that best enhance student retention (Tinto, 1987, pp. 112-118).

Hossler et al. (1990) stated that Tinto's 1987 model has been widely used as a guide in most of the multivariate research studies in attrition/retention (p. 150). However, the model did not provide an appropriate conceptual framework for my study, and so I developed my own model and instrument. Nehila (1996) stated that Tinto's (1987) model had low predictive validity. The maximal coefficient of determination for the pooled samples was 0.35 . The model was also found to be ineffective in explaining student attrition beyond the sophomore year since by the third and fourth year in college the vast majority of students had successfully coped with academic and social integration.

\section{Theory of the Present Study}

In Pascarella (1982b), the following steps were suggested in designing attrition/retention research: (1) decide upon a definition of student departure, (2) decide 
on the variables to measure, (3) determine the variable relationships from a model, and (4) describe the assumption parameters of the institution. The questions were to address the issue as to why students left or persisted in institutions of higher education.

Attrition/retention research has been conducted mostly on student populations as the subject base. This was despite the numerous recommendations by some educational researchers to include institutional personnel in the retention studies (Stiefelmeyer, 1993) Levitz and Noel (1980) reported that a concerted effort to increase student retention should force "an institution to examine itself closely, and what it observes will not always be pleasant or easy to accept" (p. 87). In addition, they stated that the interaction between the institution's services and the students' expectation can have a dramatic impact on student attrition rates.

Similarly, Jose (1978, p. 57) observed "that the attitude of faculty, administrators, and staff toward students is a significant factor in student retention." Also, Hossler et al. (1990) emphasized that "retention is everyone's business" and that "fitting in depends on the student on one hand and the institution on the other" (p. 147). Stodt and Klepper (1987) advocated that academic and student affairs administrators should work in partnership to increase retention. Lagowski (1992) reported a study showing that students dropped out of a science education program when they felt discouraged by the seemingly uncaring attitude of the science faculty. He also stated that faculty must change their attitudes in order to impact student retention positively (p. 173).

Cabrera (1992) reported that the decision to drop out or persist in college was determined from the quality of the interaction between the students and the educational 
environment. University administrators should identify institutional factors or resources that are needed to provide a quality educational environment to all students, especially those students who tend not to persist (Peters, 1987).

Tinto (1987) stated that attrition researchers of higher education have ignored and often overlooked the need to study the extent to which the institutional efforts impact student departure (p. 4). Spanbauer's (1996) experience as president of a 2-year college verified the effectiveness of collaborative leadership among administrators, faculty, and staff in bringing about a paradigm shift toward quality education (p. 1).

Hence, the following university personnel were used in the study: administrators, faculty, professional staff, and clerical/technical support staff. I used a modified version of Tinto's (1987) interactive theory of student departure. (See Figures 1 and 2.) Tinto's (1987) Longitudinal Model of Institutional Departure presented student attrition in higher education as the outcome of a longitudinal interactive process between the students' preentry attributes, intentions, educational goals and commitments, and their level of institutional academic and social integration. The students' institutional experiences modify these intentions and commitments to persist or depart from institutions of higher education. Tinto posited that high levels of student academic and social integration reduced the likelihood of student departure (pp. 112-116).

This present study's contributions to scholarly study are twofold: to demonstrate how the Melendez Model of Transactional Satisfaction Toward Student Persistence provided adequate guidance for exploratory student persistence/departure research in a 4year Midwestern public commuter university and to confirm the validity of including 
institutional personnel in the attrition/retention research process by measuring their perception of the institutional efforts impacting student attrition. My Melendez model advocates that a transactional relationship between the student and the university exists where the institutional and students' efforts are important factors impacting student persistence. Also, it differed from most of the studies on persistence/attrition in that the instrument, a dual scale survey, was specifically designed to measure personnel's perception of important institutional factors impacting attrition/retention and their level of satisfaction with the university's efforts to address these factors/activities.

Researchers in the literature recommended that variables of retention/attrition models can be added or deleted from a model to fit the need of different institutions depending upon either the lack of or the inappropriate fit of existing data (Nehila, 1996, p. 24; Bean, 1982a, p. 25). Thus, I modified Tinto's 1987 model by renaming, rearranging, or adding variables as shown in Melendez's Model of Transaction Satisfaction Toward Student Persistence. (See Figure 2.)

In my student persistence/departure model, pre-entry attributes and external environmental factors impact students' intentions for entry, delayed entry, or non-entry into an institution of higher education. Upon making the decision for entry, the students' transactional experiences within the institution will either enhance or reduce their academic and personal satisfaction with the institution. Thus, the students' intentions are modified by transactional experiences with the institution that influence their decision to persist, stop out, or drop out. The greater the level of academic and personal satisfaction by the student, the higher the tendency to persist. Nehila (1996) commented that students 
interact and are acted upon by the institutional environment, which then affects future interactions (p. 27)

In the present study, pre-entry characteristic data were omitted for two reasons: students were not being surveyed, and the study focused on only attrition/retention factors experienced within the university after matriculation. For students already in universities, persistence/departure was reported as more dependent upon academic and social abilities than on family background (Nehila, 1996, p. 25).

\section{Related Studies}

Joseph's (1995) study on student retention determined the extent to which the constructs of Tinto's (1987) model of student departure were useful for explaining freshman-to-sophomore-year persistence of first-generation college students in different institutions of higher education. The data were collected with a survey of 331 firstgeneration college students enrolled in West Virginia public institutions of higher education during the fall semester of 1992. Four types of institutions were used in the study: associates of arts colleges, baccalaureate colleges, and master's and research universities.

The variables--age, social integration, and institutional commitment--were found to have significant and direct effects on persistence. Yet these effects were inconsistent with the hypothesized Tinto model. Joseph concluded that both of the factors influencing persistence and the degree of influence upon persistence varied depending upon the particular group of students under consideration. For further study, Joseph recommended 
that colleges and universities interested in increasing retention of first-generation college students should conduct their own institutional research to determine why some of these students stay or depart from their institution. This will enable institutions of higher education to identify characteristics on their own campuses that can be changed to improve the chances of first-generation students to persist until graduation.

The results indicated that the variables from Tinto's (1987) model were not effective in explaining persistence of the first-generation college students in the study sample. Thus, another theoretical model is necessary to understand student persistence in the 1990s, especially as it relates to persistence of first-generation college students.

Parker (1995) sought to measure the social climate and the institutional attitudes of community college faculty, staff, and administrators that influenced economically disadvantaged and minority student persistence. He used a qualitative methodology with interviews, questionnaires, and classroom panel discussions to obtain students' perceptions of factors impacting student attrition/retention. Parker (1995) developed his own survey questionnaire from the review of related literature on retention. The theoretical base of his study was that the educational system should provide successful paths for societal upward mobility (Parker, 1995, p. 10).

Also, he emphasized that minority and economically disadvantaged students have relatively few opportunities for success due to dysfunctional family structures, low economic mobility, and biased systems of education. Parker synthesized Spady's (1970), Pascarella's (1980), and Tinto's $(1975,1987)$ models, which reasoned that sociological and interactive elements between institutional aspects and student characteristics impact 
student attrition/retention. He posited and advanced Pascarella's (1982b) thesis that the interaction of background characteristics with institutional characteristics. along with formal and informal student contact, determined whether students persisted or dropped out (Parker, 1995. p. 145).

The data were analyzed by rewriting notes and transcribing and coding tape recordings into an overall summary. The notes were reviewed for ethnographical cultural symbols, relationships, and emergent themes. Cognitive maps or charts of the evolving schema were developed to identify common themes and causal processes.

The significance of the study was to test whether internal institutional procedures, patterns, structures, and behaviors contributed to the student attrition/retention process Parker (1995) concluded that the student attrition/retention process is a simple equation where "student characteristics + institutional characteristics + what transpires in the interaction of the two [culture, perceptions, expectations, interaction] = impact on students' desires to persist or drop out" (p. 145). This confirmed Pascarella's thesis that students and institutional interaction impact student attrition/retention. Students enter community colleges with expectations of being empowered to improve their economic and social status. However, they encounter a different cultural mentality dominated by faculty and administrators. The Melendez model also stipulates that student persistence is influenced by a transactional relationship between the student and the institution.

Parker recommended a need to establish a forum to discuss cultural and school climate issues that affect student attrition/retention. For further research, he posed the question: What is the impact of faculty's and administrators' attitudes toward 
economically disadvantaged and minority students? Also, he recommended researching how the teacher's and administrator's racial identity and educational development influence their interpretation of the behavior of the economically disadvantaged and minority group. He also proposed that the more an institution assumes responsibility for the students' social interaction, the more it will be empowered to reduce attrition.

Stiefelmeyer (1993) claimed that reducing the student dropout rate in the state's 2year colleges would increase the amount of students transferring to 4-year institutions ( $p$. 10). She studied the perception of Alabama's educators of 2-year colleges regarding the status of the implementation of the state-recommended retention strategies. She measured which strategies were implemented and were most effective. She also studied which student retention efforts were being recommended as effective in increasing student success and retention. The major contribution of this applied study was to enhance administrative decision making concerning the present and future status of the statewide retention strategies. The study was based upon the need to identify which of the 52 strategies and tactics recommended by the 1985 Alabama Task Force on Retention were being perceived as carried out or effective.

Stiefelmeyer used Cantrell's (1986) ranking order of the task force's recommendations on retention programs and tactics as the variable base for her study. The ranking orders of the retention efforts were as follows: (1) academic excellence is a prerequisite; (2) effective student development programs are essential; (3) the fit of each individual student with his or her needs and interests is also a prerequisite; (4) interpersonal approaches in the classroom are essential; (5) increased advisor competency 
is essential; and (6) developmental programs to meet the academic needs of underprepared and undecided students are essential. Stiefelmeyer's study was a follow-up on the recommendations by the Alabama Task Force on Retention and in Cantrell's (1986) study.

Stiefelmeyer (1993) developed her own survey instrument to measure the respondents' perception of retention strategies in the colleges. It consisted of a 29-item instrument. Each item-question required two sets of responses: a yes/no/not sure and a 5point Likert scale in which 1 was not effective and 5 was being extremely effective. The survey also contained one open-ended question to obtain suggestions for new attrition/retention strategies. The data were collected from 312 of 330 returned usable surveys. Descriptive statistics of means, frequencies, and percentages were used to analyze the data and test the research questions regarding which retention programs were perceived as put into effect and effective.

The findings and conclusions concerning Alabama's junior colleges' retention practices were as follows:

1. The strongest practices being implemented by priority were ensuring studentcentered student development, enhancing the image of academic excellence, and providing adequate developmental educational opportunities.

2. The weakest retention practices reported were providing appropriate support for retention practices, enhancing interpersonal relations within the classroom, ensuring that students find their fit in the institution, and providing a viable academic advisor program. 
Recommendations from the study were to place more emphasis on personnel's suggestions for improving student retention, to prioritize mandatory retention practices in a 5-year strategic plan. to conduct more surveys statewide to ascertain current retention practices, and to conduct more studies comparing the perceptions of administrators. faculty counselors, and students regarding retention issues.

White's (1993) study investigated the relationship between the integrated model of instructional and student services and student persistence. She based her study on Tinto's (1987) theory of student departure, which stated that the students' institutional academic and social experiences influence their educational intentions, commitments, and skills to stay or depart from institutions of higher education. She used qualitative methodology in her study as a field-based approach to explore and discover factors relating to student persistence in the natural settings of two Texas community colleges whose students transferred to the University of Texas at Austin. Twenty-eight in-depth interviews were conducted by the researcher of college vice-presidents, deans, directors, counselors, chairpersons, and a manager.

The data were analyzed using the constant comparative method and the formulation of an emerging design. The data consisted of transcripts from taped interviews, field notes, and school documents. Results provided information as to what level of student persistence is contributed by the collaborative efforts of instructional and student services.

The findings indicated that the respondents identified instruction, assessment, placement in proper courses, strong academic advisement, orientation, developmental 
courses, financial aid, tutoring, and career counseling as influential factors contributing to student persistence. A very strong emphasis was placed on instruction at both colleges. Instruction was identified as a major factor, along with qualified and committed instructors, to promoting persistence at both colleges. Academic advisement and proper placement in courses were consistently favored themes. White (1993) concluded that collaborative institutional efforts between instructional and student services were necessary to improve the educational process of students and thus to increase levels of student persistence. The dissertation was an applied study that used contemporary student persistence and organizational theories as a guide to understanding the relationship of instructional and student services to student persistence.

No theoretical advancements were advocated. One of the recommendations for further research was to investigate the collective perception of students, administrators and faculty on the effectiveness of programs and factors that contribute to student persistence. Numerous other similar studies were conducted using Tinto's $(1975,1987)$ theory or model (Berry, 1993; Klimovich, 1994; Napoli, 1996; Perone, 1994; Peterson, 1992; Pietropaolo, 1994; Rivero Y Hornos, 1993; Wade, 1995; Waggoner, 1994; Wood, 1994). The results in these studies were similar to those already reported.

\section{Summary}

The literature indicated a growing concern over student attrition/retention among administrators, educators, and institutional researchers of higher education. Institutions of higher learning have realized that maintaining students enrolled is more cost effective than 
recruiting new ones. Student retention research evolved from an atheoretical period, before the 1960 s, to the present time where departure theories and models place the cause and solution of retention on the student.

Retention strategies, programs, and research are varied and the effectiveness and findings are often critiqued as contradictory or ineffective. This is so because many of the studies are conducted using different theories, models, subjects, demographics, or research methodologies. The major theoreticians were Bean (1980, 1983, 1985), Rootman (1972), Spady (1970), and Tinto (1975, 1987). Pascarella (1982b) and Terenzini (1982) have conducted extensive studies on student retention by investigating different institutional factors as independent research variables influencing student attrition.

The main focus of student retention research has been primarily on the students' ability to obtain high levels of academic and social integration (Tinto, 1987). Yet, Joseph (1995) and Nehila (1996) reported incidences where Tinto's (1987) model did not provide adequate levels of statistical validation for retention research

In the literature, I found statements implying that institutional efforts directly and indirectly impact student persistence. Levitz and Noel (1980) recommended that institutions of higher learning should assess their educational environment to identify factors conducive to enhancing student retention. Jose (1978) and Lagowski (1992) affirmed that personnel's attitudes toward students influence student retention. Thus, the Melendez Model of Transactional Satisfaction Toward Student Persistence was formulated as a rival hypothesis and as an alternative tool to advance the study of student persistence. 
The subjects for my study were university personnel. Joseph (1995), Parker (1995), Stiefelmeyer (1993), and White (1993) conducted studies using university personnel as research subjects. These related studies confirmed the appropriateness of using personnel of higher education institutions to ascertain pertinent findings concerning institutional factors impacting student persistence. 


\section{CHAPTER III}

\section{RESEARCH METHODOLOGY AND DESIGN}

This study used a quantitative ex post facto survey research design to identify, measure, and test factors impacting student attrition/retention as perceived by institutional personnel (administrators, faculty, and professional/technical staff) at a Midwestern university. This study was initiated after the appropriate letters of approval were received from the university. (See Appendix A.) I developed and validated the instrument-Institutional Student Persistence Survey (ISPS)--to collect and statistically analyze the data needed in this study. (See Appendix B.) The instrument identified institutional factors impacting student retention by noting if an item was important or unimportant and whether it was satisfactorily or unsatisfactorily addressed in the university.

\section{Population}

The research subjects for this study consisted of the entire population of administrators, faculty, and professional/technical staff (personnel) of the university. Sampling procedures were not used since the entire population served as the subject base for the research. The total population surveyed contained 703 subjects. The surveys were mailed to four mailing groups that were coded as follows: professionals, faculty--full-time, faculty-part-time, and clerical. There were 98 names in the professional mailing code, 
which included administrators, counselors, staff professionals, and some of their clerical and technical support staff. There were 222 full-time and 283 part-time faculty names on the mailing list. The full-time clerical code had 100 names. The administrator's group included the chancellor, vice-chancellors, deans, department chairs, and their associates and assistants. These names were scattered within the faculty and professional mailing list in that some administrators have combined faculty and administrative duties.

The demographic subgroups of the study are as follows: university status (WKR) was composed of administrator, faculty, professional staff, and clerical/technical staff; status employment time (YRS) was made up of less than 1 year, 1 to 5 years, 6 to 10 years, and 11 or more years; gender (GEN) was female and male; divisions, schools, and programs (DEPT) was composed of the Division of Arts, Division of Business \& Economics, Division of Education, Freshman Division, Division of Liberal Arts \& Sciences, School of Nursing, School of Public and Environmental Affairs, and "Other." The "Other" subgroup consisted of the Division of Continuing Education, Division of Labor Studies, General Studies Degree Program, Dental Education, School of Library and Information Science, and School of Social Work. The "Other" response selection was for educational entities that had fewer than six individuals. This was done to maintain anonymity. The teach introductory-level course(s) $(\mathrm{TCH})$ was Yes or No.

The survey was conducted at a Midwestern commuter-type public university that has undergraduate and master's degree co-educational programs. 
Instrument

With student attrition at an alarming rate of $45.8 \%$ at this Midwestern university, a study was sought to identify empirically and measure institutional dimensions impacting student attrition/retention. Thus, in this study, an instrument was developed and validated to measure the desired constructs of student attrition/retention. Tinto's (1987) Model of Student Departure provided the theoretical guide to develop the Melendez exploratory Model of Transactional Satisfaction Toward Student Persistence. Instrument items/factors were sought to fit the conceptual model. The following affective scale development procedures were used to develop and validate the instrument.

\section{Instrument Development}

Institutional factors impacting student attrition/retention were identified and compiled after the review of the related literature on retention and a review of all the programs, activities, efforts, plans, statements, and retention strategies of the Midwestern university. Similarly, items were added from the review of retention programs from colleges and universities nationwide: Barry University, 1995; Central Michigan University, 1995 Cornell University, 1996, 1993; El Camino College, 1995; Queens College, 1996; Jacksonville State University, 1996; Stanford University, 1996; University of Dayton, 1996; University of Miami, 1996; University of Pittsburgh, 1994; and Walla Walla College, 1995. Also, I reviewed Noel and Levitz's (1996) list of 23 community colleges, 20 private colleges, and 45 public colleges and universities that received awards from developing effective student retention programs. These item factors were compared with 
items used in retention research models and studies by Bean (1980), Pascarella and Terenzini (1981), and Tinto $(1975,1987,1993)$.

This process generated 131 items. These items were synthesized into 46 items by expert judges (interim chancellor, vice chancellors, assistant vice chancellor, and academic advisors) into common themes, programs, activities, and services. Then, a survey instrument was developed to measure two dependent variables: factors perceived as important or unimportant and factors (efforts) impacting student attrition/retention perceived as satisfactorily or unsatisfactorily addressed by the institution.

The instrument format was laid out so that each item was simultaneously used by the two scales: the Importance Scale on the left of the items and the Satisfaction Scale on the right of each item. Each of the two scales had a 5-point Likert-type continuous scoring response pattern. Each scale shared the same 41 items to quantify the response attitudes concerning institutional factors impacting student persistence. The Importance Scale used Very Unimportant (1), Unimportant (2), Neutral (3), Important (4), and Very Important (5). The Satisfaction Scale used Very Unsatisfactory (1), Unsatisfactory (2), Neutral (3), Satisfactory (4), and Very Satisfactory (5) as directed by Gable and Wolf (1993, pp. 66-67).

Upon further refinement, the first instrument drafted contained 41 items that were placed in alphabetical order. Two pilot tests were conducted at a different university to test for readability, ease of responding, and general understanding of the survey. In the first pilot test, 70 surveys were hand distributed; 28 surveys were returned--16 usable, 6 incomplete, and 6 blanks. Six respondents commented that they did not understand the 
term "student persistence." In the initial factor analysis using principal component analysis, there was an indication that the alphabetizing of the items did not provide the reader with the best sense of item relationship.

The redrafted instrument included an explanation of student persistence in the instructions. The items were grouped into two alphabetic subgroups: items 1 to 23 reflected the institution's efforts toward student academic and personal satisfaction and items 24 to 41 reflected the students' efforts toward academic and personal satisfaction.

In the second pilot study, 65 surveys were distributed to personnel from other departments in the same university as the first pilot study. Sixteen respondents returned the surveys--14 usable and 2 incomplete. No blank returns were received, nor did any of the returned surveys contain comments about misunderstanding the instrument. Another draft was developed after correcting typographical errors and reviewing any final suggestions by a panel of expert judges, which consisted of the interim chancellor, vice chancellors, assistant vice chancellor of student affairs, five deans, and five academic advisors. No items were omitted since they were all deemed necessary to provide a comprehensive view of the attrition/retention issue. The final draft was then sent for printing.

The ISPS is a two-part self-report questionnaire to measure the perception of administrators, faculty, and staff (personnel) concerning institutional factors impacting student persistence. The responses from Part One are the only results reported in this dissertation.

This survey study used the data collected from the ISPS to validate the instrument 
and to address the two research questions and three null hypotheses.

\section{Research Questions}

1. What university efforts are perceived by personnel as the least and the most important institutional factors impacting student retention/attrition?

2. What university efforts are perceived by personnel as the least and the most satisfactorily addressed institutional factors impacting student retention/attrition?

Null Hypotheses

1. There is no significant difference between the Importance Scale scores and the Satisfaction Scale scores of university personnel.

2. There are no significant differences among university personnel in their perception of the importance of institutional factors impacting student retention/attrition.

3. There are no significant differences among university personnel in their satisfaction with the university efforts to address institutional factors impacting student retention/attrition.

Research Questions 1 and 2 were addressed by calculating and rank ordering the mean scores of each of the 41 items and for the combined total scale scores. For Null Hypothesis 1, a t-test was conducted to identify significant differences between the total and the 41 -item mean scores of the Importance and Satisfaction Scales. Null Hypothesis 2 was tested with multivariate analyses to identify significant differences of the combined total scale scores and with each of the 41 items on the five demographic groups: university status; employment time; gender; divisions, schools, and programs; and teach introductory 
level course(s). Discriminant analysis was conducted when the divisions. schools, and programs subgroups indicated that there were significant differences in the multivariate analysis of variance. One-way analysis of variance was used to test significant differences of the individual items on the university status; employment time; and divisions, schools, and programs demographic subgroups. The Student-Neuman-Keuls--Post Hoc Multiple Comparison Procedure--was used to identify pairwise differences for all significant $\underline{\underline{F}} \mathrm{~s}$ in the analysis of variance. The I-test was used to analyze the difference between gender and teach introductory level course(s) demographic subgroups.

Null Hypothesis 3 was tested with multivariate analyses to identify significant differences using the combined total scale score and with each of the 41 items on the five demographic groups: university status; employment time; gender; divisions, schools, and programs; and teach introductory level course(s). Discriminant analysis was conducted when the university status subgroups indicated significant differences in the multivariate analysis of variance. One-way analyses of variance were used to test significant differences of the individual items on the university status; employment time; and divisions, schools, and programs subgroups. The Student-Neuman-Keuls--Post Hoc Multiple Comparison Procedure--was used to identify pairwise differences for all significant Es in the analysis of variance. I-tests were used to analyze the difference between gender and teach introductory level course(s) subgroups.

The five independent demographic variables for the five groups were:

1. University Status: Administrator, Faculty, Clerical/Technical Staff, and Professional Staff 
2. Employment Time: Less than 1 year, 1 to 5 years. 6 to 10 years, and 11 or more years

3. Gender: Female and Male

4. Divisions, Schools, and Programs: Arts, Business \& Economics, Education, Freshman, Liberal Arts \& Sciences, School of Nursing, School of Public and Environmental Affairs (SPEA), and Other. The "Other" subgroup consisted of the Division of Continuing Education, Division of Labor Studies, General Studies Degree Program, Dental Education, School of Library and Information Science, and School of Social Work

5. Teach Introductory Course(s): Yes and No.

The results from this study can provide administrators with insights on ways to increase student retention by modifying or introducing new institutional efforts. In addition, this research was to inform decision makers of areas where efficient changes can be considered to communicate, educate, and develop institutional programs, activities, and personnel that can significantly improve student retention.

\section{Instrument Validation}

This study incorporated an exploratory factor analysis, which sought to identify factors impacting student attrition. In this section, the validation process of the instrument is discussed to confirm the instrument's ability to measure the construct within a credible and dependable degree of statistical adequacy. Validation for a new instrument is very important. This is done by judgmental and empirical evidence (Gable \& Wolf, 1993, p. 
95). Judgmental evidence encompasses developing the instrument construct and items from the review of related research studies and from the expert judges. The expert judges consisted of university administrators, deans, professional staff, and academic advisors

Instrument validation provides a basis for inferential appropriateness when generalizing upon other subjects within the population or upon another population. I employed standard judgmental and empirical research procedures to obtain adequate content and construct validity for the operationalization of my exploratory student persistence model.

Content validity is concerned with the extent to which items of an instrument adequately sample the affective conceptual universe being measured (Gable \& Wolf, 1993, p. 96). This is done by taking the conceptual definition from a theoretical base and operationally defining the concept so that it can be measured.

I have done this by using Tinto's (1987) theory and model of student departure and operationalized it into the Melendez Model of Transactional Satisfaction Toward Student Persistence. (See Figure 2.) Only the transactional institutional experience of the model was used to develop the instrument and to interpret the results. The other variables and contructs of the instrument were assumed as valid and were not tested in this study.

To control for internal and external validity of the instrument contents, only activities (factors) occurring within the institutional environment were considered in this study. This limited "plausible rival hypotheses" (McMillan \& Schumacher, 1993, p. 158). Also, no pretest, posttest, or treatments were preformed.

The survey subjects included the total population of the group being studied. 
Also, the pilot study conducted on another similar university personnel group controlled for researcher bias of inclusion or exclusion of extraneous factors or rival hypotheses. Evidence of construct validity is confirmed when there is adequate evidence of construct representation for inferential generalizability and interpretability of results. This is accomplished through expert judges assisting in the item selection and by statistical analysis. The former was discussed earlier in the chapter, and the latter was accomplished through SPSS/PC+ reliability and factor analysis.

This study is based on the theoretical concept that student attrition/retention is a complex phenomena influenced by various activities espoused by a university (Bean, 1980, Noel et al., 1985; Pascarella, 1982b; Tinto, 1987). The study employed exploratory reliability and factor analysis to identify complex dimensionalities of the student persistence construct. Initially, reliability analysis was used to examine the statistical covariance and correlations between the items. The Cronbach Alpha coefficient for the Importance Scale was .95 and for the Satisfaction Scale was .91. Next, the instrument items were factor analyzed to identify the best construct factor fit(s) for the items.

The high alpha coefficients and the adequate statistical fit supported the item/factor selection and the item listing into two dimensions: items 1 to 23 as institutional efforts toward student academic and personal satisfaction, and items 24 to 41 as students' efforts toward academic and personal satisfaction. Also, the analyses confirmed the complexity of student persistence in both scales with the selection of eight final interpretable factors (Noel et al., 1985, p. 10).

In the reliability analysis, several tests were used to confirm item-content 
reliability. The high Cronbach Alpha reliability coefficients reduced the chances of a Type II error where a false null hypothesis is accepted (Gable \& Wolf. 1993, p. 217). Affective instruments with alpha coefficients of 0.70 to 0.90 are within the acceptable levels of reliability, and 0.90 to 0.99 levels are excellent. An instrument is considered to have little error variances and to be highly reliable if the coefficients are above 0.90 (McMillian \& Schumacker, 1993, p. 227).

The Cronbach Alpha coefficient was 0.9519 for the total Importance Scale, 0.9198 for the Importance Institutional subscale, and 0.9252 for the Importance Student subscale. The reliability coefficient was 0.9111 for the total Satisfaction Scale, 0.8632 for the Satisfaction Institutional subscale, and $0.865 \mathrm{l}$ for the Satisfaction Student subscale. These alpha scores indicated a high adequacy level of content reliability. The following series reliability analysis confirmed the content selection of the items within the instrument (Gable \& Wolf, 1993)

Importance Scale

When the Scale Variance if Item Deleted scores are significantly higher than the Total Scale Variance, this may also indicate the presence of extreme outlier items, which may need to be removed from the instrument. The highest item variance of 409.4026 was not larger than the Total Scale Variance of 421.6032. Again, all the items had an acceptable level of total scale variances.

The column labeled Corrected Item-Total is a crucial reliability test in that the scores represent the correlation of an item with the remaining items. The correlation of 
less than 2000 may show the need to delete the item(s) (Gable \& Wolf, 1993, p. 225). Item 11 had the lowest Corrected Item-Total Correlation of .3215 , however, it is still larger than the minimum acceptable score

The Alpha if Item Deleted is extremely important as it showed the alpha level if the particular item is deleted from the scale. A significant increase in the alpha level may point out a need to delete the item from the scale since it has low correlations with the other items. Item 11 had the highest alpha change of .9522 . Although the score is higher than the Importance Scale total alpha of .9519 , the difference of .003 is minor. Thus, this and all the other items were left in the instrument.

Therefore, the reliability analysis for the Importance Scale confirmed that all the items are acceptable representations of the content universe of the Melendez construct of student persistence. These data are summarized in Table 1.

The highest Scale Variance if Item Deleted of 140.8706 in item 11 is smaller than the total subscale variance of 149.1164 . In the Corrected Item-Total, item 11 has the lowest Corrected Item-Total Correlation of .3584 . It is still larger than the minimum acceptable score of 2000 .

The last column, Alpha if Item Deleted, showed item 11 with the highest alpha change of .9201 . Although the score is higher than the Importance Institutional subscale total alpha of .9198 , the difference of .003 is small. The total scale inter-item correlation was 3404 for this subscale. Thus, again, all the other items obtained acceptable scores to confirm the Importance Institutional subscale reliability. A summary of these data is in Table 2. 
Table 1

Reliability Analysis: Importance--Total

\begin{tabular}{|c|c|c|c|c|}
\hline Item & $\begin{array}{l}\text { Scale } \\
\text { Mean } \\
\text { if Item } \\
\text { Deleted }\end{array}$ & $\begin{array}{l}\text { Scale } \\
\text { Variance } \\
\text { if Item } \\
\text { Deleted }\end{array}$ & $\begin{array}{l}\text { Corrected } \\
\text { Item-Total } \\
\text { Correlation }\end{array}$ & $\begin{array}{l}\text { Alpha } \\
\text { if Item } \\
\text { Deleted }\end{array}$ \\
\hline 1 & 164.8378 & 403.3069 & .6466 & .9504 \\
\hline 2 & 165.2635 & 404.1546 & 4691 & .9513 \\
\hline 3 & 166.1014 & 407.4386 & 3483 & 9522 \\
\hline 4 & 165.6284 & 403.0106 & .4635 & 9514 \\
\hline 5 & 165.3581 & 405.1838 & 5184 & 9510 \\
\hline 6 & 165.8851 & 405.9255 & .3895 & 9519 \\
\hline 7 & 164.9257 & 403.2665 & .6407 & .9504 \\
\hline 8 & 165.1486 & 401.7601 & .5905 & .9506 \\
\hline 9 & 165.4189 & 403.0886 & .5181 & .9510 \\
\hline 10 & 165.3581 & 402.1906 & 5581 & .9507 \\
\hline 11 & 165.7703 & 409.4026 & .3215 & 9522 \\
\hline 12 & 165.3716 & 402.3984 & .5733 & .9507 \\
\hline 13 & 165.3851 & 402.4017 & .5582 & 9507 \\
\hline 14 & 165.1892 & 401.6374 & .6671 & .9502 \\
\hline 15 & 165.7365 & 396.5627 & .5927 & 9506 \\
\hline 16 & 165.7162 & 398.2999 & .5490 & .9509 \\
\hline 17 & 165.7162 & 3989801 & 5743 & .9507 \\
\hline 18 & 165.7027 & 396.5913 & .6657 & 9500 \\
\hline 19 & 165.6689 & 403.7332 & .4873 & .9512 \\
\hline 20 & 165.5608 & 396.2752 & .6254 & .9503 \\
\hline 21 & 166.0743 & 398.0965 & .5226 & .9511 \\
\hline 22 & 165.5473 & 396.9977 & .6530 & $.950 \mathrm{l}$ \\
\hline 23 & 165.4730 & 399.6251 & .6331 & .9503 \\
\hline 24 & 165.0270 & 400.2306 & .6951 & .9500 \\
\hline 25 & 165.3311 & 403.2978 & .5190 & .9510 \\
\hline 26 & 165.3986 & 396.9352 & .6529 & .9501 \\
\hline 27 & 165.1959 & 403.9818 & .5703 & .9507 \\
\hline 28 & 164.9730 & 403.0333 & .6218 & .9505 \\
\hline 29 & 165.1622 & 401.2933 & .6587 & .9502 \\
\hline 30 & 165.3311 & 399.6243 & .6647 & .9501 \\
\hline 31 & 164.9797 & 404.3737 & .6080 & .9506 \\
\hline 32 & 165.8986 & 399.8604 & .5105 & .9512 \\
\hline
\end{tabular}


Table 1--Continued.

\begin{tabular}{lllll}
\hline & $\begin{array}{l}\text { Scale } \\
\text { Mean } \\
\text { if Item } \\
\text { Deleted }\end{array}$ & $\begin{array}{l}\text { Scale } \\
\text { Variance } \\
\text { if Item } \\
\text { Deleted }\end{array}$ & $\begin{array}{l}\text { Corrected } \\
\text { Item-Total } \\
\text { Correlation }\end{array}$ & $\begin{array}{l}\text { Alpha } \\
\text { if Item } \\
\text { Deleted }\end{array}$ \\
\hline 33 & 165.8446 & 402.9213 & .4760 & .9513 \\
34 & 165.1216 & 400.8014 & .6647 & .9502 \\
35 & 164.9527 & 401.3515 & .6580 & .9502 \\
36 & 165.7905 & 405.0375 & .5213 & .9510 \\
37 & 166.0608 & 404.1663 & .4290 & .9517 \\
38 & 165.5068 & 406.5238 & .4704 & 9513 \\
39 & 165.2162 & 398.9869 & .6773 & .9500 \\
40 & 165.4054 & 399.4400 & .6359 & .9503 \\
41 & 165.7500 & 400.4065 & .5703 & 9507 \\
\hline
\end{tabular}

Note. Importance Scale reliability coefficient for the 41 items is Alpha $=.9519$ with 148 cases. Cases with missing scores were omitted from the analysis.

The highest item variance of 88.0001 is item 27 . It is smaller than the subscale variance of 96.2534 . For the Corrected Item-Total, item 33 has the lowest Corrected Item-Total Correlation of 4715 and is larger than the minimum acceptable score of 2000. The Alpha if Item Deleted shows item 33 with the highest alpha change of 9250 . This is still smaller than the Importance Student subscale total alpha of .9252 . Thus, all the other items obtained acceptable scores to confirm the Importance Student subscale reliability. A summary of these data is in Table 3.

\section{Satisfaction Scale}

The highest item variance of 262.4959 of item 10 is smaller than the total subscale 
Table 2

Reliability Analysis: Importance - Institutional Subscale

\begin{tabular}{|c|c|c|c|c|}
\hline Item & $\begin{array}{l}\text { Scale } \\
\text { Mean } \\
\text { if Item } \\
\text { Deleted }\end{array}$ & $\begin{array}{l}\text { Scale } \\
\text { Variance } \\
\text { if Item } \\
\text { Deleted }\end{array}$ & $\begin{array}{l}\text { Corrected } \\
\text { Item-Total } \\
\text { Correlation }\end{array}$ & $\begin{array}{l}\text { Alpha } \\
\text { if Item } \\
\text { Deleted }\end{array}$ \\
\hline 1 & 89.0811 & 139.0954 & .5899 & 9162 \\
\hline 2 & 89.5068 & 138.0476 & .4955 & 9176 \\
\hline 3 & 90.3446 & 139.7512 & .3797 & 9200 \\
\hline 4 & 89.8716 & 136.9970 & .5040 & 9175 \\
\hline 5 & 89.6014 & 138.6087 & .5556 & 9165 \\
\hline 6 & 90.1284 & 137.6501 & .4785 & 9180 \\
\hline 7 & 89.1689 & 138.7808 & .6027 & 9160 \\
\hline 8 & 89.3919 & 136.5393 & 6293 & 9152 \\
\hline 9 & 89.6622 & 137.6946 & .5329 & 9168 \\
\hline 10 & 89.6014 & 136.7448 & .5971 & 9157 \\
\hline 11 & 90.0135 & 140.8706 & .3584 & .9201 \\
\hline 12 & 89.6149 & 137.4085 & .5847 & 9160 \\
\hline 13 & 89.6284 & 137.3916 & .5696 & 9162 \\
\hline 14 & 89.4324 & 137.4716 & .6521 & .9151 \\
\hline 15 & 89.9797 & 134.4826 & .5766 & 9161 \\
\hline 16 & 89.9595 & 135.3045 & .5405 & 9169 \\
\hline 17 & 89.9595 & 135.0188 & .5999 & 9155 \\
\hline 18 & 89.9459 & 134.2420 & .6645 & 9143 \\
\hline 19 & 89.9122 & 138.8426 & .4620 & 9182 \\
\hline 20 & 89.8041 & 133.9545 & .6269 & .9150 \\
\hline 21 & 90.3176 & 134.5991 & .5374 & 9171 \\
\hline 22 & 89.7905 & 134.5205 & .6494 & .9146 \\
\hline 23 & 89.7162 & 135.3475 & .6681 & .9144 \\
\hline
\end{tabular}

Note. Importance Institutional subscale reliability coefficient for the 23 items is Alpha $=$ 9198 with 148 cases. Cases with missing scores were omitted from the analysis. 
Table 3

Reliability Analysis: Importance--Student Subscale

\begin{tabular}{lllll}
\hline & $\begin{array}{l}\text { Scale } \\
\text { Mean } \\
\text { if Item } \\
\text { Deleted }\end{array}$ & $\begin{array}{l}\text { Scale } \\
\text { Variance } \\
\text { if Item } \\
\text { Deleted }\end{array}$ & $\begin{array}{l}\text { Corrected } \\
\text { Item-Total } \\
\text { Correlation }\end{array}$ & $\begin{array}{l}\text { Alpha } \\
\text { if Item } \\
\text { Deleted }\end{array}$ \\
\hline & & & & \\
24 & 71.1892 & 86.0592 & .6939 & .9194 \\
25 & 71.4932 & 86.7142 & .5615 & .9224 \\
26 & 71.5608 & 84.3160 & .6598 & .9200 \\
27 & 71.3581 & 88.0001 & .5512 & .9225 \\
28 & 71.1351 & 87.3966 & .6166 & .9212 \\
29 & 71.3243 & 86.0302 & .6961 & 9194 \\
30 & 71.4932 & 85.0272 & .7148 & .9188 \\
31 & 71.1419 & 87.3063 & .6619 & 9204 \\
32 & 72.0608 & 85.1323 & .5390 & .9237 \\
33 & 72.0068 & 87.1768 & .4715 & .9250 \\
34 & 71.2838 & 85.8101 & .7007 & .9192 \\
35 & 71.1149 & 85.7214 & .7211 & .9189 \\
36 & 71.9527 & 87.9501 & .5405 & .9228 \\
37 & 72.2230 & 86.3241 & .5064 & .9243 \\
38 & 71.6689 & 87.8556 & .5454 & .9227 \\
39 & 71.3784 & 84.8354 & .7197 & .9186 \\
40 & 71.5676 & 85.2403 & .6610 & 9200 \\
41 & 71.9122 & 85.3052 & .6148 & .9211 \\
& & & & \\
\hline & & & & \\
\hline
\end{tabular}

Note. Importance Student subscale reliability coefficient for the 18 items is alpha $=$ .9252 with 148 cases. Cases with missing scores were omitted from the analysis.

variance of 270.1372. In Corrected Item-Total, item 2 has the lowest Corrected ItemTotal Correlation of 2391 . Although this is low, it is still higher than the minimum acceptable score of 2000 .

Alpha if Item Deleted shows item 2 with the highest alpha change of .9113. This score is slightly higher than the Satisfaction Scale alpha of .9111 , but the difference of 
002 is very small. Again, the other items obtained acceptable scores to confirm the Satisfaction Scale reliability. These data are summarized in Table 4.

The Satisfaction Institutional subscale showed the two items, 15 and 22. with the same highest scale mean of 72.9000. Yet, they are not larger than the subscale mean of 75.9154. The highest item variance of 97.4207 of item 4 is smaller than the subscale variance of 102.4967. In Corrected Item-Total, item 4 has the lowest Corrected ItemTotal Correlation of 2640 , which is larger than the minimum acceptable score of 2000 . Item 4 in column Alpha if Item Deleted had the highest alpha change of .8630 . This is still smaller than the Satisfaction Institutional subscale alpha of .8632. All the other items obtained acceptable scores confirming the Satisfaction Institutional subscale reliability. A summary of these data is in Table 5 .

For the Satisfaction Student subscale, the highest item variance of 62.6362 for item 27 is smaller than the total subscale variance of 66.3843. In Corrected Item-Total, item 27 has the lowest Corrected Item-Total Correlation of .2844, which is larger than the minimum acceptable score of 2000 . Item 25 in Alpha if Item Deleted has the highest alpha change of .8652 . This is insignificantly larger, at .001 , than the Satisfaction Institutional subscale alpha of .8651 . All the other items obtained acceptable scores and confirmed the Satisfaction Student subscale reliability. A summary of these data is in Table 6.

Gable and Wolf (1993) cited recommendations for subject-to-item ratios as 5:1 or 10:1 as most favorable. Items are said to produce more stable factor extractions if the subject-to-item ratio is over $10: 1$. The subject-to-item ratio for this study was $4.8: 1$ or 
Table 4

Reliability Analysis: Satisfaction--Total

\begin{tabular}{|c|c|c|c|c|}
\hline Item & $\begin{array}{l}\text { Scale } \\
\text { Mean } \\
\text { if Item } \\
\text { Deleted }\end{array}$ & $\begin{array}{l}\text { Scale } \\
\text { Variance } \\
\text { if Item } \\
\text { Deleted }\end{array}$ & $\begin{array}{l}\text { Corrected } \\
\text { Item-Total } \\
\text { Correlation }\end{array}$ & $\begin{array}{l}\text { Alpha } \\
\text { if Item } \\
\text { Deleted }\end{array}$ \\
\hline 1 & 128.9154 & 258.7137 & .3389 & 9103 \\
\hline 2 & 128.8154 & 262.9424 & .2391 & 9113 \\
\hline 3 & 128.7462 & 259.1366 & .4046 & .9093 \\
\hline 4 & 128.3000 & 260.8318 & .3174 & 9104 \\
\hline 5 & 129.0538 & 257.3227 & .3961 & .9095 \\
\hline 6 & 128.4308 & 260.7897 & 3678 & 9097 \\
\hline 7 & 128.7000 & 255.7620 & 4417 & 9089 \\
\hline 8 & 128.4923 & 258.1899 & 3681 & 9099 \\
\hline 9 & 128.2000 & 258.9984 & .3466 & .9101 \\
\hline 10 & 128.2154 & 262.4959 & .2650 & .9109 \\
\hline 11 & 128.7615 & 260.9117 & .3936 & .9095 \\
\hline 12 & 128.7385 & 253.5900 & .5818 & .9072 \\
\hline 13 & 128.7769 & 254.5933 & .4238 & .9093 \\
\hline 14 & 128.8000 & 255.8667 & .4106 & .9094 \\
\hline 15 & 129.0846 & 255.3494 & .5345 & 9078 \\
\hline 16 & 129.0769 & 257.2809 & .3952 & .9095 \\
\hline 17 & 128.9000 & 258.2767 & .3856 & .9096 \\
\hline 18 & 129.2923 & 251.5573 & .5929 & 9069 \\
\hline 19 & 129.0769 & 255.3584 & .4845 & .9083 \\
\hline 20 & 129.1385 & 254.0582 & 5748 & 9073 \\
\hline 21 & 128.8615 & 260.7094 & .3524 & .9099 \\
\hline 22 & 129.0846 & 255.1633 & .5557 & .9076 \\
\hline 23 & 128.9231 & 256.8778 & .4352 & .9090 \\
\hline 24 & 128.6846 & 256.1556 & .4319 & .9090 \\
\hline 25 & 128.9692 & 255.3789 & .4600 & .9087 \\
\hline 26 & 129.4615 & 258.4520 & .3573 & .9100 \\
\hline 27 & 128.6000 & 260.9860 & .3723 & .9097 \\
\hline 28 & 128.4615 & 259.4287 & .4501 & .9089 \\
\hline 29 & 128.8692 & 257.1223 & .5236 & .9081 \\
\hline 30 & 129.0231 & 253.8367 & .5890 & .9072 \\
\hline 31 & 128.9462 & 258.6250 & .4273 & .9091 \\
\hline 32 & 129.4462 & 259.8769 & .3564 & .9099 \\
\hline 33 & 128.9615 & 259.8667 & .3814 & .9096 \\
\hline
\end{tabular}


Table 4--Continued

\begin{tabular}{lllll} 
& $\begin{array}{l}\text { Scale } \\
\text { Mean } \\
\text { if Item } \\
\text { Deleted }\end{array}$ & $\begin{array}{l}\text { Scale } \\
\text { Variance } \\
\text { if Item } \\
\text { Deleted }\end{array}$ & $\begin{array}{l}\text { Corrected } \\
\text { Item-Total } \\
\text { Correlation }\end{array}$ & $\begin{array}{l}\text { Alpha } \\
\text { if Item } \\
\text { Deleted }\end{array}$ \\
\hline & & & & \\
34 & 129.0692 & 259.9719 & .3199 & .9105 \\
35 & 128.9154 & 258.6982 & .4113 & .9093 \\
36 & 128.8308 & 259.7076 & .4636 & .9089 \\
37 & 129.1846 & 257.2680 & .4657 & 9086 \\
38 & 128.8846 & 260.7540 & .3496 & .9100 \\
39 & 128.9846 & 252.9610 & 6155 & 9068 \\
40 & 128.8615 & 254.8334 & .5856 & 9073 \\
41 & 129.4615 & 256.6691 & .4550 & .9087 \\
\hline
\end{tabular}

Note. Satisfaction Scale reliability coefficient for the 41 items is Alpha $=.9111$ with 130 cases. Cases with missing scores were omitted from the analysis.

197 subjects to 41 items. This ratio level of 4.8 : I may be considered a little low and may produce slightly unstable factor analysis for adequacy in describing the factor structure of the construct being studied. However, in this study, other item analyses were used to confirm the construct validity of the items and factors.

The communalities values and the residual percentages were examined to determine validity of the item selection. Also, the Importance and Satisfaction Scales were individually factor analyzed to finalize the selection and naming of the dimensions (construct factors) to adequately explain the conceptual constructs. The following analyses were deemed necessary to address the scope of this research study: principal 
Table 5

Reliability Analysis: Satisfaction-Institutional Subscale

\begin{tabular}{|c|c|c|c|c|}
\hline Item & $\begin{array}{l}\text { Scale } \\
\text { Mean } \\
\text { if Item } \\
\text { Deleted }\end{array}$ & $\begin{array}{l}\text { Scale } \\
\text { Variance } \\
\text { if Item } \\
\text { Deleted }\end{array}$ & $\begin{array}{l}\text { Corrected } \\
\text { Item-Total } \\
\text { Correlation }\end{array}$ & $\begin{array}{l}\text { Alpha } \\
\text { if Item } \\
\text { Deleted }\end{array}$ \\
\hline l & 72.7308 & 94.6014 & .3721 & .8600 \\
\hline 2 & 72.6308 & 95.6456 & .3754 & 8596 \\
\hline 3 & 72.5615 & 95.0078 & .4418 & 8576 \\
\hline 4 & 72.1154 & 97.4207 & .2640 & 8630 \\
\hline 5 & 72.8692 & 95.1068 & .3554 & 8605 \\
\hline 6 & 72.2462 & 96.6211 & .3658 & .8598 \\
\hline 7 & 72.5154 & 93.9881 & .4112 & 8586 \\
\hline 8 & 72.3077 & 92.7418 & .4926 & .8557 \\
\hline 9 & 72.0154 & 95.3796 & .3479 & .8607 \\
\hline 10 & 72.0308 & 97.0998 & .2956 & .8620 \\
\hline 11 & 72.5769 & 96.8041 & .3853 & .8594 \\
\hline 12 & 72.5538 & 92.1405 & .5874 & .8527 \\
\hline 13 & 72.5923 & 93.0185 & .4060 & .8591 \\
\hline 14 & 72.6154 & 94.0990 & .3770 & .8600 \\
\hline 15 & 72.9000 & 93.0519 & .5500 & 8541 \\
\hline 16 & 72.8923 & 94.6550 & .3784 & .8597 \\
\hline 17 & 72.7154 & 93.2439 & .4905 & .8558 \\
\hline 18 & 73.1077 & 91.8178 & .5432 & .8538 \\
\hline 19 & 72.8923 & 93.2131 & .4864 & .8559 \\
\hline 20 & 72.9538 & 92.4010 & .5823 & .8530 \\
\hline 21 & 72.6769 & 95.7088 & .4076 & .8586 \\
\hline 22 & 72.9000 & 92.7884 & .5827 & .8532 \\
\hline 23 & 72.7385 & 93.7450 & .4598 & .8568 \\
\hline
\end{tabular}

Note. Satisfaction Institutional subscale reliability coefficient for the 23 items is alpha $=$ 8632 with 130 cases. Cases with missing scores were omitted from the analysis. 
Table 6

Reliability Analysis: Satisfaction--Student Subscale

\begin{tabular}{|c|c|c|c|c|}
\hline Item & $\begin{array}{l}\text { Scale } \\
\text { Mean } \\
\text { if Item } \\
\text { Deleted }\end{array}$ & $\begin{array}{l}\text { Scale } \\
\text { Variance } \\
\text { if Item } \\
\text { Deleted }\end{array}$ & $\begin{array}{l}\text { Corrected } \\
\text { Item-Total } \\
\text { Correlation }\end{array}$ & $\begin{array}{l}\text { Alpha } \\
\text { if Item } \\
\text { Deleted }\end{array}$ \\
\hline 24 & 52.7692 & 58.3029 & .4971 & .8575 \\
\hline 25 & 53.0538 & 57.9893 & .5224 & .8562 \\
\hline 26 & 53.5462 & 60.0637 & .3731 & .8633 \\
\hline 27 & 52.6846 & 62.6362 & .2844 & .8652 \\
\hline 28 & 52.5462 & 61.7072 & .3778 & .8619 \\
\hline 29 & 52.9538 & 59.4242 & 5600 & 8552 \\
\hline 30 & 53.1077 & 58.0968 & .5991 & 8530 \\
\hline 31 & 53.0308 & 59.8130 & .4852 & .8579 \\
\hline 32 & 53.5308 & 59.9409 & .4460 & .8595 \\
\hline 33 & 53.0462 & 60.1994 & .4571 & .8590 \\
\hline 34 & 53.1538 & 60.5808 & .3533 & 8639 \\
\hline 35 & 53.0000 & 60.5116 & .4111 & .8609 \\
\hline 36 & 52.9154 & 60.5742 & .5158 & .8573 \\
\hline 37 & 53.2692 & 58.5394 & .5743 & .8541 \\
\hline 38 & 52.9692 & 60.9448 & .3983 & .8613 \\
\hline 39 & 53.0692 & 57.7239 & 6222 & 8519 \\
\hline 40 & 52.9462 & 58.4234 & 6115 & .8528 \\
\hline 41 & 53.5462 & 58.8234 & .5087 & .8568 \\
\hline
\end{tabular}

Note. Satisfaction Student subscale reliability coefficients for the 18 items is alpha $=$ 8651 with 130 cases. Cases with missing scores were omitted from the analysis. 
components analysis (PC), principal axes factoring (PAF), eigenvalues, percentage of variance, factor matrix rotation: varimax (orthogonal) and oblimin rotations.

Since the issue of item correlation was discussed in the reliability analysis. I begin this discussion of the factor analysis with the Kaiser-Meyer-Olkin (KMO) Measure of Sampling Adequacy (MSA). The KMO is an index number that compares the magnitude of the observed correlation coefficients to the magnitude of the partial correlation coefficients. An item should be deleted or left in the instrument according to the scale KMOs or individual KMO item correlation. The SPSS/PC+ program gives KMOs for the total variable and for all the individual items (Bailey, 1993, p. 94). The individual item KMOs are found in the diagonal of the anti-image correlation matrix.

Bailey (1993) reported the KMO measures in the 0.90 s as marvelous, 0.80 s as meritorious, $0.70 \mathrm{~s}$ as middling, $0.60 \mathrm{~s}$ as mediocre, $0.50 \mathrm{~s}$ as miserable, and below 0.50 as unacceptable. Any item below 0.50 is to be dropped from the analysis. The KMOs for the individual Importance Scale items ranged between .6926 and .95048 , or mediocre to marvelous

In the Satisfaction Scale, they ranged between .54706 and .87897 or from miserable to meritorious. The total scale KMOs for Importance was 902 and for Satisfaction was .749. Thus, the items and the scale KMOs were judged adequate for both scales, confirming the decision to maintain all the present items in this study.

Final communalities resulting from the eight-factor solution are the sum of the squared correlations of each row of the factor matrix and explain only a subset of the variances. Communalities range from 0 to 1 , with 0 being no variance explained and 1 
explaining all the variance by the common factor (Gable \& Wolf, 1993, p. 23; Norusis, 1990, pp. 327-327). The communalities score for the Importance Scale ranged from .57017 to .76834 , items 7 and 23 respectively, and for the Satisfaction Scale they ranged from .53136 to .77990 , items 6 and 17 respectively. This showed that a good to a very good amount of variance is explained by each of the items in the Importance and Satisfaction Scales.

Initially, both principal component (PC) analysis and principal axes factoring (PAF) were used to consider the number of factor extractions to select. The PC results were much clearer than the PAF. The PC method correlated the institutional and student effort items better in both scales, especially so in the Importance Scale. Thus, the PC was chosen to determine the initial number of construct factor extractions. In PC, a hierarchial linear combination of the items was formed. The first component extracts the maximum variance from the data. Then, the second component extracts the next largest maximum explained variance, totally uncorrelated from the first, and so on (Norusis, 1990, p. 324; Tabachnick \& Fidell, 1996, p. 664). The analysis is printed in descending order of percentage of variance. Thus, the first few factors account for the highest percentage of the variance and the last factors are the lowest percentage of variance (Tabachnick \& Fidell, 1996, p. 638). In both the scales' two factor extractions, the student effort items were first. This suggested that these were the highest factor correlations, which accounted for the maximum explained variance. This is especially so for the Importance Scale.

The next step in determining the number of factors to extract is to look at the 
eigenvalues and their corresponding percentage of variance accounted for by each derived factor (Gable \& Wolf, 1993, p. 122). The eigenvalues or lambdas greater than or equal to 1.0 are retained, which represent a percentage of the total variances of the 41 items (Norusis, 1990 , p. 324). Only factors accounting for as much variance as a single item are retained in the selection of the number of factor extractions. The Importance Scale produced nine factors with eigenvalues (roots) greater than or equal to 1.0. This explained $67 \%$ of the total variance. These data are summarized in Tabie 7

The Satisfaction Scale analysis produced 12 factors with eigenvalues greater than or equal to 1.0 , explaining $67.7 \%$ of the total variance. According to Gable and Wolf (1993), a percentage of variance above $60 \%$ is an adequate level of factor variance for an affective scale (p. 111). This confirmed Tinto's $(1975,1987)$ theory that student departure is a complex phenomena (Noel et al., 1985, p. 10). The Scree Test plots the eigenvalues against the factors. This test is not exact and involves subjective judgment in determining where the discontinuity of the eigenvalues occurs (Tabachnick \& Fidell, 1996, p. 683). Both Scree Tests of the two scales were not very helpful in showing a clear fall off for the selection of the factor extraction. These criteria were not used to extract the number of final factors. These data are summarized in Table 8 .

After considering all the above tests, I decided to try a variety of factor extractions and rotations and review the results for the "best fit" to the conceptual constructs (Gable \& Wolf, 1993, p. 113). The final decision as to the number of factors to extract was based upon which factor rotation, oblimin or varimax, gave the best interpretability and utility of the factor solution (Tabachnick \& Fidell, 1996, pp. 672-672). 
Table 7

Factor Analysis: Importance-4l Items

\begin{tabular}{|c|c|c|c|c|c|}
\hline Items & $\begin{array}{l}\text { Item } \\
\text { KMO }\end{array}$ & Communality & Factor & Eigenvalues & $\begin{array}{l}\text { Percentage } \\
\text { of Variance }\end{array}$ \\
\hline 1 & .90232 & .70273 & 1 & 14.80222 & 36.1 \\
\hline 2 & .91386 & .57110 & 2 & 2.64309 & 42.5 \\
\hline 3 & .78552 & .68383 & 3 & 2.36246 & 48.3 \\
\hline 4 & .80531 & .75895 & 4 & 1.74288 & 52.6 \\
\hline 5 & .86640 & 64394 & 5 & 1.36186 & 55.9 \\
\hline 6 & .82309 & 64600 & 6 & 1.32325 & 59.1 \\
\hline 7 & .90039 & .57017 & 7 & 1.11905 & 61.8 \\
\hline 8 & .91989 & 62074 & 8 & 1.07050 & 64.5 \\
\hline 9 & .88386 & 62578 & 9 & 1.04740 & 67.0 \\
\hline 10 & .91798 & .55596 & & & \\
\hline 11 & .69236 & .73500 & & & \\
\hline 12 & .88971 & 63782 & & & \\
\hline 13 & .91197 & .73196 & & & \\
\hline 14 & .93758 & .67035 & & & \\
\hline 15 & .90469 & .59844 & & & \\
\hline 16 & .88606 & .56693 & & & \\
\hline 17 & .87589 & .72419 & & & \\
\hline 18 & .92946 & .65053 & & & \\
\hline 19 & .87146 & .71082 & & & \\
\hline 20 & .93035 & .62097 & & & \\
\hline 21 & .89967 & .69731 & & & \\
\hline 22 & .92473 & .60337 & & & \\
\hline 23 & .88526 & .76834 & & & \\
\hline 24 & .92160 & .72475 & & & \\
\hline 25 & .88939 & .70890 & & & \\
\hline 26 & .92500 & .74826 & & & \\
\hline 27 & .91482 & .70771 & & & \\
\hline 28 & .92972 & .69550 & & & \\
\hline 29 & .91905 & .66779 & & & \\
\hline 30 & .95048 & .59859 & & & \\
\hline 31 & .93424 & .70718 & & & \\
\hline 32 & .85294 & .68265 & & & \\
\hline 33 & .90351 & .57277 & & & \\
\hline
\end{tabular}


Table 7--Continued.

\begin{tabular}{lllll}
\hline & Item & & & \\
Items & KMO & Communality & Factor Eigenvalues & $\begin{array}{l}\text { Percentage } \\
\text { of Variance }\end{array}$ \\
\hline 34 & .92122 & .68213 & & \\
35 & .91930 & .74555 & & \\
36 & .91929 & .73555 & & \\
37 & .83286 & .69397 & & \\
38 & .89189 & .62169 & & \\
39 & .92640 & .67243 & & \\
40 & .90555 & .68411 & & \\
41 & .89272 & .75799 & & \\
\hline
\end{tabular}

The oblimin rotation assumes that the factors are correlated. This process is first tried in order to see if an adequately interpretable factor solution is found. If it is not found, then varimax factor rotation is conducted. Varimax rotation assumes that the factors are uncorrelated. The results are compared for best construct fit.

The initial oblimin rotation for the Importance Scale produced a nine-factor solution. However, this produced several one and two mid-range correlated factors that were difficult to interpret. The performance of the 8 and 10 oblimin rotations produced similar results. The varimax rotations were then performed and compared with the oblimin rotation. Ultimately, the varimax rotation provided the better fit and the oblimin rotations were discarded. The default varimax rotation for the Importance Scale resulted in nine factors.

Although the residual correlation was low at 186 (22\%), I tried a 10-factor 
Table 8

Factor Analysis: Satisfaction--41 Items

\begin{tabular}{|c|c|c|c|c|c|}
\hline Items & $\begin{array}{l}\text { Item } \\
\mathrm{KMO}\end{array}$ & Communality & Factor & Eigenvalues & $\begin{array}{l}\text { Percentage } \\
\text { of Variance }\end{array}$ \\
\hline 1 & .63798 & .70230 & 1 & 9.47301 & 23.1 \\
\hline 2 & .54706 & .73624 & 2 & 2.90516 & 30.2 \\
\hline 3 & .72503 & .70482 & 3 & 2.47437 & 36.2 \\
\hline 4 & 69933 & 63067 & 4 & 1.93398 & 40.9 \\
\hline 5 & .71132 & 69549 & 5 & 1.90420 & 45.6 \\
\hline 6 & 70034 & .53136 & 6 & 1.53497 & 49.3 \\
\hline 7 & .79876 & 62477 & 7 & 1.47419 & 52.9 \\
\hline 8 & .81851 & .65029 & 8 & 1.37814 & 56.3 \\
\hline 9 & .80828 & .54501 & 9 & 1.30215 & 59.5 \\
\hline 10 & .56066 & .70839 & 10 & 1.24062 & 62.5 \\
\hline 11 & 68659 & .72653 & 11 & 1.12455 & 65.2 \\
\hline 12 & .83456 & 68009 & 12 & 1.01696 & 67.7 \\
\hline 13 & .73398 & 60236 & & & \\
\hline 14 & .71029 & .70882 & & & \\
\hline 15 & .87897 & 61945 & & & \\
\hline 16 & 64271 & .59447 & & & \\
\hline 17 & .64138 & 77990 & & & \\
\hline 18 & .85834 & 64982 & & & \\
\hline 19 & .61892 & .71441 & & & \\
\hline 20 & .78668 & .66826 & & & \\
\hline 21 & .73685 & .66293 & & & \\
\hline 22 & .83366 & .58924 & & & \\
\hline 23 & .80861 & .71296 & & & \\
\hline 24 & .69643 & .75287 & & & \\
\hline 25 & .75921 & .70060 & & & \\
\hline 26 & .75276 & 63634 & & & \\
\hline 27 & .63379 & .59417 & & & \\
\hline 28 & .59849 & .70321 & & & \\
\hline 29 & .78775 & .71367 & & & \\
\hline 30 & .78420 & .76056 & & & \\
\hline 31 & .77233 & .69730 & & & \\
\hline 32 & .73334 & .69341 & & & \\
\hline 33 & .76150 & .73602 & & & \\
\hline
\end{tabular}


Table 8 -Continued.

\begin{tabular}{|c|c|c|c|c|c|}
\hline Items & $\begin{array}{l}\text { Item } \\
\text { KMO }\end{array}$ & Communality & Factor & Eigenvalues & $\begin{array}{l}\text { Percentage } \\
\text { of Variance }\end{array}$ \\
\hline 34 & .72736 & 70604 & & & \\
\hline 35 & .75027 & .77257 & & & \\
\hline 36 & .79137 & .72885 & & & \\
\hline 37 & 83903 & 67913 & & & \\
\hline 38 & .67491 & 69994 & & & \\
\hline 39 & 86913 & .64354 & & & \\
\hline 40 & 84372 & .63982 & & & \\
\hline 41 & 76912 & 66569 & & & \\
\hline
\end{tabular}

extraction, but it produced one-and two-item factors as did the oblimin rotation. This made interpreting the construct factors difficult. After trying six-, seven-, and eight-factor varimax extractions and comparing all the results. I chose the eight-factor extraction as the best fit for the construct interpretation of the factors. It explained $64.5 \%$ of total variance. (See Appendix C.) This was confirmed when I found the low percentage of residual correlations with absolute values less than $0.05,210(25 \%)$ in the eight varimax rotations. Residual percentages are calculated in a Residual Correlation Matrix, which is constructed from the difference between the observed correlation matrix of observed variables and the reproduced correlation matrix from the factor loadings.

Factor analysis is considered adequate when the correlations in the residual matrix are small, which indicates a close fit between observed and reproduced matrices (Tabachnick \& Fidell, 1996, pp. 637, 649). The final (best fit) eight-factor extraction was 
interpreted and named as follows (the number of items in each factor is in parentheses): Factor I Academic Satisfaction (10), Factor II Institutional Support Services Satisfaction (11), Factor III Student Services Satisfaction (8), Factor IV Student Personal Satisfaction (5), Factor V Campus Regulations (2), Factor VI Student Orientation (2), Factor VII Special Services (2), and Factor VII Academic Outcome (1). These data are summarized in Table 9.

For the Satisfaction Scale, the initial oblimin rotation produced a 12 -factor solution. This gave too many small one- and two-item factors that were scattered throughout the analysis making interpretation of the factors difficult. The 8-, 10-, and 12oblimin factor extractions again did not markedly improve interpretability when reviewed or compared with the varimax rotation. Similarly, the varimax rotation gave the best factor interpretation, and the oblimin rotations were discarded.

The initial varimax rotation for the Satisfaction Scale generated 12 factors. The residual correlation was low at $213(25 \%)$; I then tried an 8-, 10-, 12-, and 13-varimax factor extractions. The 10,12 , and 13 extractions produced many one- and two-item factors that did not provide for clearer interpretability of the factors. After comparing all the factor extractions, I chose the eight-factor extraction for the Satisfaction Scale as it gave the clearest construct interpretability. It explained an acceptable $56.3 \%$ of total variance. The percentage of residual correlations with absolute values less than 0.05 was still low at $292(35 \%)$.

The following eight conceptual factors were interpreted and named (the number of items per factor is in parentheses) from the Satisfaction Scale scores: Factor I Student 
Table 9

Factor Loading: Importance-Eight Factors

Factor Name Items Labels Loading

\begin{tabular}{|c|c|c|c|}
\hline Factor I & 35 & Students' Commitment to Her/His Education & .78856 \\
\hline Academic & 31 & Students' Attitude Toward Education & 76871 \\
\hline \multirow[t]{8}{*}{ Satisfaction } & 34 & Students' Class Attendance & 74396 \\
\hline & 28 & Instructor Effectiveness & 70247 \\
\hline & 29 & Self-Confidence as a Student & 67211 \\
\hline & 40 & Students' Sense of Self-Development & 62255 \\
\hline & 27 & Instructor Academic Expectation of Student & 61506 \\
\hline & 39 & Students' Satisfaction With Institutional & 61091 \\
\hline & 30 & Students' Academic Integration Into the Inst. & 55966 \\
\hline & 38 & Students' Practical Value of Education & .52494 \\
\hline Factor II & 17 & Remedial Course Work Services & .80846 \\
\hline Institutional & 23 & Tutoring Services & .65272 \\
\hline Support & 18 & Social Support Services for Students & .64119 \\
\hline Services & 16 & Minority Retention Efforts & .63063 \\
\hline \multirow[t]{7}{*}{ Satisfaction } & 15 & Mentoring Programs & .62593 \\
\hline & 20 & Study Skills Assessment/Development & 59625 \\
\hline & 13 & Family/Child Care Support Services & .59511 \\
\hline & 14 & Flexible Course Scheduling & .53137 \\
\hline & 22 & Tracking Students' Academic Progress & .50088 \\
\hline & 12 & Academic Support Services & .48906 \\
\hline & 24 & Adm/Fac/Staff Caring About Student Progress & .46983 \\
\hline Factor III & 8 & Freshman Division Services & .66113 \\
\hline Student & 2 & Admissions Services & .63864 \\
\hline Services & 1 & Academic Advising & .59703 \\
\hline \multirow[t]{5}{*}{ Satisfaction } & 10 & Registration Services & .58723 \\
\hline & 6 & Cashier/Bursars Services & .56354 \\
\hline & 9 & Library Services & .53447 \\
\hline & 5 & Career Counseling Services & .49075 \\
\hline & 7 & Financial Aid Services & .39912 \\
\hline
\end{tabular}


Table 9--Continued.

Factor Name Items Labels Loading

\begin{tabular}{|c|c|c|c|}
\hline Factor IV & 41 & Students' Social Integration With Institution & 73855 \\
\hline Students' & 37 & Students' Loyalty Toward the Institution & 68377 \\
\hline Personal & 32 & Students' Campus Involvement & 66681 \\
\hline Satisfaction & 26 & Campus Academic/Social Climate & 64131 \\
\hline & 25 & Adm/Fac/Staff Informal Contact With Student & 50832 \\
\hline Factor V & 3 & Campus Rules and Regulations & 77164 \\
\hline $\begin{array}{l}\text { Campus } \\
\text { Regulations }\end{array}$ & 4 & Campus Safety and Security Services & 75735 \\
\hline Factor VI & 33 & Students' Certainty of Major/Career & .53814 \\
\hline $\begin{array}{l}\text { Student } \\
\text { Orientation }\end{array}$ & 21 & Threshold Learning Communities TLC & 53296 \\
\hline Factor VII & 11 & Transfer Options & .71303 \\
\hline $\begin{array}{l}\text { Special } \\
\text { Services }\end{array}$ & 19 & Students' Internship/Employment & .47707 \\
\hline $\begin{array}{c}\text { Factor VIII } \\
\text { Academic } \\
\text { Outcome }\end{array}$ & 36 & Students' Current GPA & .56622 \\
\hline
\end{tabular}

Note. The full factor rotation matrix can be reviewed in Appendix C.

Personal Satisfaction (5), Factor II Academic Instructional Satisfaction (4), Factor III

Non-instructional Satisfaction (9), Factor IV Student Satisfaction (5), Factor V

Institutional Student Services Satisfaction (8), Factor VI Institutional Satisfaction (4),

Factor VII Special Services Satisfaction (4), and Factor VII External Personal Satisfaction

(2). These data are summarized in Table 10.

These are slightly different from the eight factors of the Importance Scale. 
Table 10

Factor Loading: Satisfaction--Eight Factors

Factor Name Items Labels

Loading

\begin{tabular}{|c|c|c|c|}
\hline Factor I & 32 & Students' Campus Involvement & .81085 \\
\hline Student & 41 & Students' Social Integration With Institution & 68613 \\
\hline Personal & 37 & Students' Loyalty Toward the Institution & 57174 \\
\hline \multirow[t]{2}{*}{ Satisfaction } & 26 & Campus Academic/Social Climate & 55095 \\
\hline & 39 & Students' Satisfaction With Institutional & 45961 \\
\hline Factor II & 17 & Remedial Course Work Services & .74543 \\
\hline Academic & 23 & Tutoring Services & .73841 \\
\hline Instructional & 20 & Study Skills Assessment/Development & 63351 \\
\hline Satisfaction & 12 & Academic Support Services & .48649 \\
\hline Factor III & 31 & Students' Attitude Toward Education & 65955 \\
\hline Non- & 40 & Students' Sense of Self-Development & 57193 \\
\hline instructional & 30 & Students' Academic Integration Into the Inst. & 54246 \\
\hline \multirow[t]{6}{*}{ Satisfaction } & 29 & Self-Confidence as a Student & .53770 \\
\hline & 19 & Students' Internship/Employment & .52593 \\
\hline & 27 & Instructor Academic Expectation of Student & .44567 \\
\hline & 18 & Social Support Services for Students & .43673 \\
\hline & 6 & Cashier/Bursars Services & 41186 \\
\hline & 33 & Students' Certainty of Major/Career & 39951 \\
\hline Factor IV & 35 & Students' Commitment to Her/His Education & .76214 \\
\hline Student & 34 & Students' Class Attendance & .72893 \\
\hline \multirow[t]{3}{*}{ Satisfaction } & 38 & Students' Practical Value of Education & .69864 \\
\hline & 36 & Students' Current GPA & .59416 \\
\hline & 4 & Campus Safety and Security Services & .41183 \\
\hline Factor V & 8 & Freshman Division Services & .63321 \\
\hline Institutional & 1 & Academic Advising & .62563 \\
\hline Student & 10 & Registration Services & .62165 \\
\hline Service & 2 & Admissions Services & .49528 \\
\hline \multirow[t]{4}{*}{ Satisfaction } & 9 & Library Services & .48705 \\
\hline & 21 & Threshold Learning Communities TLC & .47005 \\
\hline & 7 & Financial Aid Services & .39945 \\
\hline & 3 & Campus Rules and Regulations & .32140 \\
\hline
\end{tabular}


Table 10--Continued.

Factor Name Items Labels Loading

$\begin{array}{lrll}\text { Factor VI } & 24 & \text { Adm/Fac/Staff Caring About Students' Progress } & .72675 \\ \text { Institutional } & 28 & \text { Instructor Effectiveness } & 71122 \\ \text { Satisfaction } & 25 & \text { Adm/Fac/Staff Informal Contact With Students } & 66904 \\ & 5 & \text { Career Counseling Services } & .44962 \\ & & & \\ \text { Factor VII } & 15 & \text { Mentoring Programs } & .65369 \\ \text { Special } & 16 & \text { Minority Retention Efforts } & .45996 \\ \text { Services } & 22 & \text { Tracking Students' Academic Progress } & 43612 \\ \text { Satisfaction } & 11 & \text { Transfer Options } & 42580 \\ & & & \\ \text { Factor VIII } & 13 & \text { Family/Child Care Support Services } & 66157 \\ \text { External } & 14 & \text { Flexible Course Scheduling } & .45682 \\ \text { Personal } & & & \\ \text { Satisfaction } & & & \end{array}$

They even have different items within the subscales. Yet, the eight-factor importance results and the eight-factor satisfaction results have significant value for future research. These two eight-factor scales are not composed of the same items and thus should not be considered as equal entities since each scale measured a different construct.

What needs to be done in future research is to produce another instrument with fewer items that contains eight subfactors with the same items. These items should be clustered together within eight common subfactors and placed in the new instrument in that order. This will assist respondents to view items as common themes within the instrument.

To finalize this section on factor selection, I briefly mention the finding of the 
two-factor extraction on both scales. The two analyses produced factor loadings that coincided with the original ordering to the instrument. Items 1 to 23 were institutional commitment toward student academic and personal satisfaction. Items 24 to 41 were students' efforts toward academic and personal satisfaction. The two-factor extraction analysis gave general support for the instrument item orderings. The major portion of the students' efforts items were in Factor I--17 of $30(56.7 \%)$ of the Importance Scale and 15 of $19(78.9 \%)$ of the Satisfaction Scale. In Factor II, the institutional efforts were clearly in the majority in both scales: for the Importance Scale, 10 of $11(90.9 \%)$, and for the Satisfaction Scale. 19 of $22(86.4 \%)$. A summary of these data are in Tables 11 and 12 .

\section{Summary}

In summary, because of the adequate levels of empirical fit, the ISPS was found to be a valid and reliable instrument for measuring the university personnel's perception of important factors impacting on student attrition/retention and their level of satisfaction with the university's efforts to address these factors/activities. This conclusion was reached after reviewing the literature, considering the entire process of the instrument development, having the instrument content and construct reviewed by expert judges, controlling for internal and external factors by careful instrument construction, having the results confirmed by reliability and factor analysis, and conducting careful data collection procedures. Thus, the inferences and conclusion from this study can be somewhat generalized on the university personnel. This confirms that the empirically derived constructs from the factor and reliability analysis reflect the judgmental items and 
Table 11

Factor Loading: Importance--Two Factors

Factor Name Items Labels

Loading

\begin{tabular}{|c|c|c|c|}
\hline Factor I & 24 & Adm/Fac/Staff Caring About Students' Progress & .74918 \\
\hline Students' & 26 & Campus Academic/Social Climate & 72343 \\
\hline Academic & 41 & Students' Social Integration With Institution & 70589 \\
\hline and & 30 & Students' Academic Integration Into the Institution & 70171 \\
\hline Personal & 39 & Students' Satisfaction With Institutional & 68500 \\
\hline Satisfaction & 35 & Students' Commitment to Her/His Education & 67868 \\
\hline & 29 & Self-Confidence as a Student & 66344 \\
\hline & 40 & Students' Sense of Self-Development & 65388 \\
\hline & 18 & Social Support Services for Students & 64740 \\
\hline & 32 & Students' Campus Involvement & 64505 \\
\hline & 34 & Students' Class Attendance & 63877 \\
\hline & 25 & Adm/Fac/Staff Informal Contact with Student & 62722 \\
\hline & 15 & Mentoring Programs & 62431 \\
\hline & 31 & Students' Attitude Toward Education & 59438 \\
\hline & 16 & Minority Retention Efforts & .56549 \\
\hline & 17 & Remedial Course Work Services & .56092 \\
\hline & 20 & Study Skills Assessment/Development & .54527 \\
\hline & 14 & Flexible Course Scheduling & 53359 \\
\hline & 22 & Tracking Students' Academic Progress & .53312 \\
\hline & 7 & Financial Aid Services & 52171 \\
\hline & 37 & Students' Loyalty Toward the Institution & .52071 \\
\hline & 38 & Students' Practical Value of Education & 51332 \\
\hline & 23 & Tutoring Services & 49830 \\
\hline & 13 & Family/Child Care Support Services & 48936 \\
\hline & 19 & Students'Internship/Employment & 47362 \\
\hline & 12 & Academic Support Services & .46621 \\
\hline & 27 & Instructor Academic Expectation of Student & .44981 \\
\hline & 21 & Threshold Learning Communities TLC & .42936 \\
\hline & 33 & Students' Certainty of Major/Career & .42647 \\
\hline & 36 & Students' Current GPA & 42022 \\
\hline
\end{tabular}


Table 11-Continued.

Factor Name Items Labels

Loading

\begin{tabular}{lrll} 
Factor II & 6 & Cashier/Bursars Services & .73114 \\
\multicolumn{1}{c}{ Institution's } & 9 & Library Services & .70731 \\
Commitment & 10 & Registration Services & .67110 \\
Toward & 2 & Admissions Services & 66545 \\
Students' & 4 & Campus Safety and Security Services & 65505 \\
Academic & 8 & Freshman Division Services & 57572 \\
and & 3 & Campus Rules and Regulations & 56535 \\
Personal & 1 & Academic Advising & 52346 \\
Satisfaction & 28 & Instructor Effectiveness & .49791 \\
& 5 & Career Counseling Services & .46487 \\
& 11 & Transfer Options & .45978
\end{tabular}

theoretical factors.

\section{Collection of Data}

The data were collected using the Institutional Student Persistence Survey. A package was sent to each university administrator, faculty member, and staff member via interoffice mail in March 1997. The individual mailing labels and the survey instructions were pasted on the outside of the packages. Inside the package were the Chancellor's cover letter, the survey, and an intercampus self-addressed confidential envelope. (See Appendices A and B.) The survey instructions requested the respondents to note their perception on which of the items were important institutional factors impacting student retention and how satisfactory the university was addressing that item/factor. Also, the instructions mentioned that no attempt would to be made to identify the respondents. 
Table 12

Factor Loading: Satisfaction-Two Factors

Factor Name Items Labels

Loading

\begin{tabular}{|c|c|c|c|}
\hline Factor I & 41 & Social Integration With Institution & 65437 \\
\hline Student & 37 & Students' Loyalty Toward the Institution & 65170 \\
\hline Academic & 30 & Students' Academic Integration Into the Institution & 64724 \\
\hline and & 40 & Students' Sense of Self-Development & 6471 \\
\hline Personal & 39 & Students' Satisfaction With Institutional & 6395 \\
\hline Academic & 25 & Adm/Fac/Staff Informal Contact With Student & \\
\hline \multirow[t]{13}{*}{ Satisfaction } & 24 & Adm/Fac/Staff Caring About Students' Progress & 596 \\
\hline & 32 & Students' Campus Involvement & \\
\hline & 33 & Students' Certainty of Major/Career & \\
\hline & 18 & Social Support Services for Students & \\
\hline & 29 & Self-Confidence as a Student & 551 \\
\hline & 26 & Campus Academic/Social Climate & \\
\hline & 31 & Students' Attitude Toward Education & 47 \\
\hline & 36 & Students' Current GPA & \\
\hline & 5 & Career Counseling Services & 403 \\
\hline & 28 & Instructor Effectiveness & 387 \\
\hline & 19 & Students' Internship/Employment & .383 \\
\hline & 16 & Minority Retention Efforts & \\
\hline & 38 & Students' Practical Value of Education & \\
\hline $\begin{array}{l}\text { Factor II } \\
\text { Institution's }\end{array}$ & 8 & Freshman Division Services & .67 \\
\hline Institution's & 17 & Remedial Course Work Services & .632 \\
\hline \multirow{2}{*}{$\begin{array}{l}\text { Commit- } \\
\text { ment }\end{array}$} & 2 & Admissions Services & .568 \\
\hline & 22 & Tracking Students' Academic Progress & .560 \\
\hline Toward & 21 & Threshold Learning Communities TLC & .557 \\
\hline Student & 3 & Campus Rules and Regulations & .556 \\
\hline Academic & 12 & Academic Support Services & .540 \\
\hline and & 20 & Study Skills Assessment/Development & .532 \\
\hline Personal & 23 & Tutoring Services & .4881 \\
\hline \multirow[t]{6}{*}{ Satisfaction } & 15 & Mentoring Programs & 448 \\
\hline & 6 & Cashier/Bursars Services & .4397 \\
\hline & 1 & Academic Advising & 4303 \\
\hline & 10 & Registration Services & .4143 \\
\hline & 9 & Library Services & 403 \\
\hline & 35 & Students' Commitment to Her/His Education & .376 \\
\hline
\end{tabular}


Table 12--Continued.

Factor Name Items Labels Loading

7 Financial Aid Services $\quad 36990$

13 Family/Child Care Support Services $\quad 36878$

14 Flexible Course Scheduling 35318

27 Instructor Academic Expectation of Student $\quad 35306$

11 Transfer Options 33429

34 Students' Class Attendance 30471

4 Campus Safety and Security Services $\quad 28250$

Finally, it requested the survey to be returned via the enclosed intercampus envelope without placing their names on it. The names and telephone number of the researcher and university officer were provided if anyone needed more information.

The returned surveys were delivered to a special mail slot, where I picked them up. The returned envelopes were opened and noted as usable or unusable. The surveys were numbered and the scores were recorded into a data file as they were received. A Word Perfect 6.1 ASCII data file and a SPSS factor and reliability analysis program were created for the study.

After 2 weeks, the first Thank You/Reminder message was sent to all survey recipients via intercampus E-mail (Appendix A). At that point, 102 of 703 (15\%) surveys were returned. Two weeks afterward, $152(22 \%)$ surveys were received, and a Thank You/Reminder memo went to all the people surveyed. The final Thank You/Reminder Email message was sent 3 weeks after the second reminder. At that time, $185(26 \%)$ 
usable surveys had been returned. The data collection process was formally closed 1 week later since no more surveys were being received. The final count was $197(28 \%)$ usable surveys. Only partial and completed surveys were counted and recorded in the database. Blank returned questionnaires were discarded.

\section{Research Questions and Null Hypotheses}

This study sought to answer the following two research questions and three null hypotheses.

\section{Research Questions}

Research Question I asked: What university efforts are perceived by university personnel as the least and the most important institutional factors impacting student retention/attrition?

Research Question 2 asked: What university efforts are perceived by university personnel as the least and the most satisfactorily addressed institutional factors impacting student retention/attrition?

\section{Null Hypotheses}

Null Hypothesis 1 stated: There is no significant difference between the Importance Scale scores and the Satisfaction Scale scores of university personnel.

Null Hypothesis 2 stated: There are no significant differences among university personnel in their perception of the importance of institutional factors impacting student retention/attrition. 
Null Hypothesis 3 stated: There are no significant differences among university personnel in their satisfaction with the university efforts to effectively address institutional factors impacting student retention/attrition.

\section{Analysis of Data}

The data were first analyzed using the SPSS statistical computer program to identify the means, standard deviations, frequencies, and percentages. Statistical tests were later conducted to validate the instrument using factor and reliability analysis Descriptive statistical analyses were conducted on research questions 1 and 2. Inferential data analyses were conducted to address the three null hypotheses.

Research questions 1 and 2 were addressed by calculating and rank ordering the mean scores of each of the $4 \mathrm{l}$ items and for the combined total scale scores. For Null Hypothesis 1 , a t-test was conducted to identify significant differences between the mean scores of the Importance and Satisfaction Scale.

Null Hypothesis 2 was tested with multivariate analyses to identify significant differences of the combined total scale scores and with each of the 41 items on the five demographic groups: university status; employment time; gender; divisions, schools, and programs; and teach introductory level course(s). Discriminant analysis was conducted when the divisions, schools, and programs subgroups indicated that there were significant differences in the multivariate analysis of variance. One-way analyses of variances were used to test significant differences of the individual items on the university status; employment time; and divisions, schools, and programs demographic subgroups. The 
Student-Neuman-Keuis--Post Hoc Multiple Comparison Procedure--was used to identify pairwise differences for all significant $\underline{F}$ in the analysis of variance. A t-test was used to analyze the difference between gender and teach introductory level course(s) demographic subgroups.

Null Hypothesis 3 was tested with multivariate analyses to identify significant differences using the combined total scale score and with each of the 41 items on the five demographic groups: university status; employment time; gender; divisions, schools, and programs; and teach introductory level course(s). Discriminant analysis was conducted when the university status subgroups indicated significant differences in the multivariate analysis of variance. One-way analyses of variance were used to test significant differences of the individual items on the university status; employment time; and divisions, schools, and programs subgroups. The Student-Neuman-Keuls--Post Hoc Multiple Comparison Procedure--was used to identify pairwise differences for all significant $\underline{F}$ in the analysis of variance. The $t$-tests were used to analyze the difference between gender and teach introductory level course(s) subgroups.

The five independent demographic variables for the five groups were:

1. University Status: Administrator, Faculty, Clerical/Technical Staff, and

\section{Professional Staff}

2. Employment Time: Less than 1 year, 1 to 5 years, 6 to 10 years, and 11 or more years

3. Gender: Female and Male

4. Divisions, Schools, and Programs: Division of Arts, Division of Business \& 
Economics, Division of Education, Freshman Division, Division of Liberal Arts \&

Sciences, School of Nursing, School of Public and Environmental Affairs, and Other. The "Other" subgroup consisted of the Division of Continuing Education, Division of Labor Studies, General Studies Degree Program, Dental Education, School of Library and Information Science, and School of Social Work.

5. Teach Introductory Course(s): Yes and No.

Questions 1 and 2 sought to identify the least and most important and the least and most satisfactorily addressed factors impacting student attrition by listing the descending order of the means. The means were rank ordered and compared with the other scale.

Null Hypothesis I required I-test analysis of significant differences between the means of the combined total combined items and of the 41 individual item scores for the Importance and Satisfaction Scales. Salient results were reported or put into tables. The level of significance for all the statistical analyses was set at alpha $=0.05$.

Null hypotheses 2 and 3 sought the identity of significant differences within the Importance and Satisfaction Scale scores. These were addressed using the combined totaled items and by using the 41 individual item scores of both scales. The total scores for the two scales were analyzed for group congruity or significant differences of the means with multivariate analysis of variance (MANOVA). Discriminant analysis was used to find a linear combination of items that best discriminates between groups when there were significant differences reported in the multivariate analyses (Balian, 1988, p. 223). Discriminant analysis provided the results as categorical relationships of most and least important or satisfactory. This analysis was conducted specifically in the Importance 
Scale for the divisions, schools, and programs subgroups and the Satisfaction Scale university status subgroups since these were the subgroups found to have significant differences between the means in the combined total scale items.

Then, all the items for the university status, employment time, and divisions, schools and programs groups were individually analyzed for significant differences of the means using one-way analysis of variance (ANOVA). The Student Neuman-Keul (SNK) Multiple Comparison Procedures (MCP) was employed when significant differences were found within the groups (Lomax, 1992, p. 148). t-tests were used for analyzing all the items in the gender and teach introductory level course(s) subgroups.

\section{Limitations}

Three major limitations of this study were (1) possible skewing of respondents' identity due to anonymity requirements, (2) misunderstanding of the meaning of the items, and low response rate in some subgroups. Maintaining the anonymity of the respondents was a major issue in the study. The exact identification of subjects within each subgroup was sacrificed since some subjects having dual status as administrators, faculty, or staff could easily select a group where they could not be identified. This could obscure the statistical testing for congruity between the demographic groups.

Not all the respondents may have been aware of the expected meaning or context of the item factors in the instrument. They may have answered according to their own interpretation. This along with a low response rate within some of the subgroups may have caused the statistical results to be somewhat unstable and to produce limited 
generalizability.

Because this was an exploratory study, I used a shotgun-style approach to identify institutional factors impacting student attrition/retention. In a follow-up study, the factor selection could be more parsimonious in the instrument. This would increase the itemsubject ratio and give greater stability to the factor analysis. Thus, these research limitations may influence the generalizability of the results to other similar populations on the issue of institutional efforts affecting student attrition/retention.

\section{Assumptions}

The study's emphasis was to show the importance of using personnel's perceptions of institutional student retention efforts by modifying Tinto's (1987) Model of Student Departure. The assumptions were that the external commitments and pre-entry attributes are valid factors directly influencing student attrition/retention and were left out of the study for analysis. I investigated only the institutional factors that were perceived by university personnel that impacted student attrition.

The initial research assumptions were that quantitative survey methodology was appropriate for this study and adequate to provide results for limited generalizations specific to student persistence/retention. Also, Tinto's theoretical base was assumed as a viable guide to identify the framework for the study. Respondents completed the questionnaire openly and to the best of their knowledge. The data analyses were appropriate to the questions posed and the null hypotheses stated. Finally, it was assumed that the university personnel shared common institutional concerns and attitudes. 


\section{CHAPTER IV}

\section{PRESENTATION OF DATA}

The purpose of this study was to identify institutional factors impacting student retention/attrition that university personnel perceived as important and satisfactorily addressed. I developed and validated the survey instrument to measure the above constructs of the study. This study sought the answers to two research questions and three null hypotheses. This chapter presents the findings of the analysis of data of the demographic results, the two research questions, the three null hypotheses, and a summary.

\section{Demographic Results}

The survey population consisted of personnel from a Midwestern public commuter university. Five groups from the university personnel are the independent variables for this study. Each of the five demographic groups contained their own set of subgroups.

The five demographic groups with their corresponding subgroups are as follows:

1. University status: Administrators, Faculty, Clerical/Technical Staff, and Professional Staff

2. Employment time: Less than I year, I to 5 years, 6 to 10 years, and 11 or more years 
3. Gender: Female and Male

4. Division, Schools or Programs: Division of Arts; Division of Business and Economics; Division of Education; Freshman Division; Division of Liberal Arts and Sciences; School of Nursing; "SPEA"--School of Public and Environmental Affairs; and "Other"--Division of Continuing Education, Division of Labor Studies, General Studies Degree Program, Dental Education, School of Library and Information Science, and School of Social Work

5. Teach Introductory Level Course(s): Yes or No.

The number of surveys sent out to each personnel group were full-time faculty, 222, part-time faculty, 283; professional staff, 98; and full-time clerical/technical staff, 100. Administrators or professional staff personnel were among the full-time faculty and professional staff groups. The subjects classified themselves in the university status as they desired. Seven hundred and three surveys were sent to the entire personnel population. Only 197 of the $703(28 \%)$ subjects returned the questionnaire of which 193 $(27.5 \%)$ were usable for the analyses of data.

The number of returns for each of the personnel groups are as follows:

1. For the university status: 17 administrators, 109 faculty, 31 clerical/technical staff; 30 professional staff

2. For the employment time: 14 less than 1 year; 69,1 to 5 years; 53,6 to 10 years; and 7, 11 or more years

3. For gender: 70 females and 114 males

4. For the division, schools, and programs: 10 Division of Arts, 16 Division of 
Business \& Economics, 18 Division of Education, 7 Freshman Division, 54 Division of Liberal Arts \& Sciences, 11 School of Nursing, 6 School of Public and Environmental Affairs, and 57 "Other"

5. For the teach introductory level course(s): 100 Yes and 89 No.

The demographic data are summarized in Table 13. A listing of the survey items with their corresponding labels is posted in Table 14 .

\section{Research Question I}

Research Question 1 asked: What university efforts are perceived by personnel as the least and the most important institutional factors impacting student retention/attrition?

Two findings resulted from the analysis of data for this research question: the total mean score for the entire Importance Scale and the identity of the most and the least important institutional factors impacting student retention/attrition. All of the 41 items were combined to calculate the total mean score for the Importance Scale. To find the most and the least important factors, the mean scores of the 41 factors were ranked in descending order from 1 to 41 . Also, all the items scoring above $75 \%$ and below $25 \%$ of the range of the mean scores were identified as the most and least important factors, respectively (Hinkle, Wiersma, \& Jurs, 1994, pp. 52, 92).

The Importance Scale had a 5-point Likert-type response pattern with the following meanings: (1) Very Unimportant, (2) Unimportant, (3) Neutral, (4) Important, and (5) Very Important. The total mean score for the Importance Scale equaled 4.14. This indicated that the university personnel perceived the combined items in the 
Table 13

Demographic Groups of the Subject Population

\begin{tabular}{|c|c|c|}
\hline Demographic Groups & Frequency & $\%$ \\
\hline \multicolumn{3}{|l|}{ University Status } \\
\hline Administration & 17 & 8.8 \\
\hline Faculty & 109 & *56.5 \\
\hline Staff Clerical/Technical & 31 & 16.1 \\
\hline Staff Professional & 30 & 15.5 \\
\hline Missing & 6 & 3.1 \\
\hline \multicolumn{3}{|l|}{ Employment Time } \\
\hline$<1$ & 14 & 7.3 \\
\hline $1-5$ years & 69 & *35.8 \\
\hline $6-10$ years & 53 & 27.5 \\
\hline $11 \geq$ years & 50 & 25.9 \\
\hline Missing & 7 & 3.6 \\
\hline \multicolumn{3}{|l|}{ Gender } \\
\hline Male & 114 & *59.1 \\
\hline Female & 70 & 36.3 \\
\hline Missing & 9 & 4.7 \\
\hline \multicolumn{3}{|c|}{ Divisions, Schools, and Programs } \\
\hline Arts & 10 & 5.2 \\
\hline Business \& Economics & 16 & 8.3 \\
\hline Education & 18 & 9.3 \\
\hline Freshman & 7 & 3.6 \\
\hline Liberal Arts \& Sciences & 54 & 28.0 \\
\hline School of Nursing & 11 & 5.7 \\
\hline SPEA & 6 & 3.1 \\
\hline Other & 57 & *29.5 \\
\hline Missing & 14 & 7.3 \\
\hline \multicolumn{3}{|c|}{ Teach Introductory Level Course(s) } \\
\hline Yes & 89 & 46.1 \\
\hline No & 100 & *51.8 \\
\hline Missing & 4 & 2.1 \\
\hline
\end{tabular}

Note. "*" denotes the highest percentage in the group (total cases 193). 
Table 14

Items with Labels

\begin{tabular}{|c|c|}
\hline Items & Labels \\
\hline 1 & Academic Advising \\
\hline 2 & Admissions Services \\
\hline 3 & Campus Rules and Regulations \\
\hline 4 & Campus Safety and Security Services \\
\hline 5 & Career Counseling Services \\
\hline 6 & Cashier/Bursars Services \\
\hline 7 & Financial Aid Services \\
\hline 8 & Freshman Division Services \\
\hline 9 & Library Services \\
\hline 10 & Registration Services \\
\hline 11 & Transfer Options \\
\hline 12 & Academic Support Services \\
\hline 13 & Family/Child Care Support Services \\
\hline 14 & Flexible Course Scheduling \\
\hline 15 & Mentoring Programs \\
\hline 16 & Minority Retention Efforts \\
\hline 17 & Remedial Course Work Services \\
\hline 18 & Social Support Services for Students \\
\hline 19 & Student Internship/Employment \\
\hline 20 & Study Skills Assessment/Development \\
\hline 21 & Threshold Learning Communities TLC \\
\hline 22 & Tracking Students' Academic Progress \\
\hline 23 & Tutoring Services \\
\hline 24 & Adm/Fac/Staff Caring About Students' Progress \\
\hline 25 & Adm/Fac/Staff Informal Contact With Student \\
\hline 26 & Campus Academic/Social Climate \\
\hline 27 & Instructor Academic Expectation of Student \\
\hline 28 & Instructor Effectiveness \\
\hline 29 & Self-Confidence as a Student \\
\hline 30 & Students' Academic Integration Into the Institution \\
\hline 31 & Students' Attitude Toward Education \\
\hline 32 & Students' Campus Involvement \\
\hline 33 & Students' Certainty of Major/Career \\
\hline 34 & Students' Class Attendance \\
\hline 35 & Students' Commitment to Her/His Education \\
\hline
\end{tabular}


Table 14--Continued.

\begin{tabular}{ll}
\hline Items & Labels \\
\hline & \\
36 & Students' Current GPA \\
37 & Students' Loyalty Toward the Institution \\
38 & Students' Practical Value of Education \\
39 & Students' Satisfaction With Institutional \\
40 & Students' Sense of Self-Development \\
41 & Students' Social Integration With Institution \\
\hline
\end{tabular}

Importance Scale as important institutional factors impacting student retention/attrition.

The results showed that academic advising $(\underline{M}=4.75)$ was the most important institutional factor impacting student retention, ranking number 1 . In contrast, campus rules and regulations $(\underline{\mathrm{M}}=3.45)$ was the least important factor, ranking number 41 . The seven most important items were those with mean scores equal to or above 4.43. (This number was derived by finding the range between the highest and lowest mean scores, multiplying the difference by .25 and subtracting the product from the highest mean score.) Thus, seven items ranked as the most important institutional factors impacting student persistence. They are as follows:

1. Academic advising $(M=4.75)$

2. Financial aid services $(\underline{M}=4.63)$

3. Students' commitment to her/his education $(M=4.62)$

4. Instructor effectiveness $(M=4.62)$

5. Students' attitude toward education $(M=4.60)$ 
6. Adm/fac/staff caring about students' progress $(\underline{\mathrm{M}}=4.56)$

7. Students' class attendance $(\underline{M}=4.48)$

All the least important factors were items with mean scores of less than 3.775 . (This number was derived by finding the range between the highest and lowest mean scores, multiplying the difference by .25 and adding the product to the lowest mean score.) Here, six items ranked as the least important institutional factors impacting student persistence. They are as follows:

1. Students' campus involvement $(\underline{\mathrm{M}}=3.73)$, ranking 36

2. Students' certainty of major/career $(\underline{M}=3.70)$, ranking 37

3. Cashier/Bursar services $(\underline{\mathrm{M}}=3.69)$, ranking 38

4. Students' loyaity toward the institution $(\underline{\mathrm{M}}=3.53)$, ranking 39

5. Threshold Learning Communities $(\underline{M}=3.50)$ ranking 40

6. Campus rules and regulations $(\underline{M}=3.45)$, ranking 41 .

The mean scores for these factors indicated that the university personnel did not perceive these six items impacting student retention as important. A summary of these data is in Table 15.

\section{Research Question 2}

Research Question 2 stated: What university efforts are perceived by personnel as the least and the most satisfactorily addressed institutional factors impacting student retention/attrition?

The results for this research question provided a total mean score of the 41 items 
Table 15

Rank Descending Means: Importance

Variable

$\underline{\text { Rank }}$

$\underline{\mathbf{M}}$

$\underline{S D}$

Academic Advising

4.75

.73

Financial Aid Services

4.63

.73

Students' Commitment to Her/His Educational

4.62

.73

Instructor Effectiveness

4.62

Students' Attitude Toward Education

4.60

Adm/Fac/Staff Caring About Students' Progress

4.56

Students' Class Attendance

4.48

Self-Confidence as a Student

4.42

Freshman Division Services

4.42

Instructor Academic Expectation of Student

4.42

Flexible Course Scheduling

4.39

Students' Satisfaction With Institutional

4.37

Admissions Services

4.29

Stud. Academic Integration Into Institution

4.27

Registration Services

4.25

Adm/Fac/Staff Informal Contact w/Student

4.25

Career Counseling Services

4.25

Academic Support Services

4.22

Campus Academic/Social Climate

4.22

Students' Sense of Self-Development

4.20

Family/Child Care Support Services

4.16

Tutoring Services

4.15

Library Services

4.11

.91

Students' Practical Value of Education

4.09

77

Tracking Students' Academic Progress

4.07

.91

Study Skills Assessment/Development

4.02

Remedial Course Work Services

3.91

Campus Safety and Security Services

Student Internship/Employment

Social Support Services for Students

3.87

.91

Minority Retention Efforts

3.86

Transfer Options

3.84

.86

Mentoring Programs

3.83

1.00

Students' Social Integration With Institution

3.82

.91

Students' Current GPA 
Table 15--Continued.

\begin{tabular}{|c|c|c|c|}
\hline Variable & Rank & $\underline{\mathbf{M}}$ & SD \\
\hline Students' Campus Involvement & 36 & 3.73 & 1.01 \\
\hline Students' Certainty of Major/Career & 37 & 3.70 & .95 \\
\hline Cashier/Bursars Services & 38 & 3.69 & .94 \\
\hline Students' Loyalty toward the Institution & 39 & 3.53 & .96 \\
\hline Threshold Learning Communities & 40 & 3.50 & 1.08 \\
\hline Campus Rules and Regulations & 41 & 3.45 & .95 \\
\hline
\end{tabular}

and the identity of the most and the least satisfactorily addressed institutional factors impacting student attrition/retention. To find the most and least satisfactory factors, the mean scores of the 41 items were ranked in descending order from 1 to 41 .

Also, all the items scoring above $75 \%$ and below $25 \%$ of the range of the mean scores were identified as the most and least satisfactorily addressed factors, respectively.

The Satisfaction Scale has a 5-point Likert-type response pattern with the following meanings: (1) Very Unsatisfactory, (2) Unsatisfactory, (3) Neutral, (4) Satisfactory, and (5) Very Satisfactory. The total satisfaction means score was 3.22 indicating that the university personnel were not highly satisfied with the university's efforts to effectively address factors impacting student attrition/retention.

Of the individual items, the results indicated that library services $(\underline{M}=3.91)$ was the most satisfactorily addressed institutional factor impacting student retention, ranking number 1 while students' social integration with the institution $(\underline{M}=2.61)$ was the least satisfactory item, ranking 41 . 
The four most satisfactorily addressed factors were items with mean scores equal to or above 3.585. (This number was derived by finding the range between the highest and lowest mean scores, multiplying the difference by .25 and subtracting the product from the highest mean score.) The four items identified as the most satisfactorily addressed factors are as follows:

1. Library services $(\underline{M}=3.91)$

2. Registration services $(\underline{M}=3.83)$

3. Campus safety and security services $(\underline{M}=3.79)$

4. Instructor effectiveness $(\underline{\mathrm{M}}=3.63)$.

The least satisfactorily addressed factors were items below the mean scores of 2.94. (This number was derived by finding the range between the highest and lowest mean scores, multiplying the difference by 25 and adding the product to the lowest mean score.) Thus, the following are the five items classified as the least satisfactorily addressed factors impacting student retention:

1. Students' loyalty toward the institution ( $\underline{M}=2.91)$, ranking 37

2. Social support services for students $(\underline{M}=2.79)$, ranking 38

3. Campus academic/social climate $(\underline{M}=2.67)$, ranking 39

4. Students' campus involvement $(\mathrm{M}=2.63)$, ranking 40

5. Students' social integration with institution $(\mathbf{M}=2.61)$, ranking 41 .

All the least satisfactory scores indicated that the university personnel perceived these factors impacting student attrition/retention as unsatisfactorily addressed. The data are summarized in Table 16. 
Table 16

Rank Descending Means: Satisfaction

Variable

$\underline{\text { Rank }}$

$\underline{\mathbf{M}}$

$\underline{S D}$

Library Services

3.91

.91

Registration Services

3.83

.81

Campus Safety and Security Services

3.79

.85

Instructor Effectiveness

3.63

.75

Cashier/Bursar Services

3.58

.77

Freshman Division Services

3.56

.97

Instructor Academic Expectation of Student

3.46

.77

Adm/Fac/Staff Caring About Students' progress

3.43

.94

Flexible Course Scheduling

3.40

.98

Family/Child Care Support Services

3.36

1.03

Financial Aid Services

3.31

.97

Admissions Services

3.31

.83

Campus Rules and Regulations

3.31

.80

Students' Current GPA

3.31

.66

Academic Support Services

3.29

.85

Transfer Options

Students' Sense of Self-Development

Students' Practical Value of Education

3.29

.68

3.26

.82

Threshold Learning Communities--TLC

3.23

.77

Self-Confidence as a Student

3.21

.77

Remedial Course Work Services

3.21

.77

Tutoring Services

3.20

.87

Students' Commitment to Education

3.17

.91

Academic Advising

3.16

.85

Students' Satisfaction With Institutional

3.16

.95

$\mathrm{Adm} / \mathrm{Fac} / \mathrm{Staff}$ Informal Contact With Students

3.13

.81

Students' Certainty of Major/Career

3.13

.98

Tracking Students' Academic Progress

3.11

.78

Students' Academic Integration Into the Inst.

Mentoring Programs

3.09

.81

28

3.07

.84

Students' Internship/Employment

3.06

.80

Students' Attitude Toward Education

3.06

.88

Minority Retention Efforts

3.05

.83

Study Skills Assessment/Development

Students' Class Attendance

31

3.00

.96

33

3.00

.85

34

3.00

.93 
Table 16--Continued.

\begin{tabular}{llll} 
Variable & $\underline{\text { Rank }}$ & $\underline{\text { M }}$ & SD \\
\hline Career Counseling Services & 36 & 2.95 & .96 \\
Students' Loyalty Toward the Institution & 37 & 2.91 & 82 \\
Social Support Services for Students & 38 & 2.79 & .90 \\
Campus Academic/Social Climate & 39 & 2.67 & .96 \\
Students' Campus Involvement & 40 & 2.63 & .87 \\
Students' Social Integration With Institution & 41 & 2.61 & .88 \\
\hline
\end{tabular}

\section{Null Hypothesis 1}

Null Hypothesis 1 states: There is no significant difference between the Importance Scale scores and the Satisfaction Scale scores of university personnel.

In this hypothesis, I-tests were used to test for significant differences between the total mean scores and the 41 item mean scores of the Importance Scale and Satisfaction Scale. The total mean score of the Importance Scale was 4.14 , and 3.22 for the Satisfaction Scale. The t-test results of the total means scores produced a t-value of 20.32 with 124 degrees of freedom and a probability level of .0001 . This indicated that there was a significant difference between the Importance and Satisfaction Scales scores.

Therefore, Null Hypothesis I was rejected for the total mean scores of the Importance and Satisfaction Scales. Thus, the results indicated that the respondents' perception of the importance of these factors was greater than how satisfactorily they perceived the university's efforts to address factors impacting student attrition/retention.

The t-tests results between the Importance and Satisfaction Scales scores of the 41 
individual items showed that there were significant differences in 38 items. The results of both the multivariate analysis and the t-tests indicated that the scores were consistently higher for the Importance Scale than for the Satisfaction Scale. Personnel considered the factors important, but they did not perceive the university's efforts impacting student retention as highly satisfactorily addressed.

The rank order comparison of the seven top important items with their corresponding Satisfaction scales ranking are as follows:

l. Academic advising $(\underline{M}=4.75)$ ranked 1 in importance and $24(\underline{M}=3.16)$ in satisfaction.

2. Financial aid services $(\underline{M}=4.63)$ ranked 2 in importance and $11(\underline{M}=3.31)$ in satisfaction.

3. Students' commitment to her/his education $(\underline{M}=4.62)$ ranked 3 in importance and $23(\mathrm{M}=3.16)$ in satisfaction.

4. Instructor effectiveness $(\underline{M}=4.62)$ ranked 4 in importance and $4(\underline{M}=3.63)$ in satisfaction.

5. Students' attitude toward education $(\underline{M}=4.60)$ ranked 5 in importance and 32 $(\underline{M}=3.05)$ in satisfaction.

6. Adm/fac/staff caring about students' progress $(\underline{M}=4.56)$ ranked 6 in importance and $8(M=4.3 .4)$ in satisfaction.

7. Students' class attendance $(M=4.48)$ ranked 7 in importance and $35(\underline{M}=$ $3.00,60 \%)$ in satisfaction.

The comparison between the rank order of the Importance and the Satisfaction 
Scales indicated the following relationship:

1. Financial aid services ranked 2, instructor effectiveness ranked 4, and adm/fac/staff caring about students' progress ranked 6; all of these ranked high in importance and were relatively satisfactorily addressed.

2. Academic advising ranked 1 , students' commitment to her/his education ranked 3, students' attitude toward education ranked 5, and students' class attendance ranked 7; these all ranked high in importance but below 21 in satisfaction. These data are summarized in Table 17.

In comparing the rank order of the 41 individual items between the Satisfaction and Importance Scales, the following four items were perceived by personnel as the most satisfactorily addressed factors by the university:

1. Library services $(\underline{M}=3.91)$ ranked 1 in satisfaction and $23(\underline{M}=4.11)$ in importance.

2. Registration services $(\underline{M}=3.83)$ ranked 2 in satisfaction and $15(\underline{M}=4.25)$ in importance.

3. Campus safety and security services $(\underline{M}=3.79)$ ranked 3 in satisfaction and 28 $(\underline{M}=3.90)$ in importance.

4. Instructor effectiveness $(\underline{M}=3.63)$ ranked 4 in satisfaction and $4(\underline{M}=4.62)$ in importance.

The comparison between the rank order of satisfaction with importance indicated that the item "instructor's effectiveness" ranked high as satisfactorily addressed and importance though it was not perceived as highly satisfactorily addressed; registration 
Table 17

Rank Descending Means: Importance/Satisfaction

\begin{tabular}{|c|c|c|c|c|}
\hline \multirow[b]{2}{*}{ Variable } & \multicolumn{2}{|c|}{ Importance } & \multicolumn{2}{|c|}{ Satisfaction } \\
\hline & Rank & $\underline{M}$ & Rank & $\underline{\mathbf{M}}$ \\
\hline Academic Advising* & 1 & 4.75 & 24 & 3.16 \\
\hline Financial Aid Services* & 2 & 4.63 & 11 & 3.31 \\
\hline Students' Commitment to Education* & 3 & 4.62 & 23 & 3.16 \\
\hline Instructor Effectiveness ${ }^{*}$ & 4 & 4.62 & 4 & 3.63 \\
\hline Students' Attitude Toward Education* & 5 & 4.60 & 32 & 3.05 \\
\hline Adm/Fac/Staff Caring About Std. Progress* & 6 & 4.56 & 8 & 3.43 \\
\hline Students' Class Attendance* & 7 & 4.48 & 35 & 3.00 \\
\hline Self-Confidence as a Student* & 8 & 4.42 & 21 & 3.21 \\
\hline Freshman Division Services* & 9 & 4.42 & 6 & 3.56 \\
\hline Instructor Academic Expectation of Std.* & 10 & 4.42 & 7 & 3.46 \\
\hline Flexible Course Scheduling ${ }^{*}$ & 11 & 4.39 & 9 & 3.40 \\
\hline Student Satisfaction With Institution* & 12 & 4.37 & 25 & 3.13 \\
\hline Admissions Services* & 13 & 4.29 & 12 & 3.31 \\
\hline Stud. Academic Integration Into the Inst.* & 14 & 4.27 & 29 & 3.07 \\
\hline Registration Services* & 15 & 4.25 & 2 & 3.83 \\
\hline Adm/Fac/Staff Informal Contact w/Stds* & 16 & 4.25 & 26 & 3.13 \\
\hline Career Counseling Services* & 17 & 4.25 & 36 & 2.95 \\
\hline Academic Support Services* & 18 & 4.22 & 15 & 3.29 \\
\hline Campus Academic/Social Climate* & 19 & 4.22 & 39 & 2.67 \\
\hline Student Sense of Self-Development* & 20 & 4.20 & 17 & 3.26 \\
\hline Family/Child Care Support Services & 21 & 4.16 & 10 & 3.36 \\
\hline Tutoring Services* & 22 & 4.15 & 22 & 3.17 \\
\hline Library Services* & 23 & 4.11 & 1 & 3.91 \\
\hline Student Practical Value of Education* & 24 & 4.09 & 18 & 3.23 \\
\hline Tracking Student Academic Progress* & 25 & 4.07 & 28 & 3.09 \\
\hline Study Skills Assessment/Development* & 26 & 4.02 & 34 & 3.00 \\
\hline Remedial Course Work Services* & 27 & 3.91 & 21 & 3.20 \\
\hline Campus Safety and Security Services & 28 & 3.90 & 3 & 3.79 \\
\hline Student Internship/Employment* & 29 & 3.89 & 31 & 3.06 \\
\hline Social Support Services for Students* & 30 & 3.87 & 38 & 2.79 \\
\hline Minority Retention Efforts* & 31 & 3.86 & 33 & 3.00 \\
\hline Transfer Options* & 32 & 3.84 & 16 & 3.29 \\
\hline Mentoring Programs* & 33 & 3.83 & 30 & 3.06 \\
\hline
\end{tabular}


Table 17--Continued.

\begin{tabular}{|c|c|c|c|c|}
\hline \multirow[b]{2}{*}{ Variable } & \multicolumn{2}{|c|}{ Importance } & \multicolumn{2}{|c|}{ Satisfaction } \\
\hline & Rank & $\underline{\mathbf{M}}$ & Rank & $\underline{\mathbf{M}}$ \\
\hline Students' Social Integration With Inst. ${ }^{*}$ & 34 & 3.82 & 41 & 2.61 \\
\hline Students' Current GPA* & 35 & 3.79 & 14 & 3.31 \\
\hline Students' Campus Involvement* & 36 & 3.73 & 40 & 2.63 \\
\hline Students' Certainty of Major/Career* & 37 & 3.70 & 27 & 3.11 \\
\hline Cashier/Bursars Services & 38 & 3.69 & 5 & 3.58 \\
\hline Students' Loyalty Toward the Institution* & 39 & 3.53 & 37 & 2.91 \\
\hline Threshold Learning Communities* & 40 & 3.50 & 19 & 3.21 \\
\hline Campus Rules and Regulations & 41 & 3.45 & 13 & 3.31 \\
\hline
\end{tabular}

services ranked high as satisfactorily addressed and mid-range in importance; library services ranked the highest as satisfactorily addressed and mid-range in importance; and campus safety and security services ranked high as satisfactorily addressed but low in importance

Though library services and campus safety and security services were satisfactorily addressed, they are not as important as other factors. In contrast, instructor effectiveness and registration services factors are functioning satisfactorily and are important factors impacting student retention. These data are summarized in Tables 18 .

\section{Null Hypothesis 2}

Null Hypothesis 2 states: There are no significant differences among university personnel in their perception of the importance of institutional factors impacting student retention/attrition. 
Table 18

Rank Descending Means: Satisfaction/Importance

\begin{tabular}{|c|c|c|c|c|}
\hline \multirow[b]{2}{*}{ Variable } & \multicolumn{2}{|c|}{ Satisfaction } & \multicolumn{2}{|c|}{ Importance } \\
\hline & Rank & $\underline{\mathbf{M}}$ & Rank & $\underline{\mathbf{M}}$ \\
\hline Library Services* & 1 & 3.91 & 23 & 4.11 \\
\hline Registration Services* & 2 & 3.83 & 15 & 4.25 \\
\hline Campus Safety and Security Services & 3 & 3.79 & 28 & 3.90 \\
\hline Instructor Effectiveness* & 4 & 3.63 & 4 & 4.62 \\
\hline Cashier/Bursar Services & 5 & 3.58 & 38 & 3.69 \\
\hline Freshman Division Services* & 6 & 3.56 & 9 & 4.42 \\
\hline Instructor Academic Expectation of Std. ${ }^{*}$ & 7 & 3.46 & 10 & 4.42 \\
\hline Adm/Fac/Staff Caring About Std. Progress & 8 & 3.43 & 6 & 4.56 \\
\hline Flexible Course Scheduling* & 9 & 3.40 & 11 & 4.39 \\
\hline Family/Child Care Support Services* & 10 & 3.36 & 21 & 4.16 \\
\hline Financial Aid Services* & 11 & 3.31 & 2 & 4.63 \\
\hline Admissions Services* & 12 & 3.31 & 13 & 4.29 \\
\hline Campus Rules and Regulations & 13 & 3.31 & 41 & 3.45 \\
\hline Students' Current GPA* & 14 & 3.31 & 35 & 3.79 \\
\hline Academic Support Services* & 15 & 3.29 & 18 & 4.22 \\
\hline Transfer Options* & 16 & 3.29 & 32 & 3.84 \\
\hline Students' Sense of Self-Development* & 17 & 3.26 & 20 & 4.20 \\
\hline Students' Practical Value of Education* & 18 & 3.23 & 24 & 4.09 \\
\hline Threshold Learning Communities--TLC* & 19 & 3.21 & 40 & 3.50 \\
\hline Self-Confidence as a Student* & 20 & 3.21 & 8 & 4.42 \\
\hline Remedial Course Work Services* & 21 & 3.20 & 27 & 3.91 \\
\hline Tutoring Services* & 22 & 3.17 & 22 & 4.15 \\
\hline Students' Commitment to Education* & 23 & 3.16 & 3 & 4.62 \\
\hline Academic Advising* & 24 & 3.16 & 1 & 4.75 \\
\hline Students' Satisfaction With Institutional* & 25 & 3.13 & 12 & 4.37 \\
\hline Adm/Fac/Staff Informal Contact With Std. ${ }^{*}$ & 26 & 3.13 & 16 & 4.25 \\
\hline Students' Certainty of Major/Career* & 27 & 3.11 & 37 & 3.70 \\
\hline Tracking Students' Academic Progress* & 28 & 3.09 & 25 & 4.07 \\
\hline Students' Academic Integration Into Inst. * & 29 & 3.07 & 14 & 4.27 \\
\hline Mentoring Programs* & 30 & 3.06 & 33 & 3.83 \\
\hline Students’ Internship/Employment* & 31 & 3.06 & 29 & 3.89 \\
\hline Students' Attitude Toward Education* & 32 & 3.05 & 5 & 4.60 \\
\hline Minority Retention Efforts* & 33 & 3.00 & 31 & 3.86 \\
\hline Study Skills Assessment/Development* & 34 & 3.00 & 26 & 4.02 \\
\hline
\end{tabular}


Table 18--Continued.

Variable

$\frac{\text { Satisfaction }}{\operatorname{Rank} \quad \underline{M}} \frac{\text { Importance }}{\text { Rank } \underline{M}}$

Students' Class Attendance*

Career Counseling Services*

35

36

Students' Loyalty Toward the Institution* 37

Social Support Services for Students*

38

Campus Academic/Social Climate*

39

Students' Campus Involvement*

40

Students' Social Integration With Inst.*

41

$3.00 \quad 7$

$2.95 \quad 17$

4.48

$2.91 \quad 39$

4.25

$2.79 \quad 30$

3.53

$2.67 \quad 19$

3.87

$2.63 \quad 36$

4.22

2.6134

3.73

3.82

${ }^{*} \mathrm{D}<05$

This hypothesis was tested using multivariate analysis of variance, one-way analysis of variance, and t-tests. Multivariate analysis of variance simultaneously analyzes multiple dependent variables to determine whether there are significant differences among the multiple independent variables (Lomax, 1992, p. 318). Thus, the 41 items became the dependent variables and the five demographic groups with their corresponding subgroups became the multiple independent variables on the Importance Scale.

The five demographic variables were university status; employment time; gender; division, schoois, and programs; and teach introductory level course(s). If significant differences were found among the subgroups, then discriminant analysis was preformed to further determine the relationship of the significant differences. After the multivariate analysis, one-way analysis of variances or t-tests indicated if there were significant differences among the independent subgroups on 41 dependent variables. 


\section{University Status Group}

The university status group contained four subgroups: administrators, faculty, professional staff, and clerical/technical staff. The multivariate analysis of variance for the Importance Scale scores on the university status group indicated an F-ratio of 1.06356 with 123 and 306.52 degrees of freedom and a probability of .333 . This showed that there was no significant difference among the four university status subgroups. Therefore, Null Hypothesis 2 for the university status group was retained. (See Table 19.)

The one-way analysis of variance of the 41 items indicated that five items were significantly different between the subgroups. Thus, Null Hypothesis 2 was rejected for these five items. The following was the relationship among the four university status subgroups and the items of significant difference:

1. The clerical/technical staff $(\underline{M}=3.93)$ perceived campus rules and regulations as significantly more important than did the administrators, $\underline{M}=3.27 ; \underline{F}(3,178)=4.06 ; p$ $=.01$,

2. The clerical/technical staff $(\underline{M}=4.61)$ perceived registration services as significantly more important than did the administrators, $\underline{M}=4.10 ; \underline{E}(3,179)=3.27 ; R=$ .02 ,

3. The clerical/technical staff $(\underline{M}=4.74)$ perceived admission services as significantly more important than did the faculty, $\underline{M}=4.12 ; E(3,178)=3.97 ; \mathfrak{R}=.01$,

4. The clerical/technical staff $(M=4.13)$ perceived students' current GPA as significantly more important than did the faculty, $\mathbf{M}=3.67 ; E(3,180)=3.21 ; \mathfrak{R}=.02$,

5. The clerical/technical staff $(M=4.20)$ perceived cashier/bursar services as 
Table 19

MANOVAt-Test (Wilks): Importance Total Scale

\begin{tabular}{llllll}
\hline Group & $\underline{N}$ & Value & $\underline{F / t}$ & $\underline{\mathrm{df}}$ & $\mathrm{p}$ \\
\hline WKR & 146 & .34477 & $1.06356 \mathrm{E}$ & 123 and 306.52 & .333 \\
YRS & 145 & .35135 & $.98982 \mathrm{E}$ & 123 and 303.52 & 218 \\
GEN & 144 & .67589 & $1.19299 \mathrm{t}$ & 41 and 102 & .236 \\
DEPT & 141 & .04482 & $1.29599 \mathrm{E}$ & 287 and 655 & $.004^{*}$ \\
TCH & 129 & .67889 & $1.00366 \underline{\mathrm{t}}$ & 41 and 87 & 482 \\
\hline
\end{tabular}

$*_{p}<05$

more important than did the faculty $(\mathrm{M}=3.49)$ and administrators, $\underline{\mathrm{M}}=3.53 ; \underline{\mathrm{F}}(3,177)=$ $6.48, R=00$.

6. The professional staff $(\underline{M}=3.93)$ perceived cashier/bursar services as significantly more important than did the faculty, $\underline{M}=3.49 ; \underline{F}(3,177)=6.48: \underline{p}=.00$

These results indicated that clerical/technical staff perceived five items as greater in importance than did administrators or faculty. Also, the professional staff perceived one item as more important than did the faculty. A summary of these data is in Table 20.

\section{Employment Time Group}

The employment time demographic group contained four subgroups: those employed less than 1 year, 1 to 5 years, 6 to 10 years, and 11 or more years. The multivariate analysis of variance on the four subgroups of the employment time group produced an E-ratio of 99 with 123 and 303.52 degrees of freedom and a probability level 
Table 20

One-way ANOVA:Importance--WKR 41 Items

\begin{tabular}{|c|c|c|c|c|c|c|c|c|}
\hline \multirow[b]{2}{*}{ Item } & \multirow[b]{2}{*}{$\underline{N}$} & \multirow[b]{2}{*}{$\underline{F}$} & \multirow[b]{2}{*}{ R } & \multicolumn{4}{|c|}{ Means if Sig Dif } & \multirow{2}{*}{$\begin{array}{l}\text { Group/s } \\
\text { Sig. Dif. }\end{array}$} \\
\hline & & & & $\mathrm{ADM}$ & FAC & SPR & $\mathrm{SCL}$ & \\
\hline 1 & 185 & 1.96 & 12 & & & & & \\
\hline 2 & 181 & 3.97 & $.01^{*}$ & 4.12 & 4.14 & 4.38 & 4.74 & SCL/FAC \\
\hline 3 & $18 I$ & 4.06 & $.01^{*}$ & 3.27 & 3.41 & 3.52 & 3.93 & SCL/ADM \\
\hline 4 & 185 & 2.17 & .09 & & & & & \\
\hline 5 & 183 & 1.03 & .38 & & & & & \\
\hline 6 & 180 & 6.48 & $.00^{*}$ & 3.53 & 3.49 & 3.93 & 4.20 & SCL/ADM+FAC/SPR \\
\hline 7 & 182 & .88 & .45 & & & & & \\
\hline 8 & 181 & 1.40 & .24 & & & & & \\
\hline 9 & 181 & 1.72 & 16 & & & & & \\
\hline 10 & 182 & 3.27 & $.02^{*}$ & 4.10 & 4.29 & 4.36 & 4.61 & SCL/ADM \\
\hline 11 & 178 & .77 & 97 & & & & & \\
\hline 12 & 178 & .74 & .53 & & & & & \\
\hline 13 & 185 & 1.00 & .40 & & & & & \\
\hline 14 & 184 & .29 & .83 & & & & & \\
\hline 15 & 183 & .77 & .51 & & & & & \\
\hline 16 & 185 & .24 & .87 & & & & & \\
\hline 17 & 183 & 1.11 & .35 & & & & & \\
\hline 18 & 182 & .12 & 95 & & & & & \\
\hline 19 & 184 & 2.08 & .10 & & & & & \\
\hline 20 & 179 & 1.18 & .32 & & & & & \\
\hline 21 & 175 & 1.25 & .29 & & & & & \\
\hline 22 & 183 & .35 & .79 & & & & & \\
\hline 23 & 182 & 1.67 & .18 & & & & & \\
\hline 24 & 184 & .62 & .60 & & & & & \\
\hline 25 & 184 & .75 & .53 & & & & & \\
\hline 26 & 184 & 1.42 & .24 & & & & & \\
\hline 27 & 184 & 1.18 & .32 & & & & & \\
\hline 28 & 184 & 1.95 & .12 & & & & & \\
\hline 29 & 183 & .40 & .43 & & & & & \\
\hline 30 & 177 & .92 & .43 & & & & & \\
\hline 31 & 182 & 1.70 & .17 & & & & & \\
\hline 32 & 180 & .39 & .76 & & & & & \\
\hline 33 & 183 & 1.58 & .20 & & & & & \\
\hline 34 & 183 & 1,78 & .15 & & & & & \\
\hline
\end{tabular}


Table 20--Continued.

\begin{tabular}{|c|c|c|c|c|c|c|c|c|}
\hline \multirow[b]{2}{*}{ Item } & \multirow[b]{2}{*}{$\underline{N}$} & \multirow[b]{2}{*}{$\underline{\mathbf{E}}$} & \multirow[b]{2}{*}{ R } & \multicolumn{4}{|c|}{ Means if Sig Dif } & \multirow{2}{*}{$\begin{array}{l}\text { Group/s } \\
\text { Sig. Dif. }\end{array}$} \\
\hline & & & & $\mathrm{ADM}$ & FAC & SPR & SCL & \\
\hline 35 & 183 & 81 & .49 & & & & & \\
\hline 36 & 183 & 3.21 & $.02^{*}$ & 3.82 & 3.67 & 3.87 & 4.13 & $\mathrm{SCL} / \mathrm{FAC}$ \\
\hline 37 & 183 & .29 & .84 & & & & & \\
\hline 38 & 175 & .12 & .95 & & & & & \\
\hline 39 & 182 & 1.22 & .31 & & & & & \\
\hline 40 & 182 & 1.42 & .24 & & & & & \\
\hline 41 & 184 & .23 & .88 & & & & & \\
\hline
\end{tabular}

Note. Personnel subgroups WKR abbreviations: ADM - Administrators. FAC - Faculty, SPR--Staff Professional, and SCL--Staff Clerical/Technical. The " p" denotes significant difference between the subgroups.

${ }^{*} \mathfrak{p}<.05$

of .218. This indicated that there was no significant difference among the four groups.

Therefore, the Null Hypothesis 2 was retained. (Again, see Table 19.)

The one-way analysis of variance of the 41 items and the employment time subgroups of the Importance Scale showed one item with significant differences. Those employed 1 to 5 years $(\underline{M}=4.06)$ perceived library services as significantly more important than those employed 11 or more years, $\underline{M}=3.55 ; \underline{E}(3,180)=3.81 ; \mathfrak{p}=.01$. Thus, Null Hypothesis 2 was rejected for this item. This showed that, except for one item-library service, the years of employment did not influence the importance level of how employees perceived factors impacting student persistence. These data are summarized in Table 21. 
Table 21

Qne-way ANOVA: Importance--YRS 41 Items

\begin{tabular}{|c|c|c|c|c|c|c|c|c|}
\hline \multirow[b]{2}{*}{ Item } & \multirow[b]{2}{*}{$\underline{\mathbf{N}}$} & \multirow[b]{2}{*}{$\underline{E}$} & \multirow[b]{2}{*}{ R } & \multicolumn{4}{|c|}{ Means if Sig Dif } & \multirow{2}{*}{$\begin{array}{l}\text { Group/s } \\
\text { Sig. Dif. }\end{array}$} \\
\hline & & & & $<1$ & $1-5$ & $6-10$ & $11 \geq$ & \\
\hline 1 & 184 & .47 & .71 & & & & & \\
\hline 2 & 181 & 12 & 95 & & & & & \\
\hline 3 & 180 & .73 & .54 & & & & & \\
\hline 4 & 184 & .18 & .91 & & & & & \\
\hline 5 & 181 & 2.05 & .11 & & & & & \\
\hline 6 & 179 & 1.14 & .34 & & & & & \\
\hline 7 & 182 & 62 & .60 & & & & & \\
\hline 8 & 180 & .75 & .52 & & & & & \\
\hline 9 & 180 & 1.53 & .21 & & & & & \\
\hline 10 & 178 & .51 & .68 & & & & & \\
\hline 11 & 177 & .59 & .63 & & & & & \\
\hline 12 & 177 & 2.22 & .09 & & & & & \\
\hline 13 & 185 & .92 & .43 & & & & & \\
\hline 14 & 183 & .40 & .75 & & & & & \\
\hline 15 & 182 & 1.11 & .35 & & & & & \\
\hline 16 & 184 & 23 & .87 & & & & & \\
\hline 17 & 182 & 17 & .92 & & & & & \\
\hline 18 & 181 & .73 & 53 & & & & & \\
\hline 19 & 183 & 3.81 & $.01^{*}$ & 4.07 & 4.06 & 3.96 & 3.55 & $1 / 11 \geq ; 6 / 11 \geq$ \\
\hline 20 & 178 & 51 & .68 & & & & & \\
\hline 21 & 174 & 1.32 & .27 & & & & & \\
\hline 22 & 182 & .14 & .94 & & & & & \\
\hline 23 & 181 & .14 & .93 & & & & & \\
\hline 24 & 183 & 1.14 & .33 & & & & & \\
\hline 25 & 183 & .23 & .88 & & & & & \\
\hline 26 & 183 & .97 & .41 & & & & & \\
\hline 27 & 183 & .55 & .65 & & & & & \\
\hline 28 & 183 & 2.15 & .09 & & & & & \\
\hline 29 & 182 & .62 & .60 & & & & & \\
\hline 30 & 176 & 1.42 & .24 & & & & & \\
\hline 31 & 181 & .48 & .70 & & & & & \\
\hline 32 & 179 & .73 & .54 & & & & & \\
\hline 33 & 182 & .22 & .89 & & & & & \\
\hline
\end{tabular}


Table 21 -Continued.

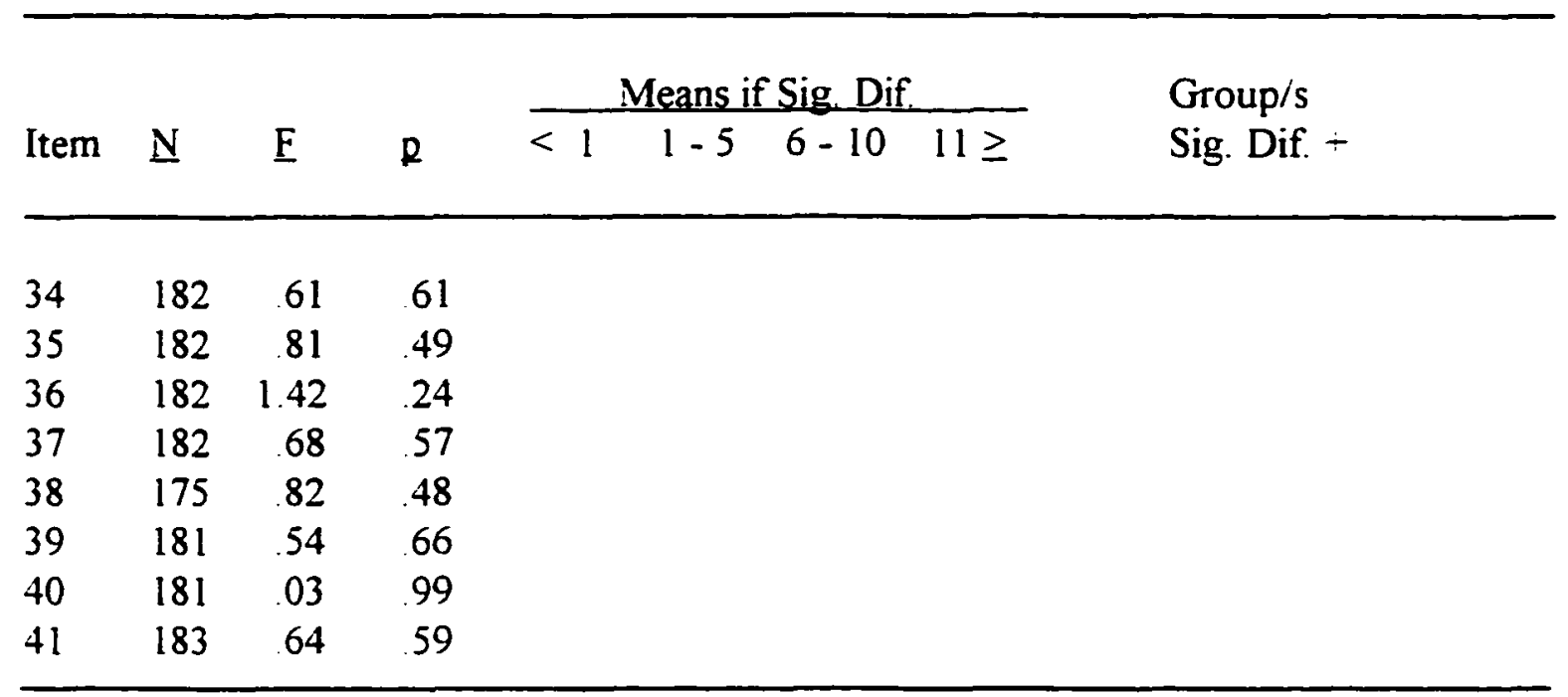

Note. $1 / 11 \geq$ denote 1 year and $11 \geq$ are significantly different. $6 / 11 \geq$ denotes 6 years and $11 \geq$ are significantly different.

$*_{p}<05$

\section{Gender Group}

The gender demographic group contained a selection of female or male. The multivariate analysis on the 41 items and the gender subgroups showed a t-value of 1.193 with 41 and 102 degrees of freedom and a probability level of 236 . Here, there was no significant difference between females and males. Therefore, the Null Hypothesis 2 was retained. (See Table 19.)

The t-test analysis of the 41 items between the females and males indicated 3 of the 41 items were significantly different. Thus, Null Hypothesis 2 was rejected for these 3 items. The items and the corresponding significant analysis are as follows:

1. Females $(M=4.04)$ perceived campus safety and security services as 
significantly more important than did males, $\underline{M}=3.73 ; \mathrm{t}(181)=2.07 ; \mathrm{R}=04$.

2. Females $(\underline{M}=4.02)$ perceived students' internship/employment as significantly more important than did males, $\underline{M}=3.72 ; \mathrm{t}(180)=2.27 ; \mathfrak{p}=03$.

3. Females $(\underline{M}=3.88)$ perceived students' campus involvement as significantly more important than did males, $\underline{M}=3.50 ; \mathrm{t}(170)=2.43 ; \mathrm{R}=.02$.

Thus, the results indicated that females perceived these three items as more important than did the males. Otherwise, females and males were congruent in their perception of the importance of these items. Thus, the results indicated that gender had little or no influence on the perception of personnel concerning the importance of factors impacting student persistence. A summary of these data is in Table 22.

\section{Divisions, Schools, and Programs Group}

The divisions, schools, and programs demographic group contained eight subgroups. The multivariate analysis of variance indicated an E-ratio of 1.296 with 287 and 655 degrees of freedom and a probability of .004 . Here, there were significant differences within the eight subgroups. Therefore, Null Hypothesis 2 was rejected for the total mean score. (See Table 19.)

Since there were significant differences among the subgroups of the total mean scores in the multivariate analysis, discriminant analysis was performed to identify the specific relationship of the significant differences among the eight subgroups of this independent variable. The 41 items became the set of predictor (dependent) variables (Tabachnick \& Fidell, 1996, pp. 507-574). 
Table 22

\section{t-Test: Importance--Gender 41 Items}

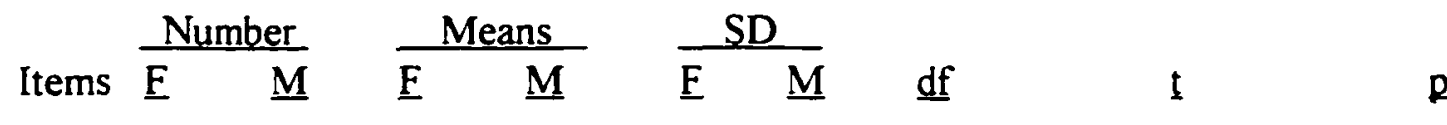

\begin{tabular}{|c|c|c|c|c|c|c|c|c|c|}
\hline 1 & 114 & 69 & 4.78 & 4.74 & .70 & .67 & 181 & .39 & .68 \\
\hline 2 & 112 & 68 & 4.27 & 4.34 & .95 & .80 & 178 & -.51 & 19 \\
\hline 3 & 111 & 68 & 3.54 & 3.35 & .93 & .91 & 177 & 1.32 & .19 \\
\hline 4 & 113 & 70 & 4.04 & 3.73 & 1.01 & 92 & $18 I$ & 2.07 & $.04^{*}$ \\
\hline 5 & 111 & 69 & 4.26 & 4.26 & .78 & .66 & 178 & .00 & 10 \\
\hline 6 & 110 & 68 & 3.75 & 3.62 & 93 & 90 & 176 & 97 & 34 \\
\hline 7 & 112 & 69 & 4.63 & 4.67 & 79 & .53 & 179 & -.30 & .77 \\
\hline 8 & 112 & 67 & 4.47 & 4.36 & 81 & .83 & 177 & .91 & .36 \\
\hline 9 & 111 & 68 & 4.15 & 4.06 & .93 & 88 & 177 & .67 & .50 \\
\hline 10 & 111 & 69 & 4.34 & 4.14 & .86 & .77 & 178 & 1.56 & .12 \\
\hline 11 & 111 & 65 & 3.82 & 3.88 & .90 & .78 & 174 & -.43 & .67 \\
\hline 12 & 110 & 67 & 4.16 & 4.36 & .85 & .67 & 175 & -1.59 & .11 \\
\hline 13 & 114 & 70 & 4.19 & 4.16 & .89 & .79 & 182 & .28 & .78 \\
\hline 14 & 113 & 69 & 4.44 & 4.36 & .79 & .69 & 180 & .70 & .48 \\
\hline 15 & 112 & 69 & 3.93 & 3.75 & .97 & .99 & 179 & 1.17 & 24 \\
\hline 16 & 113 & 70 & 3.91 & 3.86 & 1.01 & 1.01 & 181 & 34 & .73 \\
\hline 17 & 113 & 69 & 3.88 & 4.00 & 2.88 & 4.00 & 180 & -.88 & 38 \\
\hline 18 & 114 & 67 & 3.91 & 3.81 & -.89 & 89 & 179 & .78 & 44 \\
\hline 19 & 114 & 68 & 4.02 & 3.72 & -.86 & .84 & 180 & 2.27 & $.03^{*}$ \\
\hline 20 & 112 & 66 & 4.07 & 3.97 & .93 & 1.05 & 176 & .67 & .50 \\
\hline 21 & 107 & 67 & 3.58 & 3.42 & 1.05 & 1.12 & 172 & .97 & .34 \\
\hline 22 & 113 & 68 & 4.04 & 4.15 & .98 & .78 & 179 & -.74 & .46 \\
\hline 23 & 113 & 68 & 4.18 & 4.15 & .87 & .72 & 179 & .24 & .81 \\
\hline 24 & 114 & 68 & 4.58 & 4.54 & .75 & .68 & 180 & .31 & .75 \\
\hline 25 & 114 & 68 & 4.28 & 4.22 & .87 & .75 & 180 & .48 & .64 \\
\hline 26 & 114 & 68 & 4.22 & 4.21 & .93 & .87 & 180 & .10 & .92 \\
\hline 27 & 114 & 68 & 4.38 & 4.50 & .75 & .61 & 180 & -1.15 & .25 \\
\hline 28 & 114 & 68 & 4.61 & 4.66 & .77 & .56 & 180 & -.44 & .66 \\
\hline 29 & 113 & 68 & 4.44 & 4.45 & .78 & .67 & 179 & .40 & .69 \\
\hline 30 & 112 & 64 & 4.27 & 4.28 & .76 & .79 & 174 & -.11 & .91 \\
\hline 31 & 114 & 66 & 4.60 & 4.62 & .73 & .55 & 178 & -.24 & .81 \\
\hline 32 & 112 & 66 & 3.88 & 3.50 & .93 & 1.10 & 176 & 2.43 & $.02^{*}$ \\
\hline 33 & 114 & 67 & 3.79 & 3.57 & .99 & .87 & 179 & 1.52 & .13 \\
\hline 34 & 114 & 67 & 4.54 & 4.40 & .73 & .68 & 179 & 1.21 & .23 \\
\hline
\end{tabular}


Table 22--Continued.

\begin{tabular}{|c|c|c|c|c|c|c|c|c|c|}
\hline \multirow[b]{2}{*}{ Items } & \multicolumn{2}{|c|}{ Number } & \multicolumn{2}{|c|}{ Means } & \multicolumn{2}{|c|}{ SD } & \multirow[b]{2}{*}{ df } & \multirow[b]{2}{*}{$t$} & \multirow[b]{2}{*}{ R } \\
\hline & $\underline{F}$ & $\underline{\mathbf{M}}$ & $\underline{F}$ & $\underline{\mathbf{M}}$ & $\underline{F}$ & $\underline{\mathbf{M}}$ & & & \\
\hline 35 & 114 & 67 & 4.60 & 4.70 & .75 & .57 & 179 & -.99 & .33 \\
\hline 36 & 114 & 67 & 3.80 & 3.78 & 79 & .11 & 179 & .19 & .85 \\
\hline 37 & 114 & 67 & 3.63 & 3.37 & .94 & .95 & 179 & 1.77 & .08 \\
\hline 38 & 108 & 67 & 4.13 & 4.06 & .78 & .76 & 173 & .59 & .56 \\
\hline 39 & 114 & 67 & 4.37 & 4.37 & .80 & .71 & 179 & -.04 & .97 \\
\hline 40 & 114 & 66 & 4.16 & 4.30 & 86 & .72 & 178 & -1.16 & .25 \\
\hline 41 & 114 & 68 & 3.85 & 3.78 & .88 & .96 & 180 & .51 & .61 \\
\hline
\end{tabular}

${ }^{*} \mathrm{R}<05$

The following is the distribution of the 41 cases that were processed for each department in this analysis with their corresponding group centroids (means): 7 Division of Arts $(\underline{M}=2.181) ; 13$ Division of Business and Economics $(\underline{M}=1.468) ; 11$ Division of Education ( $\underline{\mathrm{M}}=-2.898) ; 11$ Freshman Division $(\underline{\mathrm{M}}=1.148) ; 42$ Division of Liberal Arts and Science $(\underline{\mathrm{M}}=.013) ; 9$ School of Nursing $(\underline{\mathrm{M}}=.346) ; 6$ SPEA-School of Public and Environmental Affairs-- $(\underline{M}=-.938)$; and 46 "Other." Caution must be taken when interpreting these scores since the responses in some of the subgroups were low.

The data indicated that only the first discriminant function was statistically significant at alpha $=.05$ with Chi-square at 358.65 and $p=.0026$. The discriminant function coefficients are ranked by descending algebraic values. The cutoff value for selecting significant items is determined by taking one-half the absolute value of the highest coefficient $(1.04771 / 2=|.52385|)$. 
The discriminant function coefficients and the descending order of group centroids (means) of function 1 defined the characteristics distinguishing the eight subgroups as those who perceive the following nine attrition/retention factors on a continuum from very unimportant to very important. In effect, the discriminant analysis results indicated that the personnel in the Division of Arts $(\underline{M}=2.181)$; Division of Business and Economics $(\underline{M}$ $=1.468) ;$ Freshman Division $(\underline{\mathrm{M}}=1.148)$; School of Nursing $(\underline{\mathrm{M}}=.346)$; and Division of Liberal Arts and Science $(\underline{M}=013)$ perceived (1) Academic advising $(-1.048),(2)$ Selfconfidence as a student $(-1.042),(3)$ Threshold Learning Communities $(-850),(4)$ Family/child care support services (-.608), and (5) Registration services (-.593) as more important than did the personnel in "Other"--Division of Continuing Education, Division of Labor Studies, General Studies Degree Program, Dental Education, School of Library and Information Science, and School of Social Work-- $(\underline{\mathrm{M}}=-.186)$; School of Public and Environmental Affairs $(\underline{M}=-.938)$; and Division of Education $(\underline{M}=-2.898)$. (The number and sign in the parenthesis show the direction and the relative intensity of the perception.)

In contrast, the personnel from the Division of Education ( $\underline{M}=-2.898)$; School of Public and Environmental Affairs $(\underline{M}=-.938)$; and "Other"-Division of Continuing Education, Division of Labor Studies, General Studies Degree Program, Dental Education, School of Library and Information Science, and School of Social Work- $\mathbf{M}=$ -.186) perceived (1) Career counseling services (.882), (2) Students' current GPA (.719), (3) Students' commitment to her/his education (718), and (4) Academic support services (.602) as more important than the personnel from Division of Liberal Arts and Sciences 
$(\underline{M}=.013) ;$ School of Nursing $(\underline{M}=.346) ;$ Freshman Division $(\underline{M}=1.148)$; Division of Business and Economics $(\underline{\mathrm{M}}=1.468)$; and Division of Arts $(\underline{\mathrm{M}}=2.181)$.

The discriminant analysis results indicated that personnel in the Division of Arts, Business and Economics, Freshman. Liberal Arts and Science, and the School of Nursing considered items of academic and social integration as more important than did those in the School of Public and Environmental Affairs. Other, and Division of Education.

Conversely, those in the School of Public and Environmental Affairs; Other: and Division of Education considered items related to academic integration and career orientation as more important than did the personnel in the Division of Arts, Business and Economics, Freshman, Liberal Arts and Science; and the School of Nursing. This indicated that some personnel perceive a factor as important while personnel from another department may not consider the factor with the same level of importance. A summary of these data is in Tables 23 to 26.

The one-way analysis of variance results of the divisions, schools, and programs subgroups indicated that 5 of the $4 \mathrm{l}$ items were significantly different. Thus, the Null Hypothesis 2 was rejected for these 5 items in this demographic group. The results are as follows:

1. Personnel in the "Other" (Division of Continuing Education, Division of Labor Studies, General Studies Degree Program, Dental Education, School of Library and Information Science, and School of Social Work $)(M=3.75)$ perceived campus rules and regulations as significantly more important than did those in the Division of Liberal Arts and Sciences, $M=3.26 ; E(7,166)=1.85 ; \mathfrak{p}=.05$. 
Table 23

Discriminant Analysis: Importance Cases-DEPT

\begin{tabular}{lll}
\hline & DEPT & Number of Cases \\
\hline 1 & 7.0 Arts \\
& 2 & 13.0 Business \& Economics \\
& 3 & 11.0 Education \\
& 4 & 7.0 Freshman \\
& 5 & 42.0 Liberal Arts \& Science \\
& 6 & 9.0 School of Nursing \\
& 7 & 6.0 SPEA \\
& 8 & 46.0 OTHERS \\
\cline { 2 - 2 } & & 141.0
\end{tabular}

Note. Cases in groups defined by the group, Divisions, Schools, and Programs: 193 (Unweighted) cases were processed, 52 of these were excluded from the analysis, 7 had missing or out-of-range group codes, 38 had at least one missing discriminating variable, 7 had both, and 141 (Unweighted) cases were used in the analysis.

Table 24

Discriminant Functions: Importance--DEPT

\begin{tabular}{lllll}
\hline $\begin{array}{c}\text { After } \\
\text { Function }\end{array}$ & Wilk's Lambda & Chi-square & df & p \\
\hline 0 & .0448158 & 358.64990 & 287 & $.0026^{*}$ \\
1 & .1023865 & 263.22453 & 240 & .1451 \\
2 & .1822382 & 196.63188 & 195 & .4538 \\
3 & .2927726 & 141.87546 & 152 & .7108 \\
4 & .4333772 & 96.57494 & 111 & .8336 \\
5 & .6099133 & 57.10764 & 72 & .9001 \\
6 & .8063227 & 24.86383 & 35 & .8982 \\
\hline
\end{tabular}

${ }^{*} \mathrm{p}<.05$. 
Table 25

Discriminant Function Coefficients: Importance--DEPT

\begin{tabular}{|c|c|c|}
\hline Item & $\begin{array}{l}\text { Function l } \\
\text { Weight }\end{array}$ & Rank Order \\
\hline 10 & -.59340 & 5 \\
\hline 11 & 27966 & \\
\hline 12 & .60158 & 4 \\
\hline 13 & -.60843 & 6 \\
\hline 14 & -.09090 & \\
\hline 15 & 26767 & \\
\hline 16 & .32567 & \\
\hline 17 & .12810 & \\
\hline 18 & -.15914 & \\
\hline 19 & .34280 & \\
\hline 1 & -1.04771 & 9 \\
\hline 20 & .09186 & \\
\hline 21 & -.84958 & 7 \\
\hline 22 & .03782 & \\
\hline 23 & -10185 & \\
\hline 24 & .09921 & \\
\hline 25 & -.11835 & \\
\hline 26 & .03568 & \\
\hline 27 & .12298 & \\
\hline 28 & -.27922 & \\
\hline 29 & -1.04205 & 8 \\
\hline 2 & .03572 & \\
\hline 30 & .33808 & \\
\hline 31 & .08533 & \\
\hline 32 & -.40309 & \\
\hline 33 & .44931 & \\
\hline 34 & .09955 & \\
\hline 35 & .71844 & 3 \\
\hline 36 & .71921 & 2 \\
\hline 37 & .13423 & \\
\hline 38 & -.51133 & \\
\hline 39 & .36680 & \\
\hline 3 & -.13991 & \\
\hline 40 & -.19486 & \\
\hline
\end{tabular}


Table 25-Continued.

\begin{tabular}{rll}
\hline Item & $\begin{array}{l}\text { Function 1 } \\
\text { Weight }\end{array}$ & Rank Order \\
\hline 41 & .09912 & \\
4 & -06358 & 1 \\
5 & .88165 & \\
6 & .13513 & \\
7 & -.13930 & \\
8 & .14699 & \\
9 & .21226 & \\
\hline
\end{tabular}

Table 26

Discriminant Functions GToup Means (Centroids): Importance--DEPT

\begin{tabular}{lr}
\hline Group & Function 1 \\
& \\
\hline & \\
2 & 2.18141 \\
3 & 1.46809 \\
4 & -2.89753 \\
5 & 1.14841 \\
6 & .01265 \\
7 & .34557 \\
8 & -.93754 \\
& -.18560 \\
\hline
\end{tabular}


2. Personnel in the "Other" (Division of Continuing Education. Division of Labor Studies. General Studies Degree Program. Dental Education, School of Library and Information Science, and School of Social Work $)(\underline{M}=4.21)$ perceived admission services as significantly more important than did those in the Division of Liberal Arts and Sciences, $\underline{\mathrm{M}}=3.43 ; \underline{\mathrm{E}}(7,170)=1.77 ; \mathfrak{p}=.10$.

3. Personnel in the "Other"--Division of Continuing Education, Division of Labor Studies, General Studies Degree Program, Dental Education, School of Library and Information Science, and School of Social Work--( $\underline{M}=4.02)$ perceived cashier/bursar services as significantly more important than did those in the Division of Liberal Arts and Sciences, $M=3.43 ; \underline{F}(7,165)=3.24 ; \mathfrak{l}=.00$.

4. Personnel in the "Other"--Division of Continuing Education, Division of Labor Studies, General Studies Degree Program, Dental Education, School of Library and Information Science, and School of Social Work--( $\underline{M}=4.51)$ perceived registration services as significantly more important than did those in the Division of Business and Economics, $\underline{\mathrm{M}}=3.81 ; \underline{\mathrm{E}}(7,167)=2.04 ; \mathfrak{R}=.05$.

5. Personnel in the Division of Education $(\underline{M}=4.17)$ perceived Threshold Learning Communities as significantly more important than did those in the Division of Arts $(\underline{M}=2.70)$ and those in the Division of Liberal Arts and Sciences $(\underline{M}=3.21)$. Also, personnel in the Freshman Division $(M=4.29)$ perceived Threshold Learning Communities as significantly more important than did those in the Division of Arts, $\mathbf{M}=$ $2.70 ; E(3,163)=3.42 ; R=.00$.

The one-way analysis of variance results indicated that the "Other" subgroup and 
the Division of Education perceived institutional factors impacting student persistence as significantly more important than did those in the Division of Liberal Arts and Sciences, the Division of Business and Economics, and the Division of Arts. A summary of these data is in Table 27

Teach Introductory Level Course(s) Group

The multivariate analysis of variance of the teach introductory level course(s) demographic variable indicated an F-ratio of 1.07496 with 41 and 105 degrees of freedom and a probability of 376 . Hence, there was no significant difference with this group for the Importance Scale. Therefore, Null Hypothesis 2 was retained for this group. (See Table 19.)

The results for the t-test analyses of the teach introductory level course(s) group among the 41 individual items indicated that 7 of the 41 items were significantly different. Thus, Null Hypothesis 2 was rejected for these 7 items. The statistical relationship between the Yes or No subgroups and these 5 items are as follows:

1. Personnel who did not teach introductory level course $(\mathrm{s})(\underline{M}=3.64)$ perceived campus rules and regulations as significantly more important than did those who taught introductory level course(s), $\mathbf{M}=3.22 ; \mathrm{t}(182)=-3.00 ; \mathfrak{R}=.00$.

2. Personnel who did not teach introductory level course $(s)(\underline{M}=4.13)$ perceived campus safety and security services as significantly more important than did those who taught introductory level course $(s)(\mathrm{M}=3.61 ; \mathrm{t}(186)=-3.63 ; \mathrm{p}=.00)$.

3. Personnel who did not teach introductory level course(s) $(M=3.93)$ perceived 
Table 27

One-way ANOVA:Importance--DEPT 41 Items

\begin{tabular}{|c|c|c|c|c|c|c|c|c|c|c|c|c|}
\hline \multirow[b]{2}{*}{ Item } & \multirow[b]{2}{*}{$\mathbf{N}$} & \multirow[b]{2}{*}{$\mathbf{E}$} & \multirow[b]{2}{*}{ R } & \multicolumn{8}{|c|}{ Means if Sig Dif } & \multirow{2}{*}{$\begin{array}{l}\text { Group/s } \\
\text { Sig Dif }+\end{array}$} \\
\hline & & & & ARTS & BUS & EDU & FRE & LAS & SNU & SPEA & OTH & \\
\hline 1 & 177 & 1.68 & .12 & & & & & & & & & \\
\hline 2 & 173 & 1.47 & .18 & & & & & & & & & \\
\hline 3 & 173 & 1.85 & $.05^{*}$ & 3.20 & 3.27 & 3.31 & 3.86 & 3.26 & 3.45 & 3.83 & 3.75 & OTH/LAS \\
\hline 4 & 177 & 1.77 & $.05^{*}$ & 3.60 & 3.75 & 3.71 & 4.29 & 3.74 & 3.82 & 4.33 & 4.21 & OTH/LAS \\
\hline 5 & 174 & 1.79 & .09 & & & & & & & & & \\
\hline 6 & 172 & 3.24 & $.00^{*}$ & 3.50 & 3.33 & 3.44 & 4.43 & 3.43 & 3.64 & 4.17 & 4.02 & OTH/LAS \\
\hline 7 & 174 & 1.59 & .14 & & & & & & & & & \\
\hline 8 & 174 & 1.71 & .11 & & & & & & & & & \\
\hline 9 & 173 & .83 & .56 & & & & & & & & & \\
\hline 10 & 174 & 2.04 & $.05^{*}$ & 3.90 & 3.81 & 4.31 & 4.29 & 4.19 & 4.09 & 4.50 & 4.51 & OTH/BUS \\
\hline 11 & 170 & .66 & .70 & & & & & & & & & \\
\hline 12 & 172 & .72 & .66 & & & & & & & & & \\
\hline 13 & 177 & .81 & .57 & & & & & & & & & \\
\hline 14 & 176 & .39 & .91 & & & & & & & & & \\
\hline 15 & 175 & .57 & .78 & & & & & & & & & \\
\hline 16 & 177 & 1.01 & .42 & & & & & & & & & \\
\hline 17 & 176 & 1.00 & .43 & & & & & & & & & \\
\hline 18 & 175 & .74 & .64 & & & & & & & & & \\
\hline 19 & 176 & 1.76 & .09 & & & & & & & & & \\
\hline 20 & 172 & .41 & .89 & & & & & & & & & \\
\hline 21 & 170 & 3.42 & $.00^{*}$ & 2.70 & 3.50 & 4.17 & 4.29 & 3.21 & 3.44 & 4.00 & 3.58 & EDU+FRE/ART; EDU/LAS \\
\hline 22 & 174 & .53 & .81 & & & & & & & & & \\
\hline
\end{tabular}


Table 27--Continued.

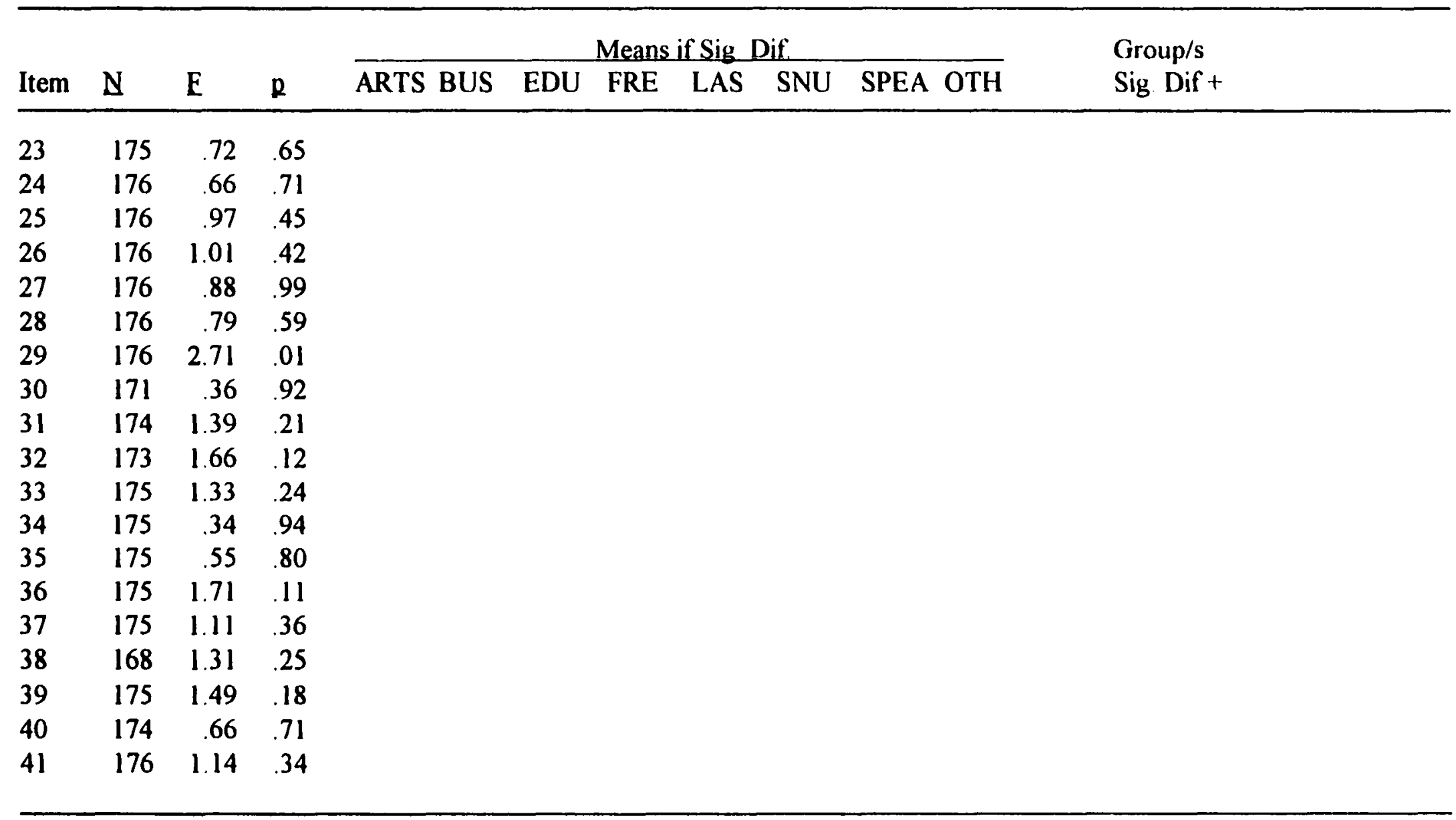

Note "EDU+FRE/ART" denotes that EDU and FRE are significantly different from ART. "EDU/LAS" denotes that EDU and LAS are significantly different. "OTH/ BUS" denotes that BUS and OTH are significantly different. "OTH/LAS" denotes that OTH and LAS are significantly different ${ }^{*} \mathrm{p}<.05$. 
cashier/bursar services as significantly more important than did those who taught introductory level course $(\mathrm{s})(\underline{\mathrm{M}}=3.37 ; \mathrm{t}(181)=-4.23 ; \mathrm{R}=00)$

4. Personnel who did not teach introductory level course $(s)(\underline{M}=4.73)$ perceived financial aid services as significantly more important than did those who taught introductory level course(s) $(\underline{\mathrm{M}}=4.50 ; \underline{\mathrm{t}}(183)=-2.14, \mathfrak{R}=.03)$.

5. Personnel who did not teach introductory level course(s) $(\underline{M}=4.43)$ perceived registration services as significantly more important than did those who taught introductory level course(s) $(\underline{\mathrm{M}}=4.01 ; \mathrm{t}(183)=-3.36 ; \mathrm{p}=.00)$.

6. Personnel who did not teach introductory level course $(s)(\underline{M}=3.68)$ perceived Threshold Learning Communities as significantly more important than did those who taught introductory level course $(\mathrm{s})(\underline{\mathrm{M}}=3.32 ; \mathrm{t}(176)=-2.24 ; \mathfrak{p}=.03)$

7. Personnel who did not teach introductory level course $(s)(\underline{M}=4.72)$ perceived instructor effectiveness as significantly more important than did those who taught introductory level course $(\mathrm{s})(\underline{\mathrm{M}}=4.49 ; \mathrm{t}(185)=-2.10 ; \mathrm{p}=.04)$.

Thus, personnel who did not teach introductory level course(s) perceived all seven of the institutional factors as significantly more important than did those who taught introductory level course(s). A summary of these data is in Table 28 .

\section{Null Hypothesis 3}

Null Hypothesis 3 states: There are no significant differences among the university personnel in their satisfaction with the university efforts to effectively address institutional factors impacting student retention/attrition. For the Satisfaction Scale, Null Hypothesis 3 
Table 28

\section{t-Test: Importance--Teach Introductory Level Course(s) 41 Items}

Item $\frac{\text { Number }}{\text { Yes No }} \frac{\text { Means }}{\text { Yes No }} \frac{\text { SD }}{\text { Yes No df } \quad t \quad ~}$

\begin{tabular}{|c|c|c|c|c|c|c|c|c|c|}
\hline I & 88 & 100 & 4.69 & 4.80 & .91 & .53 & 186 & -.99 & 32 \\
\hline 2 & 85 & 99 & 4.16 & 4.39 & 1.01 & .79 & 182 & -1.72 & 09 \\
\hline 3 & 85 & 99 & 3.22 & 3.64 & 1.00 &, .86 & 182 & -3.00 & $00^{*}$ \\
\hline 4 & 88 & 100 & 3.61 & 4.13 & 1.08 & .87 & 186 & -3.63 & $00^{*}$ \\
\hline 5 & 86 & 99 & 4.22 & 4.25 & .76 & .75 & 183 & -.29 & .78 \\
\hline 6 & 84 & 99 & 3.37 & 3.93 & .92 & .87 & 181 & -4.23 & $.00^{*}$ \\
\hline 7 & 86 & 99 & 4.50 & 4.73 & .90 & .51 & 183 & -2.14 & $03^{*}$ \\
\hline 8 & 84 & 100 & 4.38 & 4.44 & .99 & .67 & 182 & -.48 & 63 \\
\hline 9 & 84 & 100 & 4.01 & 4.17 & 1.00 & .83 & 182 & -1.17 & .24 \\
\hline 10 & 85 & 100 & 4.04 & 4.43 & .98 & .66 & 183 & -3.36 & $.00^{*}$ \\
\hline 11 & 82 & 99 & 3.74 & 3.90 & .93 & .79 & 178 & -1.22 & 23 \\
\hline 12 & 82 & 99 & 4.27 & 4.19 & .88 & .74 & 179 & .64 & .53 \\
\hline 13 & 89 & 99 & 4.16 & 4.16 & .90 & .83 & 186 & -.03 & 97 \\
\hline 14 & 88 & 99 & 4.33 & 4.44 & .87 & .64 & 185 & -1.04 & .30 \\
\hline 15 & 87 & 99 & 3.75 & 3.91 & 1.11 & .91 & 184 & -1.09 & .28 \\
\hline 16 & 88 & 100 & 3.82 & 3.89 & 1.10 & 1.02 & 186 & -.46 & .64 \\
\hline 17 & 87 & 99 & 3.98 & 3.85 & .99 & .89 & 184 & .94 & .35 \\
\hline 18 & 85 & 100 & 3.81 & 3.91 & .99 & .84 & 183 & -.73 & 47 \\
\hline 19 & 87 & 100 & 3.80 & 3.97 & .91 & 83 & 185 & -1.29 & 20 \\
\hline 20 & 84 & 98 & 3.94 & 4.08 & 1.07 & .89 & 180 & -.97 & .33 \\
\hline 21 & 85 & 93 & 3.32 & 3.68 & 1.18 & .96 & 176 & -2.24 & $.03^{*}$ \\
\hline 22 & 86 & 100 & 4.00 & 4.13 & .98 & .85 & 184 & -.97 & .33 \\
\hline 23 & 85 & 100 & 4.12 & 4.17 & .88 & .78 & 183 & -.43 & .67 \\
\hline 24 & 87 & 100 & 4.54 & 4.58 & .85 & .64 & 185 & -.37 & .72 \\
\hline 25 & 87 & 100 & 4.34 & 4.16 & .83 & .83 & 185 & 1.52 & .13 \\
\hline 26 & 87 & 100 & 4.18 & 4.24 & .96 & .88 & 185 & -.42 & .68 \\
\hline 27 & 87 & 100 & 4.39 & 4.44 & .84 & .59 & 185 & -.47 & .64 \\
\hline 28 & 87 & 100 & 4.49 & 4.72 & .93 & .51 & 185 & -2.10 & $.04^{*}$ \\
\hline 29 & 86 & 100 & 4.38 & 4.45 & .83 & .69 & 184 & -.60 & .55 \\
\hline 30 & 81 & 99 & 4.30 & 4.25 & .86 & .72 & 178 & .37 & 71 \\
\hline 31 & 85 & 100 & 4.52 & 4.67 & .70 & .57 & 183 & -1.51 & .13 \\
\hline 32 & 85 & 98 & 3.64 & 3.81 & 1.03 & .99 & 181 & -1.14 & .26 \\
\hline 33 & 86 & 100 & 3.57 & 3.81 & 1.04 & .87 & 184 & -1.72 & .09 \\
\hline
\end{tabular}


Table 28--Continued.

\begin{tabular}{|c|c|c|c|c|c|c|c|c|c|}
\hline \multirow[b]{2}{*}{ Item } & \multicolumn{2}{|c|}{ Number } & \multicolumn{2}{|c|}{ Means } & \multicolumn{2}{|c|}{ SD } & \multirow[b]{2}{*}{ df } & \multirow[b]{2}{*}{$t$} & \multirow[b]{2}{*}{ R } \\
\hline & Yes & No & Yes & No & Yes & No & & & \\
\hline 34 & 86 & 100 & 4.49 & 4.47 & .85 & 66 & 184 & .17 & .87 \\
\hline 35 & 86 & 100 & 4.62 & 4.63 & .86 & .61 & 184 & -.13 & .90 \\
\hline 36 & 86 & 100 & 3.72 & 3.86 & .82 & .71 & 184 & -1.24 & .22 \\
\hline 37 & 86 & 100 & 3.45 & 3.58 & .97 & .95 & 184 & -.90 & .37 \\
\hline 38 & 81 & 97 & 4.07 & 4.11 & .82 & .75 & 175 & -.33 & .74 \\
\hline 39 & 85 & 100 & 4.34 & 4.38 & .89 & .68 & 183 & -.34 & 74 \\
\hline 40 & 86 & 99 & 4.16 & 4.23 & 87 & .79 & 183 & -.57 & 57 \\
\hline 41 & 87 & 100 & 3.80 & 3.84 & .90 & .93 & 185 & -.26 & 79 \\
\hline
\end{tabular}

${ }^{*} \mathbb{R}<05$.

was tested using multivariate analysis, one-way analysis of variance, and t-tests to identify significant differences within the five personnel groups. The five demographic groups (variables) were university status, employment time; gender, division, schools and programs, and teach introductory level course(s). The results of this section are presented in the same order as listed for the other demographic groups.

\section{University Status Group}

The university status group contained four subgroups: administrators, faculty, professional staff, and clerical/technical staff. The multivariate analysis of variance for the Satisfaction Scale indicated a significant difference within only the university status group. The multivariate analysis of variance produced an E-ratio of 1.564 with 123 and 252.59 degrees of freedom and $p=.002$. Therefore, Null Hypothesis 3 was rejected for the 
university status subgroups. Discriminant analysis was preformed to identify the specific relationship of the significant differences within the four subgroups of the university status group. (See Table 29.)

In the discriminant analysis of the university group, the 41 individual items became the set of predictor dependent variables (Tabachnick \& Fidell, 1996, pp. 507-574). There were 128 of the 193 cases processed in this analysis. The cases were distributed as follows among personnel: 15 administrators; 67 faculty; 26 clerical/technical staff; and 20 professional staff. Caution must be taken when making generalizations of these results since the responses in some of the groups were low.

The discriminant analysis results showed that two of the three functions were statistically significant at alpha $=.05$. Function 1 has a Chi-square of 177.26 and $p=.001$. Function 2 has a Chi-square of 104.53 and $p=.034$. The discriminant function coefficients are ranked in descending algebraic values. The cutoff value for the selection of the discriminant coefficients was determined by taking one-half of the absolute value of the highest item coefficient. These data are summarized in Tables 30 to 32 .

\section{Eunction 1}

The cutoff item coefficient for Function 1 was item 15-mentoring programs-$(.615 / 2=|.308|)$. By using the function item coefficients numbers and the descending order of the university subgroup centroids (means) of Function I, a relationship was defined among the four subgroups of the university status group and the 13 items with significant differences. The centroid scores with their algebraic signs indicated the 
Table 29

MANQVA/t-Test (Wilks): Satisfaction Total Scale

\begin{tabular}{llllll}
\hline Group & $\underline{N}$ & Value & $\underline{F}$ & $\underline{\text { df }}$ & $\mathfrak{p}$ \\
\hline WKR & 128 & .18337 & 1.56379 & 123 and 252.59 & $.002^{*}$ \\
YRS & 127 & 26058 & 1.14920 & 127 and 249.59 & 179 \\
GEN & 127 & .69148 & .92497 & 41 and 85 & .601 \\
DEPT & 126 & .03724 & 1.17295 & 287 and 551 & .058 \\
TCH & 129 & .67889 & 1.00366 & 41 and 87 & .482 \\
\hline
\end{tabular}

${ }^{*} \mathrm{p}<05$

Table 30

Discriminant Analysis: Satisfaction Cases--WKR

WKR Number of Cases

$\begin{array}{ll}1 & 15.0 \text { ADMINISTRATORS } \\ 2 & 67.0 \text { FACULTY } \\ 3 & 26.0 \text { CLERICAL/TECHNICAL STAFF } \\ 4 & 20.0 \text { PROFESSION STAFF }\end{array}$

Total

$\overline{128.0}$

Note. Groups defined by University status: 193 (Unweighted) cases were processed, 65 of these were excluded from the analysis, 2 had missing or out-of-range group codes, 59 had at least one missing discriminating variable, 4 had both, 128 (Unweighted) cases were used in the analysis, 5 students' current GPA (-.418), and $6 \mathrm{adm} / \mathrm{fac} / \mathrm{staff}$ caring about students' progress $(-.334)$. 
Table 31

Discriminant Functions: Satisfaction--WKR

\begin{tabular}{llrrl}
$\begin{array}{l}\text { After } \\
\text { Function }\end{array}$ & Wilks' Lambda & Chi-square & df & R \\
\hline 0 & .1833661 & 177.26026 & 123 & $.0010^{*}$ \\
1 & .3677579 & 104.53453 & 80 & $.0342^{*}$ \\
2 & .6748747 & 41.09236 & 39 & .3790 \\
\hline
\end{tabular}

${ }^{*} R<05$

direction and intensity of the relationships among the subgroups and the items with significant differences. Also, the subgroup centroids (means) defined the characteristics distinguishing those who perceived the following 13 items on a continuum from very unimportant to very important.

The results of the discriminant analysis for the university status subgroup indicated that professional the staff $(\underline{M}=1.840)$ and administrators $(\underline{M}=378)$ perceived the following six items as more satisfactorily addressed than did the clerical/technical staff $(\underline{M}$ $=-.369)$ and faculty $(\underline{M}=-.689)$ :

1. Campus safety and security services $(-.482)$

2. Instructor academic expectation of students $(-.480)$

3. Students' sense of self-development $(-.472)$

4. Flexible course scheduling (-.438).

Conversely, faculty $(\underline{M}=-.689)$ and clerical/technical staff $(\underline{M}=-.369)$ perceived 
Table 32

Discriminant Function Coefficients: Satisfaction--WKR

\begin{tabular}{|c|c|c|c|c|}
\hline Item & $\begin{array}{l}\text { Function } \\
\text { Weight }\end{array}$ & Rank & $\begin{array}{l}\text { Function } 2 \\
\text { Weight }\end{array}$ & Rank \\
\hline 10 & .08919 & & -.72518 & 12 \\
\hline 11 & .03890 & & -.22641 & \\
\hline 12 & .25378 & & .20890 & \\
\hline 13 & -04884 & & .62296 & \\
\hline 14 & -.43807 & 10 & 32096 & \\
\hline 15 & .61496 & 1 & .07698 & \\
\hline 16 & -.30295 & & -44488 & 7 \\
\hline 17 & -.11535 & & 53922 & 2 \\
\hline 18 & .15807 & & -.70391 & 11 \\
\hline 19 & .05330 & & .33479 & \\
\hline 1 & -10034 & & -.31208 & \\
\hline 20 & .33092 & 7 & -.45344 & 8 \\
\hline 21 & -.07728 & & .13164 & \\
\hline 22 & -.24222 & & -.48822 & 9 \\
\hline 23 & .00525 & & .16546 & \\
\hline 24 & -.33410 & 8 & .63771 & 1 \\
\hline 25 & .14736 & & -.08231 & \\
\hline 26 & -.20328 & & 19979 & \\
\hline 27 & -.48001 & 12 & -.01737 & \\
\hline 28 & .03449 & & .02666 & \\
\hline 29 & .36326 & 5 & .33352 & \\
\hline 2 & .00925 & & .22895 & \\
\hline 30 & .37646 & 4 & -.37753 & 5 \\
\hline 31 & -.19975 & & -.09010 & \\
\hline 32 & .07162 & & .47448 & 3 \\
\hline 33 & -.21713 & & -.31733 & \\
\hline 34 & .32509 & 6 & -.51384 & 10 \\
\hline 35 & .09344 & & .16469 & \\
\hline 36 & -.41813 & 9 & -.39462 & 6 \\
\hline 37 & -.26968 & & -.00428 & \\
\hline 38 & .16419 & & .05332 & \\
\hline 39 & .46946 & 3 & .37636 & \\
\hline 3 & .06919 & & -.05757 & \\
\hline 40 & -.47188 & 11 & -.13448 & \\
\hline
\end{tabular}


Table 32--Continued.

\begin{tabular}{rllll}
\hline & $\begin{array}{l}\text { Function } \\
\text { Weight }\end{array}$ & Rank & $\begin{array}{l}\text { Function 2 } \\
\text { Weight }\end{array}$ & Rank \\
\hline 41 & -.07263 & & .05431 & \\
4 & -.48192 & 13 & .23958 & \\
5 & .23806 & & .13300 & \\
6 & .48830 & 2 & .39560 & 4 \\
7 & -.07300 & & .15203 & \\
8 & .04202 & & -.07080 & \\
9 & .11650 & & 25484 & \\
\hline
\end{tabular}

the following items as more satisfactorily addressed than did the administrators $(\underline{M}=378)$ and Professional staff $(\underline{M}=1.840)$.

1. Mentoring programs (.615)

2. Cashier/Bursar services (.488)

3. Students' satisfaction with institutional experience (.469)

4. Students' academic integration into the institution (.376)

5. Self-confidence as a student (.363)

6. Students' class attendance (.325)

7. Study skill assessment and development (.331).

The results of the discriminant analysis indicated that the professional staff and the administrators perceive the same 13 items as more satisfactorily addressed than did the clerical/technical staff and faculty. Conversely, the clerical/technical staff and faculty seem to perceive these items differently than did the professional staff and administrators. 


\section{Function 2}

The cutoff item coefficient number for Function 2 was item 10--registration services $(-.725 / 2=|.363|)$. The function coefficients of the items and the descending order of the subgroup centroids (means) of Function 2 defined the characteristics distinguishing the particular relationship of the significant differences among the subgroup.

The centroid scores with their algebraic signs indicated the direction and intensity of the relationship among the university status subgroups and the 12 items of significant differences. The results of the discriminant analysis indicated that administrators $(\underline{M}=$ $2.060)$ and faculty $(\underline{M}=.008)$ perceived the following four factors as more satisfactorily addressed than did the professional staff $(\underline{\mathrm{M}}=-.371)$ and clerical/technical staff $(\underline{\mathrm{M}}=$ 1.339):

1. Adm/fac/staff caring about students' progress (.615)

2. Remedial course work services (.539)

3. Students' campus involvement (.474)

4. Cashier/bursar services (.396).

Conversely, clerical/technical staff $(\underline{\mathrm{M}}=-1.339)$ and professional staff $(\underline{\mathrm{M}}=-.371)$ perceived the following eight factors as more satisfactorily addressed than did the faculty $(\underline{M}=.008)$ and administrators $(\underline{M}=2.060)$ :

1. Students' academic integration into the institution (-.378)

2. Students' current GPA (-.395)

3. Minority retention efforts $(-.445)$ 
4. Study skill assessment and development (-.453)

5. Tracking students' academic progress $(-.488)$

6. Students' class attendance $(-514)$

7. Social support services for students $(-.704)$

8. Registration services (-.725).

In Function 2 of the discriminant analysis, administrators and faculty perceived the four factors impacting student persistence as more satisfactorily addressed than did professional staff and clerical/technical staff, whereas professional staff and clerical/technical staff perceive the eight factors impacting student persistence as more satisfactorily addressed than did administrators and faculty. However, clerical/technical staff and faculty disagreed in both functions as to what items are satisfactorily addressed by the university. A summary of the data is in Table 33

The results of the one-way analysis of variance of the university status group indicated that there were 11 of the 41 items with significant differences. Thus, Null Hypothesis 3 was rejected for these 11 items. The results provided the following relationship among the four university status subgroups and the 11 items of significant differences:

1. Administrators $(\underline{M}=3.88)$ perceived Freshman Division services as significantly more satisfactorily addressed than did the profession staff, $M=3.44 ; E(3$, 171) $=5.60 ; \mathfrak{p}=.00$

2. Administrators $(\underline{M}=3.76)$ perceived academic support services as significantly more satisfactorily addressed than did the faculty $(M=3.18)$ and profession staff $(M=$ 
Table 33

Discriminant Functions Group Means (Centroids): Satisfaction-WKR

\begin{tabular}{lrrr} 
Group & Function 1 & Function 2 & Function 3 \\
\hline 1 & .37796 & 2.06006 & -.99959 \\
2 & -.68853 & .08254 & .44029 \\
3 & 1.84035 & -37122 & .35892 \\
4 & -.36935 & -1.33896 & -1.19189 \\
\hline
\end{tabular}

3.04); The clerical/technical staff perceived academic support services as significantly more satisfactorily addressed than did the faculty $(\underline{\mathrm{M}}=3.18)$ and professional staff, $\underline{\mathrm{M}}=$ $3.04, E(3,168)=4.32 ; \mathfrak{p}=01$.

3. Administrators $(\underline{M}=4.00)$ perceived family/child care support services as significantly more satisfactorily addressed than did the faculty $(\underline{\mathrm{M}}=3.29)$, clerical/ technical staff $(\underline{M}=3.35)$, and professional staff, $\underline{M}=3.17 ; \underline{E}(3,176)=2.71 ; p=.05$.

4. Administrators $(\underline{M}=3.47)$, faculty $(\underline{M}=3.14)$, and, professional staff $(\underline{M}=$ 2.72) perceived student satisfaction with institution as significantly more satisfactorily addressed than did the clerical/technical staff, $\underline{\mathrm{M}}=3.32 ; \underline{\mathrm{F}}(3,172)=4.24 ; \mathrm{p}=.01$.

5. The clerical/technical staff $(\underline{M}=3.97)$ perceived Freshman Division services as significantly more satisfactorily addressed than did the faculty, $\underline{M}=3.43 ; \underline{F}(3,173)=$ $2.62 ; p=.05$.

6. The clerical/technical staff $(\underline{M}=3.19)$ perceived social support services for students as significantly more satisfactorily addressed than did the faculty, $\mathrm{M}=2.73 ; \mathrm{E}(3$, 
$177)=2.51 ; \mathfrak{R}=.05$

7. The clerical/technical staff $(M=3.37)$ perceived tutoring services as significantly more satisfactorily addressed than did the faculty $(\underline{\mathrm{M}}=3.22)$ and professional staff, $\underline{M}=2.77 ; \underline{F}(3,174)=3.52 ; \mathfrak{p}=.05$.

8. The clerical/technical staff $(\underline{M}=4.00)$ perceived cashier/bursar services as significantly more satisfactorily addressed than did the faculty $(\underline{M}=3.45)$ and professional staff, $\underline{M}=3.44 ;(E(3,171)=5.60 ; \mathfrak{p}=.00$.

9. The clerical/technical staff $(\underline{M}=3.26)$ perceived career counseling services as significantly more satisfactorily addressed than did the professional staff, $\underline{\mathrm{M}}=2.61 ; \underline{\mathrm{F}}(3$, $171)=2.36 ; p=.05$

10. The clerical/technical staff $(\underline{M}=2.94)$ perceived students' social integration with institution as significantly more satisfactorily addressed than did the professional staff, $\underline{M}=2.38 ; \underline{E}(3,174)=2.97 ; \mathfrak{R}=.03$.

11. The faculty $(\underline{M}=3.58)$ perceived flexible course scheduling as significantly more satisfactorily addressed than did the professional staff $(\mathrm{M}=3.07)$ and clerical/technical staff, $\underline{M}=3.03 ; \mathrm{E}(3,179)=4.13 ; \mathfrak{R}=.01$.

12. The faculty $(\underline{M}=3.37)$ perceived $\mathrm{adm} / \mathrm{fac} / \mathrm{staff}$ caring about students' progress as significantly more satisfactorily addressed than did the professional staff, $\mathbf{M}=$ $3.33 ; E(3,180)=3.52 ; p=.02$.

The results of the one-way analysis of variance indicated that administrators perceived one item with more satisfaction than did the faculty and one item with more satisfaction than did the clerical/technical staff, and two different items with more 
satisfaction than did the professional staff. The clerical/technical staff perceived four different items with more satisfaction than did the faculty and four different items with more satisfaction than did the professional staff. The faculty perceived one item with more satisfaction than did the clerical/technical staff and one item with more satisfaction than did the professional staff. A summary of the data is in Table 34 .

\section{Employment Time Group}

The employment time demographic group contained four subgroups as follows: those employed less than 1 year, 1 to 5 years, 6 to 10 years, and 11 or more years. The multivariate analysis of variance produced an E-ratio of 1.150 with 127 and 249.59 degrees of freedom and a probability level of 179 for the Satisfaction Scale. Thus, there were no significant differences among the four subgroups of the employment time group. Therefore, the Null Hypothesis 3 was retained.

The results of the one-way analysis of variance for the 41 individual items of the Satisfaction Scale and the four subgroups of the employment time group indicated that 3 of the 41 items were significantly different. The Null Hypothesis 3 was rejected for these 3 items. The results showed the following:

1. Those employed less than 1 year $(M=3.85)$ perceived admission services as significantly more satisfactorily addressed than did those employed 6 to 10 years, $\underline{M}=$ $3.27 ; E(3,177)=1.95 ; \mathfrak{R}=.01$.

2. Those employed less than 1 year $(\mathbf{M}=3.71)$ perceived tutoring services as significantly more satisfactorily addressed than did those employed 11 or more years, $\mathbf{M}=$ 
Table 34

One-way ANOVA: Satisfaction--WKR 41 Items

\begin{tabular}{|c|c|c|c|c|c|c|c|c|}
\hline \multirow[b]{2}{*}{ Item } & \multirow[b]{2}{*}{$\underline{\mathrm{N}}$} & \multirow[b]{2}{*}{$\underline{F}$} & \multirow[b]{2}{*}{ R } & \multicolumn{4}{|c|}{ Means if Sig Dif } & \multirow{2}{*}{$\begin{array}{l}\text { Group/s } \\
\text { Sig. Dif. + }\end{array}$} \\
\hline & & & & $\mathrm{ADM}$ & FAC & SPR & SCL & \\
\hline 1 & 182 & .59 & 62 & & & & & \\
\hline 2 & 176 & 1.04 & 38 & & & & & \\
\hline 3 & 177 & 81 & 49 & & & & & \\
\hline 4 & 181 & 1.98 & .12 & & & & & \\
\hline 5 & 174 & 2.36 & $.05^{*}$ & 3.00 & 2.95 & 2.61 & 3.26 & SCL/SPR \\
\hline 6 & 174 & 5.60 & $.00^{*}$ & 3.88 & 3.45 & 3.44 & 4.00 & $\begin{array}{l}\text { SCL/FAC }+ \text { SPR: } \\
\text { ADM/SPR }\end{array}$ \\
\hline 7 & 177 & 0.2 & .99 & & & & & \\
\hline 8 & 176 & 2.62 & $.05^{*}$ & 3.65 & 3.43 & 3.50 & 3.97 & SCL/FAC \\
\hline 9 & 177 & 1.55 & .20 & & & & & \\
\hline 10 & 179 & .87 & .46 & & & & & \\
\hline 11 & 172 & .48 & 70 & & & & & \\
\hline 12 & 171 & 4.32 & $.01^{*}$ & 3.76 & 3.18 & 3.04 & 3.55 & $\begin{array}{l}\mathrm{ADM} / \mathrm{FAC}+\mathrm{SPR} \\
\mathrm{SCL} / \mathrm{FAC}+\mathrm{SPR}\end{array}$ \\
\hline 13 & 179 & 2.71 & $.05^{*}$ & 4.00 & 3.29 & 3.17 & 3.35 & $\mathrm{ADM} / \mathrm{SCL}+\mathrm{FAC}+\mathrm{SPR}$ \\
\hline 14 & 182 & 4.13 & .01 & 3.55 & 3.58 & 3.07 & 3.03 & $\mathrm{FAC} / \mathrm{SPR}+\mathrm{SCL}$ \\
\hline 15 & 179 & 2.35 & .07 & & & & & \\
\hline 16 & 181 & .31 & .82 & & & & & \\
\hline 17 & 180 & 2.64 & .05 & & & & & \\
\hline 18 & 180 & 2.51 & $.05 *$ & 2.65 & 2.73 & 2.70 & 3.19 & $\mathrm{SCL} / \mathrm{FAC}$ \\
\hline 19 & 180 & .47 & .70 & & & & & \\
\hline 20 & 173 & 1.89 & .13 & & & & & \\
\hline 21 & 166 & 1.07 & 36 & & & & & \\
\hline 22 & 177 & .14 & .83 & & & & & \\
\hline 23 & 177 & 2.62 & $.05^{*}$ & 3.12 & 3.22 & 2.77 & 3.37 & SCL+FAC/SPR \\
\hline 24 & 183 & 3.52 & $.02 *$ & 3.59 & 3.59 & 3.33 & 3.12 & FAC/SPR \\
\hline 25 & 181 & 1.26 & .30 & & & & & \\
\hline 26 & 182 & .01 & .97 & & & & & \\
\hline 27 & 183 & .90 & .44 & & & & & \\
\hline 28 & 183 & 1.24 & .30 & & & & & \\
\hline 29 & 176 & .81 & .48 & & & & & \\
\hline 30 & 172 & 1.31 & .27 & & & & & \\
\hline 31 & 178 & .87 & .41 & & & & & \\
\hline 32 & 177 & 1.17 & .32 & & & & & \\
\hline
\end{tabular}


Table 34--Continued.

\begin{tabular}{|c|c|c|c|c|c|c|c|c|}
\hline \multirow[b]{2}{*}{ Item } & \multirow[b]{2}{*}{$\underline{N}$} & \multirow[b]{2}{*}{$\underline{\mathbf{E}}$} & \multirow[b]{2}{*}{ R } & \multicolumn{4}{|c|}{ Means if Sig Dif. } & \multirow{2}{*}{$\begin{array}{l}\text { Group/s } \\
\text { Sig. Dif. + }\end{array}$} \\
\hline & & & & $\mathrm{ADM}$ & FAC & SPR & $\mathrm{SCL}$ & \\
\hline 33 & 176 & .65 & .58 & & & & & \\
\hline 34 & 179 & 1.61 & 19 & & & & & \\
\hline 35 & 174 & 1.56 & .20 & & & & & \\
\hline 36 & 174 & .85 & 47 & & & & & \\
\hline 37 & 178 & 98 & 40 & & & & & \\
\hline 38 & 171 & 2.41 & 07 & & & & & \\
\hline 39 & 175 & 4.24 & $01^{*}$ & 3.47 & 3.14 & 2.72 & 3.32 & $\begin{array}{l}\mathrm{ADM}+\mathrm{SCL}+\mathrm{FAC} \\
/ \mathrm{SPR}\end{array}$ \\
\hline 40 & 175 & 1.66 & 18 & & & & & \\
\hline 41 & 177 & 2.97 & $.03^{*}$ & 2.29 & 2.64 & 2.38 & 2.94 & SCL/SPR \\
\hline
\end{tabular}

Note. "P" denotes significant difference between the subgroup. "+" denotes the paired groups having significant differences. Subgroup University status abbreviations: ADM-Administrators, FAC--Faculty, SPR--Professional Staff, and SCL--Clerical/technical Staff. $R<.05$.

$2.93 ; \underline{E}(3,172)=3.16 ; p=.03$

3. Those employed 1 to 5 years $(\underline{M}=3.36)$ and 6 to 10 years $(\underline{M}=3.49)$

perceived campus rules and regulations as significantly more satisfactorily addressed than did those employed 11 or more years, $\underline{M}=2.98 ; \underline{F}(3,172)=3.77 ; \mathfrak{p}=.01$.

The results of the one-way analysis of variance for the employment time subgroups indicated that those employed less than 1 year perceived one item with more satisfaction than did those employed 6 to 10 years and one item with more satisfaction than did those employed 11 or more years. Also those employed 1 to 5 years and those employed 6 to 10 years both perceived the same items with more satisfaction than did those employed 11 
or more years. Thus, those with fewer years of employment perceived 38 of the 41 items as significantly more satisfactorily addressed than did those with many years of employment. The summary for this data is found in Table 35 .

\section{Gender Group}

The multivariate analysis of variance of the Satisfaction Scale scores on the gender demographic group of female or male indicated an F-ratio of 925 with 41 and 85 degrees of freedom with a probability of 601 . Thus, there was no significant difference between the gender subgroups. Therefore, Null Hypothesis 3 was retained. (See Table 29.)

The t-test results of the 41 items and the gender subgroups indicated that only one item was significantly different. It showed that male personnel $(\underline{M}=3.27)$ perceived students' certainty of major/career with significantly more satisfaction than did female personnel, $\underline{\mathrm{M}}=3.01 ; \mathrm{t}(172)=-2.08 ; \mathrm{p}=.04$. Thus, Null Hypothesis 3 was rejected for this item. The summary for this data is found in Table 36.

Divisions, Schools, and Programs Group

The results showed the division, schools, and programs demographic group with the following eight subgroups: Division of Arts, Division of Business and Economics, Division of Education, Freshman Division, Division of Liberal Arts and Sciences, School of Nursing, School of Public and Environmental Affairs, and "Other"--Division of Continuing Education, Division of Labor Studies, General Studies Degree Program, Dental Education, School of Library and Information Science, and School of Social Work. 
Table 35

One-way ANOVA: Satisfaction--YRS 41 Items

$$
\begin{aligned}
& \text { Means if Sig. Dif Group/s }
\end{aligned}
$$

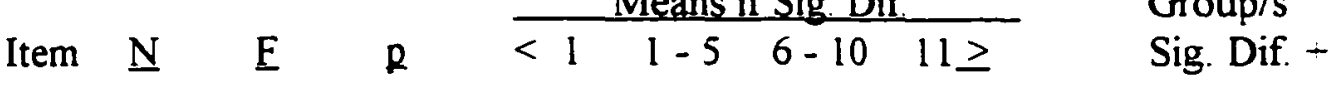

$$
\begin{aligned}
& \begin{array}{llll}
1 & 180 & 1.81 & 15
\end{array} \\
& \begin{array}{lllllllll}
2 & 175 & 1.95 & 01^{*} & 3.85 & 3.27 & 3.27 & 3.26 & <1 / 6-10
\end{array}
\end{aligned}
$$

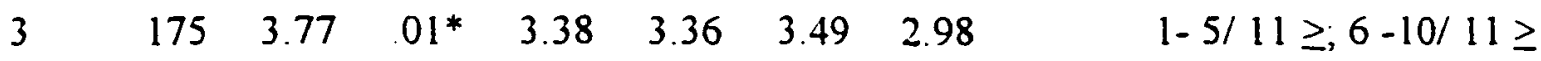

$$
\begin{aligned}
& 4 \quad 179 \quad 2.79 \quad 04 \\
& \begin{array}{llll}
5 & 172 & 53 & .66
\end{array} \\
& \begin{array}{llll}
6 & 172 & .76 & .52
\end{array} \\
& \begin{array}{llll}
7 & 176 & 1.65 & 18
\end{array} \\
& \begin{array}{llll}
8 & 174 & .29 & .83
\end{array} \\
& \begin{array}{llll}
9 & 175 & 41 & 74
\end{array} \\
& \begin{array}{llll}
10 & 177 & 2.01 & .11
\end{array} \\
& \begin{array}{llll}
11 & 170 & .57 & .63
\end{array} \\
& \begin{array}{llll}
12 & 169 & 1.66 & .18
\end{array} \\
& \begin{array}{llll}
13 & 178 & .76 & .52
\end{array} \\
& \begin{array}{llll}
14 & 180 & .87 & .46
\end{array} \\
& \begin{array}{llll}
15 & 177 & 26 & .85
\end{array} \\
& \begin{array}{llll}
16 & 179 & 1.07 & .36
\end{array} \\
& \begin{array}{llll}
17 & 178 & 08 & 97
\end{array} \\
& \begin{array}{llll}
18 & 178 & 1.75 & 16
\end{array} \\
& \begin{array}{llll}
19 & 178 & .15 & .93
\end{array} \\
& \begin{array}{llll}
20 & 171 & .05 & 99
\end{array} \\
& \begin{array}{llll}
21 & 164 & 3.15 & .03
\end{array} \\
& \begin{array}{llll}
22 & 175 & .82 & 48
\end{array}
\end{aligned}
$$

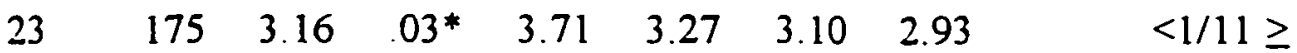

$$
\begin{aligned}
& \begin{array}{llll}
24 & 181 & .87 & .46
\end{array} \\
& \begin{array}{llll}
25 & 179 & 1.02 & .39
\end{array} \\
& \begin{array}{llll}
26 & 180 & 1.26 & .29
\end{array} \\
& \begin{array}{llll}
27 & 181 & 2.07 & .11
\end{array} \\
& \begin{array}{llll}
28 & 181 & .65 & .58
\end{array} \\
& \begin{array}{llll}
29 & 174 & 2.18 & .09
\end{array} \\
& \begin{array}{llll}
30 & 170 & .52 & .67
\end{array} \\
& \begin{array}{llll}
31 & 176 & .40 & .76
\end{array} \\
& \begin{array}{llll}
32 & 175 & 1.31 & .27
\end{array} \\
& \begin{array}{llll}
33 & 174 & 1.95 & .12
\end{array} \\
& \begin{array}{llll}
34 & 177 & 2.25 & .09
\end{array}
\end{aligned}
$$


Table 35--Continued.

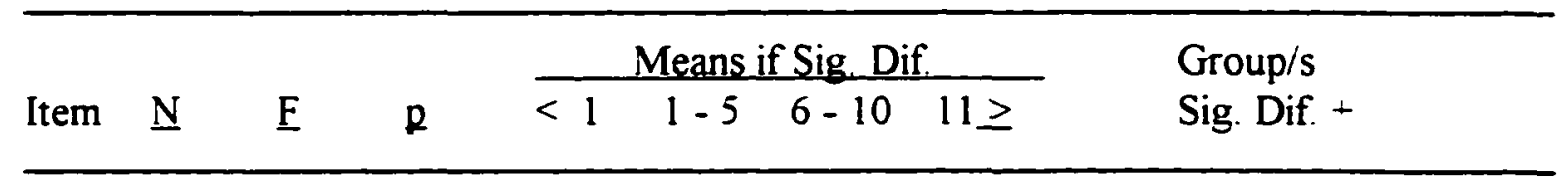

$\begin{array}{rrrr}35 & 172 & 1.24 & .30 \\ 36 & 172 & 1.22 & .31 \\ 37 & 176 & 1.19 & .32 \\ 38 & 170 & .56 & .64 \\ 39 & 173 & 1.60 & .19 \\ 40 & 173 & .76 & .52 \\ 41 & 175 & 1.31 & .27\end{array}$

Note. " $<1 / 11 \geq$ " denotes that less than 1 year and 11 or more years are significantly different. " $<1 / 6-10$ " denotes that less than 1 year and $6-10$ years are significantly different. " $1-5 / 11 \geq$ " denotes that $1-5$ and 11 or more years are significantly different. " $6-10 / 11 \geq$ " denotes that $6-10$ years and 11 or more years are significantly different

${ }^{*} \mathrm{p}<.05$

The multivariate analysis on the Satisfaction Scale scores of the 41 items and the subgroups indicated an E-ratio of 1.17295 with 287 and 551 degrees of freedom and a probability level of 058 . Hence, there was no significant difference among the eight subgroups. Therefore, Null Hypothesis 3 was retained. (See Table 29.)

The results of the one-way analysis of variance with the 41 items and the eight subgroups of the divisions, schools, and programs group showed 6 of the 41 items with significant difference among the subgroups. Therefore, Null Hypothesis 3 was rejected for these 6 items. The following are the six factors in relationship to the subgroups (please note that the "Other" subgroup is composed of the Division of Continuing Education, Division of Labor Studies, General Studies Degree Program, Dental Education, School of Library and Information Science, and School of Social Work). 
Table 36

t-Test: Satisfaction-Gender 41 Items

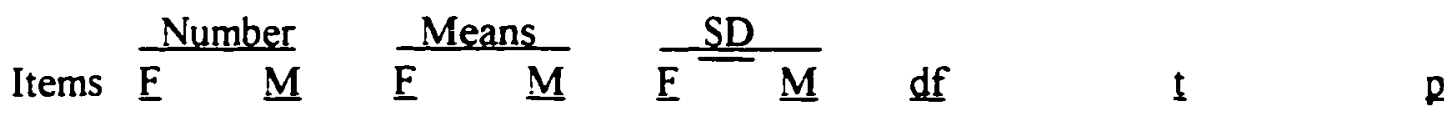

\begin{tabular}{|c|c|c|c|c|c|c|c|c|c|}
\hline 1 & 112 & 67 & 3.10 & 3.30 & 1.00 & .85 & 177 & -1.37 & 17 \\
\hline 2 & 110 & 64 & 3.26 & 3.39 & .86 & .79 & 172 & -.96 & 34 \\
\hline 3 & 110 & 65 & 3.38 & 3.17 & .80 & .80 & 173 & 1.70 & .09 \\
\hline 4 & 112 & 67 & 3.80 & 3.76 & .96 & .68 & 177 & .32 & .75 \\
\hline 5 & 109 & 63 & 2.93 & 2.97 & .92 & 1.06 & 170 & -.27 & 79 \\
\hline 6 & 108 & 64 & 3.56 & 3.61 & .84 & .66 & 170 & -.37 & .72 \\
\hline 7 & 111 & 65 & 3.26 & 3.40 & 1.04 & .86 & 174 & -.91 & 37 \\
\hline 8 & 110 & 64 & 3.55 & 3.61 & .95 & 1.03 & 172 & -.35 & .72 \\
\hline 9 & 110 & 65 & 3.87 & 3.98 & .95 & .86 & 173 & -.78 & .44 \\
\hline 10 & 110 & 66 & 3.83 & 3.83 & .83 & .80 & 174 & -.05 & 96 \\
\hline 11 & 108 & 61 & 3.25 & 3.28 & .70 & .61 & 167 & -.27 & 79 \\
\hline 12 & 107 & 62 & 3.26 & 3.34 & 84 & .89 & 167 & -.56 & .57 \\
\hline 13 & 112 & 65 & 3.25 & 3.52 & 1.07 & .95 & 175 & -1.70 & .09 \\
\hline 14 & 112 & 67 & 3.35 & 3.46 & 1.02 & .94 & 177 & -.75 & .46 \\
\hline 15 & 111 & 66 & 3.00 & 3.17 & .81 & .82 & 175 & -1.32 & 19 \\
\hline 16 & 112 & 67 & 2.96 & 3.06 & 1.02 & .89 & 177 & -.63 & .55 \\
\hline 17 & 112 & 66 & 3.17 & 3.27 & .85 & .94 & 176 & -.75 & .45 \\
\hline 18 & 112 & 66 & 2.82 & 2.74 & .97 & .81 & 176 & .56 & 58 \\
\hline 19 & 113 & 64 & 3.02 & 3.13 & .90 & .88 & 175 & -.77 & .44 \\
\hline 20 & 109 & 62 & 3.02 & 2.97 & .83 & .91 & 169 & .37 & .71 \\
\hline 21 & 99 & 65 & 3.28 & 3.11 & .76 & .81 & 162 & 1.41 & .16 \\
\hline 22 & 111 & 63 & 3.07 & 3.13 & .70 & .85 & 172 & -.43 & .67 \\
\hline 23 & 110 & 65 & 3.20 & 3.12 & .91 & .93 & 173 & .54 & .59 \\
\hline 24 & 113 & 67 & 3.40 & 3.49 & .98 & .88 & 178 & -.65 & .52 \\
\hline 25 & 112 & 66 & 3.13 & 3.12 & 1.02 & .94 & 176 & .08 & .93 \\
\hline 26 & 113 & 66 & 2.66 & 2.67 & .95 & .98 & 177 & -.02 & .98 \\
\hline 27 & 113 & 67 & 3.40 & 3.55 & .77 & .74 & 178 & -1.31 & .19 \\
\hline 28 & 113 & 67 & 3.58 & 3.70 & .80 & .63 & 178 & -1.03 & .31 \\
\hline 29 & 108 & 66 & 3.19 & 3.24 & .81 & .73 & 172 & -.47 & .64 \\
\hline 30 & 108 & 63 & 3.08 & 3.02 & .86 & .83 & 169 & .50 & .62 \\
\hline 31 & 110 & 66 & 3.03 & 3.08 & .86 & .81 & 174 & -.37 & .71 \\
\hline 32 & 111 & 64 & 2.61 & 2.67 & .92 & .80 & 173 & -.43 & .67 \\
\hline 33 & 110 & 64 & 3.01 & 3.27 & .84 & .67 & 172 & -2.08 & $.04^{*}$ \\
\hline 34 & 110 & 66 & 3.03 & 3.02 & .87 & 1.02 & 174 & .08 & .93 \\
\hline
\end{tabular}


Table 36--Continued.

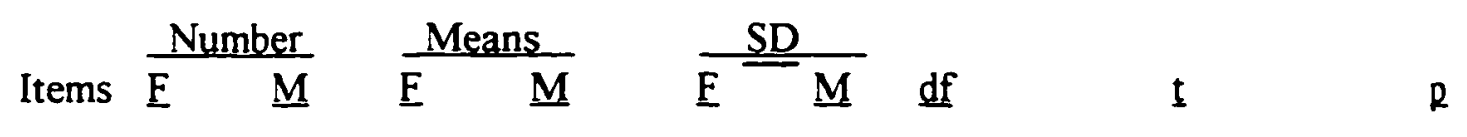

\begin{tabular}{rrrrrrrrrrr}
\hline 35 & 108 & 63 & 3.25 & 3.08 & .82 & .89 & 169 & 1.27 & .25 \\
36 & 108 & 63 & 3.31 & 3.32 & .72 & .59 & 169 & -.11 & 91 \\
37 & 110 & 65 & 2.85 & 3.02 & .87 & .76 & 173 & -1.31 & .19 \\
38 & 105 & 65 & 3.24 & 3.25 & .78 & .77 & 168 & -.07 & .95 \\
39 & 109 & 65 & 3.09 & 3.20 & .83 & .80 & 172 & -.84 & .40 \\
40 & 109 & 64 & 3.21 & 3.39 & .84 & .77 & 171 & -1.40 & .16 \\
41 & 110 & 65 & 2.62 & 2.58 & .94 & .81 & 173 & .24 & .81 \\
\hline
\end{tabular}

${ }^{*} R<.05$

1. Personnel in the Division of Education $(\underline{M}=3.47)$ and "Other" $(\underline{M}=3.16)$ perceived students' class attendance as significantly more satisfactorily addressed than did those in Division of Arts, $\underline{M}=2.20 ; \underline{F}(7,164)=2.66 ; p=01$.

2. Personnel in the Division of Liberal Arts \& Sciences $(\underline{\mathrm{M}}=3.10)$ and "Other" $(\underline{M}=3.02)$ perceived career counseling services as significantly more satisfactorily addressed than did those in Division of Business and Economics, $\underline{M}=2.25 ; \underline{F}(7,160)=$ $2.50 ; p=.02$.

3. Personnel in "Other" $(\underline{M}=4.19)$ perceived library services as significantly more satisfactorily addressed than did those in Division of Business and Economics, $\mathrm{M}=3.33$; $E(7,163)=2.07 ; R=.05$.

4. Personnel in "Other" $(M=3.12)$ perceived tutoring services as significantly more satisfactorily addressed than did those in Division of Business and Economics, $\mathbf{M}=$ 
2.29: $\underline{F}(7,163)=1.50 ; \mathrm{R}=05$.

5. Personnel in "Other" $(\underline{M}=3.32)$, Division of Education $(\underline{M}=3.18)$ and Division of Liberal Arts \& Sciences $(\underline{M}=3.06)$ perceived students' attitude toward education as significantly more satisfactorily addressed than did those in Freshman Division, $\underline{\mathrm{M}}=2.14 ; \underline{\mathrm{F}}(7,163)=3.07 ; \mathrm{R}=.01$.

6. Personnel in the School of Public and Environmental Affairs $(\underline{M}=4.00)$ perceived instructor academic expectation of students as significantly more satisfactorily addressed than did those in Division of Arts, $\underline{M}=2.90 ; \underline{F}(7,168)=2.52 ; R=02$.

The results of the one-way analysis of variance for the demographic groups indicated that personnel of the "Other" subgroup considered five of the six items as significantly different. Personnel in the Division of Education and the Division of Business and Economics each have two items with significant difference. All the other departments have one item of significant difference. These data are summarized in Table 37.

\section{Teach Introductory Level Course(s) Group}

The teach introductory level course(s) demographic group contained a "Yes or No" response format. The results for the multivariate analysis on the Satisfaction Scale scores and the subgroups showed a t-value of 1.004 with 41 and 102 degrees of freedom and a probability level of .482 . Hence, there was no significant difference between the subgroups. Therefore, Null Hypothesis 3 was retained on the teach introductory level course(s) group. (See Table 29.)

The results for the t-test analysis with the 41 individual items as the dependent 
Table 37

One-way ANOVA: Satisfaction--DEPT 41 Items

\begin{tabular}{|c|c|c|c|c|c|c|c|c|c|c|c|c|}
\hline \multirow[b]{2}{*}{ Item } & \multirow[b]{2}{*}{$\mathbf{N}$} & \multirow[b]{2}{*}{$\mathrm{E}$} & \multirow[b]{2}{*}{$p$} & \multicolumn{8}{|c|}{ Means if Sig Dif } & \multirow{2}{*}{$\begin{array}{l}\text { Group/s } \\
\text { Sig. Dif }+\end{array}$} \\
\hline & & & & ARTS & BUS & EDU & FRE & LAS & SNU & SPEA & $\mathrm{OTH}$ & \\
\hline 1 & 174 & .63 & .73 & & & & & & & & & \\
\hline 2 & 168 & 1.10 & .37 & & & & & & & & & \\
\hline 3 & 170 & .76 & .62 & & & & & & & & & \\
\hline 4 & 174 & .65 & .71 & & & & & & & & & \\
\hline 5 & 167 & 2.50 & $.02 *$ & 3.33 & 2.25 & 2.81 & 2.14 & 3.10 & 3.10 & 3.00 & 3.02 & LAS+OTH/BUS \\
\hline 6 & 167 & 1.57 & .15 & & & & & & & & & \\
\hline 7 & 170 & 1.32 & .25 & & & & & & & & & \\
\hline 8 & 170 & 1.08 & .38 & & & & & & & & & \\
\hline 9 & 170 & 2.07 & $.05^{*}$ & 3.80 & 3.33 & 3.93 & 4.14 & 3.82 & 4.00 & 383 & 4.19 & OTH/BUS \\
\hline 10 & 171 & .85 & .55 & & & & & & & & & \\
\hline 11 & 164 & 1.12 & .35 & & & & & & & & & \\
\hline 12 & 165 & 2.04 & .05 & & & & & & & & & \\
\hline 13 & 171 & 1.33 & .24 & & & & & & & & & \\
\hline 14 & 174 & .74 & .64 & & & & & & & & & \\
\hline 15 & 172 & 1.08 & .38 & & & & & & & & & \\
\hline 16 & 174 & 86 & .54 & & & & & & & & & \\
\hline
\end{tabular}




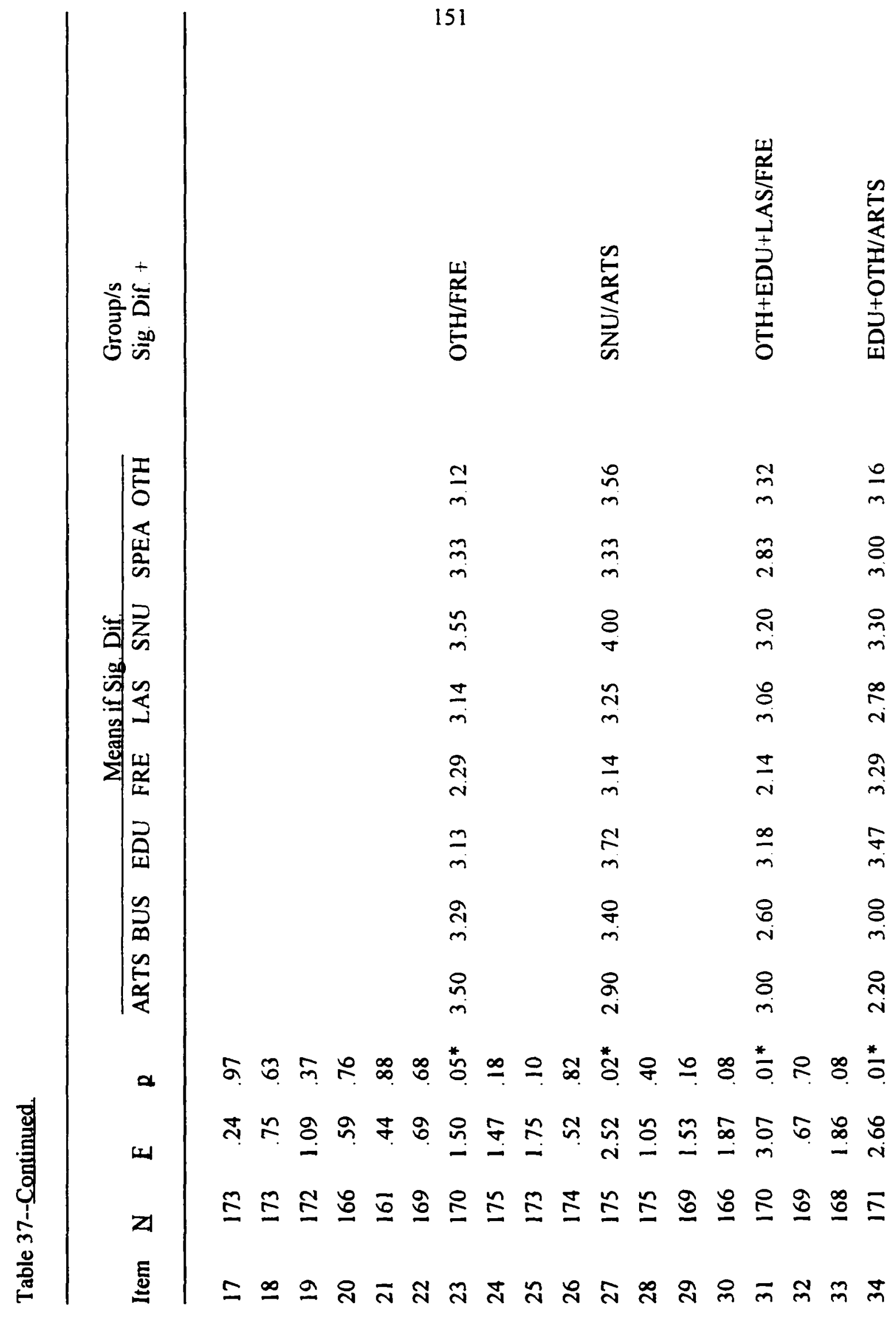


Table 37--Continued.

\begin{tabular}{|c|c|c|c|c|c|c|c|}
\hline \multirow{2}{*}{ Item } & \multirow[b]{2}{*}{$\mathbf{N}$} & \multirow[b]{2}{*}{$\underline{\mathbf{F}}$} & \multirow[b]{2}{*}{ p } & \multicolumn{3}{|c|}{ Means if Sig Dif } & \multirow{2}{*}{$\begin{array}{l}\text { Group/s } \\
\text { Sig. Dif. + }\end{array}$} \\
\hline & & & & ARTS BUS & FRE LAS SNU & SPEA OTH & \\
\hline
\end{tabular}

$\begin{array}{rrrr}35 & 168 & 1.90 & .07 \\ 36 & 167 & .96 & .46 \\ 37 & 170 & .58 & .77 \\ 38 & 164 & .96 & .47 \\ 39 & 169 & .69 & .68 \\ 40 & 168 & 1.57 & .15 \\ 41 & 169 & .78 & .61\end{array}$

Note. "EDU+OTH/ARTS" denotes that Education and Other are significantly different from Arts. "LAS+OTH/BUS" denotes that Liberal Arts and Sciences are significantly different from Business. "OTH/BUS" denotes that "Other" is significantly different from Business. "OTH/FRE" denotes that "Other" is significantly different from Freshman Division. "SNU/ARTS" denotes that School of Nursing is significantly different from Arts. "OTH+EDU+LAS/FRE" denotes that "Other," Education, and Liberal Arts and Sciences are significantly different from Freshman Division.

${ }^{*} \mathrm{R}<.05$. 
variables and the two subgroups of the teach introductory level course(s) as the independent variables indicated that 4 of the 41 items showed significant differences. Thus. Null Hypothesis 3 was rejected for these 4 items of the Satisfaction Scale. The following are the four items that showed significant differences between the Yes or No subgroups

1. Personnel who taught introductory level course(s) $(\underline{M}=3.95)$ perceived campus safety and security services as significantly more satisfactorily addressed than did those who did not teach introductory level course(s), $\underline{M}=3.64 ; \mathrm{t}(18 \mathrm{l})=2.48 ; \mathrm{p}=.01$.

2. Personnel who taught introductory level course(s) $(\underline{M}=3.56)$ perceived flexible course scheduling as significantly more satisfactorily addressed than did those who did not teach introductory level course(s), $\underline{M}=3.27 ; \mathrm{t}(182)=2.04 ; \mathrm{R}=04$.

3. Personnel who taught introductory level course $(s)(\underline{M}=3.60)$ perceived adm/fac/staff informal contact with students as significantly more satisfactorily addressed than did those who did not teach introductory level course $(s), \underline{M}=3.28 ; t(183)=2.34 ; p$ $=.02$.

4. Personnel who did not teach introductory level course(s) $(\underline{M}=3.73)$ perceived cashier/bursar services as significantly more satisfactorily addressed than did those who taught introductory level course(s), $\underline{M}=3.40 ; \mathrm{t}(174)=-2.90 ; \mathrm{R}=.00$.

The results of the analysis of variance of the 41 items indicated that 3 of the 4 items of significantly more satisfaction were of personnel who taught introductory level course(s). None of the 3 items have anything directly to do with instruction. The item that personnel who did not teach introductory level course(s) considered as more 
satisfactorily addressed was not instructional either. All of the 4 items of significant differences were institutional factors that directly provided services to the student. The results are summarized in Table 38 .

\section{Summary of Findings}

This chapter presented the results of the demographic profile of the respondents and of the two research questions and three null hypotheses. The university personnel groups and subgroups were classified as multiple independent variables. The mean scores from the Importance Scale and Satisfaction Scale were the dependent variables.

For the multivariate analysis of variance and discriminant analyses, the 41 items were the multiple dependent variables. Also, the 41 items were analyzed separately as dependent variables in the one-way analysis of variance and in the t-tests to indicate if there were significant differences within the subgroups. The 41 items provided individual mean scores that were rank ordered from the most to the least important or satisfactory factors. The five demographic independent variables were as follows: university status; employment time; gender; division, schools, and programs; and teach introductory level course(s). Each of these groups contained different amounts of subgroups.

The results indicated that the university personnel perceived all of the items as important institutional factors impacting student retention/attrition. The six least important factors were students' campus involvement, students' certainty of major/career, cashier/bursar services, students' loyalty toward the institution, Threshold Learning Communities, and campus rules and regulations. The seven most important 
Table 38

t-Test: Satisfaction--Teach Introductory Course(s) 41 Items

Items $\frac{\text { Number }}{\text { Yes No }} \frac{\text { Means }}{\text { Yes No }} \frac{\text { SD }}{\text { Yes No }}$ df $t$

\begin{tabular}{|c|c|c|c|c|c|c|c|c|c|}
\hline 1 & 86 & 98 & 3.20 & 3.12 & .96 & .96 & 182 & .53 & 60 \\
\hline 2 & 82 & 96 & 3.34 & 3.27 & .77 & .88 & 176 & .57 & .57 \\
\hline 3 & 81 & 98 & 3.35 & 3.28 & .85 & .76 & 177 & .58 & 56 \\
\hline 4 & 85 & 98 & 3.95 & 3.64 & .79 & .89 & 181 & 2.48 & $.01^{*}$ \\
\hline 5 & 79 & 97 & 2.97 & 2.91 & .95 & 96 & 174 & .47 & 64 \\
\hline 6 & 80 & 96 & 3.40 & 3.73 & .70 & .79 & 174 & -2.90 & $00^{*}$ \\
\hline 7 & 82 & 97 & 3.32 & 3.30 & .83 & 1.08 & 177 & .12 & 90 \\
\hline 8 & 81 & 97 & 3.52 & 3.61 & .98 & .97 & 176 & -61 & 54 \\
\hline 9 & 81 & 97 & 3.86 & 3.94 & .93 & .90 & 177 & -.54 & 59 \\
\hline 10 & 83 & 98 & 3.84 & 3.82 & .80 & .83 & 179 & .22 & 83 \\
\hline 11 & 78 & 96 & 3.27 & 3.30 & .70 & .67 & 172 & -.32 & .75 \\
\hline 12 & 78 & 95 & 3.15 & 3.39 & .93 & .78 & 171 & -1.82 & .07 \\
\hline 13 & 85 & 96 & 3.31 & 3.41 & .99 & 1.07 & 179 & -.65 & .52 \\
\hline 14 & 86 & 98 & 3.56 & 3.27 & 97 & .98 & 182 & 2.04 & $.04^{*}$ \\
\hline 15 & 82 & 99 & 3.13 & 3.00 & .80 & .81 & 179 & 1.12 & .27 \\
\hline 16 & 84 & 99 & 3.01 & 2.99 & 1.01 & 93 & 181 & 1.50 & .88 \\
\hline 17 & 84 & 98 & 3.10 & 3.30 & .89 & 85 & 180 & -1.55 & 12 \\
\hline 18 & 83 & 99 & 2.78 & 2.80 & .86 & .95 & 180 & -11 & 91 \\
\hline 19 & 84 & 98 & 3.05 & 3.06 & .82 & .93 & 180 & -10 & .92 \\
\hline 20 & 82 & 93 & 2.91 & 3.08 & .89 & .81 & 173 & -1.25 & 21 \\
\hline 21 & 79 & 89 & 3.15 & 3.27 & .82 & .74 & 166 & -.98 & 33 \\
\hline 22 & 83 & 96 & 3.20 & 2.99 & .88 & .73 & 177 & 1.79 & .08 \\
\hline 23 & 83 & 96 & 3.16 & 3.17 & .96 & .87 & 177 & -.07 & .94 \\
\hline 24 & 86 & 99 & 3.60 & 3.28 & .89 & .97 & 183 & 2.34 & $.02^{*}$ \\
\hline 25 & 85 & 98 & 3.26 & 3.02 & 1.03 & .93 & 181 & 1.65 & .10 \\
\hline 26 & 85 & 99 & 2.75 & 2.60 & .99 & .95 & 182 & 1.10 & .27 \\
\hline 27 & 86 & 99 & 3.41 & 3.49 & .80 & .75 & 183 & -.77 & .44 \\
\hline 28 & 86 & 99 & 3.69 & 3.59 & .77 & .72 & 183 & .91 & .37 \\
\hline 29 & 81 & 97 & 3.20 & 3.23 & .81 & .74 & 176 & -.25 & .80 \\
\hline 30 & 76 & 98 & 3.04 & 3.10 & .87 & .83 & 172 & -.48 & .63 \\
\hline 31 & 81 & 99 & 3.01 & 3.08 & .89 & .79 & 178 & -.55 & .59 \\
\hline 32 & 81 & 98 & 2.59 & 2.67 & .79 & .94 & 177 & -.62 & .54 \\
\hline 33 & 81 & 97 & 3.07 & 3.12 & .69 & .86 & 176 & -.42 & .67 \\
\hline
\end{tabular}


Table 38--Continued.

\begin{tabular}{|c|c|c|c|c|c|c|c|c|c|}
\hline \multirow[b]{2}{*}{ Items } & \multicolumn{2}{|c|}{ Number } & \multicolumn{2}{|c|}{ Means } & \multicolumn{2}{|c|}{$\mathrm{SD}$} & \multirow[b]{2}{*}{ df } & \multirow[b]{2}{*}{$t$} & \multirow[b]{2}{*}{ p } \\
\hline & Yes & No & Yes & No & Yes & $\overline{\mathrm{No}}$ & & & \\
\hline 34 & 83 & 98 & 2.95 & 3.04 & 1.00 & .87 & 179 & -.64 & .52 \\
\hline 35 & 78 & 98 & 3.18 & 3.14 & .89 & .83 & 174 & .28 & .78 \\
\hline 36 & 79 & 97 & 3.29 & 3.32 & .56 & .74 & 174 & -.28 & .78 \\
\hline 37 & 81 & 99 & 2.99 & 2.85 & .77 & .86 & 178 & 1.13 & .26 \\
\hline 38 & 77 & 96 & 3.31 & 3.18 & .75 & .78 & 171 & 1.15 & .25 \\
\hline 39 & 78 & 99 & 3.17 & 3.11 & .87 & .77 & 175 & .45 & .65 \\
\hline 40 & 79 & 98 & 3.30 & 3.22 & .76 & 87 & 175 & .64 & .52 \\
\hline 41 & 80 & 99 & 2.60 & 2.63 & .88 & 89 & 177 & -.20 & 84 \\
\hline
\end{tabular}

${ }^{*} R<.05$.

factors were academic advising, financial aid services, students' commitment to her/his education, instructor effectiveness, students' attitude toward education, adm/fac/staff caring about students' progress, and students' class attendance.

The university personnel were generally not highly satisfied with the institution's efforts to address factors impacting student attrition/retention. The five least satisfactorily addressed factors were students' loyalty toward the institution, social support services for students, campus academic/social climate, students' campus involvement, and students' social integration with institution. The four most satisfactorily addressed factors were library services, registration services, campus safety and security services, and instructor effectiveness.

The results showed that there was a significant difference between the Importance Scale mean scores and the Satisfaction Scale mean scores. This indicated that although 
the university personnel considered the factors important they did not perceive the items as satisfactorily addressed. The results showed 38 of the 41 items with significant differences between the two scales.

The results indicated that there were no significant differences among the total Importance Scale scores for the university status, employment time, gender, and the teach introductory level course(s) groups. However, there were significant differences among the division, schools, and programs subgroups. All of the one-way analysis of variance tests and t-tests showed significant differences among the subgroups in only a few of the items. This indicated that as a whole, the personnel groups were in harmony in their perception of the importance of the factors impacting student retention/attrition, but there were differences of opinion on a few individual items.

The results indicated that there were no significant differences among the total Satisfaction Scale scores for the employment time; gender; division, schools, and programs; and the teach introductory level course(s) groups. However, there were significant differences among the university status subgroups. All of the one-way analysis of variance and t-tests showed significant differences in only a few items among the subgroups. This indicated that overall personnel did not highly perceive the institutional factors impacting student retention/attrition as satisfactorily addressed. 


\section{CHAPTER V}

\section{SUMMARY, CONCLUSIONS, AND RECOMMENDATIONS}

The purpose of this study was to identify the least and most important institutional factors impacting student attrition/retention and to identify the least and most satisfactorily addressed factors impacting student persistence. The survey population consisted of administrators, faculty, professional staff, and clerical/technical staff from a Midwestern university

Consequently, I developed and validated the instrument to measure the study's constructs. Also, the study sought to determine if there were significant differences among the means scores of the demographic groups and their subgroups for the Importance and Satisfaction Scales.

The literature review provided a descriptive account of the historical development and the identity of critical issues in student departure theories and models. From the literature of related research studies, the judgmental and theoretical construct base of the instrument items was confirmed. It showed that a small percentage of research studies used institutional personnel as research subjects even though many theorists and researchers recommended doing so (Noel, 1978; Steifelmeyer, 1993; Tinto, 1987).

Student attrition/departure has been an issue of concern for administrators in 
institutions of higher education for many years (Pervin et al., 1966; Nehila, 1996). Bean (1985), Noel (1978), Pascarella (1982b), Terenzini (1982), and Tinto (1987) were the main researchers and theoreticians who provided the theoretical framework for this study, for the construct items, and for the developed instrument.

Tinto (1975) developed the first widely accepted theory and model to explain student departure in institutions of higher learning. He synthesized the 1975 Model of Student Departure from current literature, from Durkheim's (1961) studies on suicide, and from Spady's (1970) sociological theory of shared group values and friendship relationships as reflective of student dropouts (Bean, 1982a, p. 21).

Later, Tinto (1987) revised his 1975 Model of Institutional Departure by using Van Gennep's (1960) studies on students' rites of passage as the locus of control for student departure decisions. Again, Tinto (1987) developed his Longitudinal Model of Institutional Departure by synthesizing concepts from other attrition/retention studies ( $p$. 114). His model posited student attrition in higher education as the result of a longitudinal interactive process between the students' pre-entry attributes, intentions, educational goals and commitments, and their level of academic and social integration within the institution. The individual's interactive institutional experiences and external commitment would modify students' initial intentions, goals, and institutional commitments, at which time they could decide to depart from institutions of higher education.

Tinto's (1987) theory proposed that student departure can be directly and indirectly linked to the students' level of academic and social integration with the institution. I used Tinto's theory as a guide to develop the model and subsequently the 
instrument for this study. I found that Tinto's theory and model were adequate starting points for the study and instrument development. However, I found that the historical tendency with student attrition studies was to label departing students as psychological or sociological misfits. These theories were in effect blaming the students for their departure in an arena where there were more students than seats. However, I proposed that these sociologically and psychologically based theories are obsolete and ineffective in describing student persistence/departure in the 1990s and beyond. Student persistence/departure is an issue of the university's ability to interest and provide an environment where students can achieve appropriate levels of academic and personal satisfaction through quality academic and personal services. This is especially important for first-year students in that they have the highest departure rate in institutions of higher learning.

The current market relationship between students and institutions of higher learning has changed (Spanbauer, 1996, p. 8). Fewer students are available to attend college, and many more post-secondary organizations exist. The marketplace for collegeage students is very competitive. Students can choose where they want to continue their education. With growing scholarships, grants, and affordable transportation, students can go anywhere in the nation or world to study. If they are not satisfied with how an institution is meeting their academic expectations, they can readily move to another institution that is sensitive to their academic and personal satisfaction.

The significance of this study was the introduction of an exploratory model and survey instrument. The Melendez model proposes a more pragmatic approach to the study of student retention/attrition as an alternative rival hypothesis. The alternative 
hypothesis advocates that the institution's efforts directly and indirectly impact student persistence/departure. The instrument provided a way to identify salient factors and to measure how satisfactorily addressed are the institutional efforts impacting student attrition/retention. The data provided a way to test congruity among subject groups.

I developed the model by synthesizing concepts from other models and theories on retention and by modifying Tinto's (1987) Model of Institutional Departure. The Melendez Model of Transactional Satisfaction Toward Student Persistence concurs with other models and theories that student persistence is a time-sensitive longitudinal process. The conceptual difference between Tinto's (1987) model and my model is that Tinto posited that student departure is influenced by the students' level of academic and social integration within the institution, whereas the Melendez model posited that student persistence/departure is influenced by the quality of the institution's efforts toward providing students with academic and personal satisfaction. Thus, the accountability for student retention rests primarily with the institution.

As a result, I concluded that a transactional relationship exists between the students as the consumers and the institution as the service provider. The students' preentry attributes and external factors influence their academic and personal commitments. This impacts on the students' disposition of intentions toward entry, delayed entry, or non-entry into an institution of higher learning.

Upon entry into the university, students have positive or negative transactional experiences within the institution. The significance of the transactional experience is determined by the quality of the institution's and the students' efforts toward academic 
and personal satisfaction. This experience influences the students' disposition of intention to persist. stop out, or depart. Thus, the higher the quality of institutional commitment and effort toward student academic and personal satisfaction, the higher the level of student persistence.

A survey instrument was developed and validated from this model. It can provide future researchers with a tool to identify ways to efficiently reduce student attrition. Also, the findings from this study can provide reliable data to assist in identifying important attrition/persistence factors for the development of visionary and strategic plans to address student attrition issues. Results from this study can inform decision makers as to where available resources can be shifted to develop personnel and efficient institutional efforts to significantly improve student persistence and to reduce student attrition.

\section{Methodology}

This study was conducted using survey research methodology to measure the university personnel's perception of important factors impacting student attrition/retention. The study also sought to measure personnel's perception on how satisfactorily addressed were these student persistence factors. Descriptive and inferential statistical analyses were conducted to analyze the data and to address the two research questions and three null hypotheses.

Taking Jose's (1978), Noel et al.'s (1985), Parker's (1995), and Stiefelmeyer's (1993) recommendations of using university personnel to study student attrition/retention, the subject population consisted of university personnel from the following categories: 
administrators, faculty, professional staff, and clerical/technical staff. This study was limited to the personnel of a Midwestern public commuter university.

A survey package was sent to 703 subjects: 98 professionals, which included administrators, counselors, professional staff; 222 full-time faculty; 283 part-time faculty; and 100 full-time clerical/technical staff. The administrators were the chancellor, vicechancellors, deans, department chairs, their associates and assistants. Of the $193(27.5 \%)$ usable returned surveys, $17(8.8 \%)$ were administrators, $109(56.5 \%)$ were faculty, 31 (16.1\%) were clerical/technical staff, $30(15.5 \%)$ were professional staff. and $6(3.1 \%)$ refrained from noting their personnel status.

This study tested only university personnel's perception of the institution's efforts toward students' academic and personal satisfaction. However, caution should be taken when generalizing the results of this study onto all the personnel since some of the subgroups obtained low survey return rates, and the results may produce some unstable statistical analyses.

\section{Instrument}

Since no instrument was found in the literature review to measure the construct using university personnel, I developed, validated, and used the instrument for this study: the Institutional Student Persistence Survey, ISPS. The adequacy of the instrument was determined by construct and content validation. The student retention/attrition construct was operationalized into factors/items for the instrument. These instrument items were validated through expert judges, content materials from the literature and theorists, and 
empirical statistics of factor and reliability analyses. I especially used items from Tinto's (1987) theory and model of student departure. The instrument reliability and validation analyses and the university subject population responses produced more than adequate judgmental and statistical results to confirm the reliability of using Tinto's (1987) theory as a guide to study student departure and of using the Melendez model for the instrument foundation and for interpreting the results.

The validation process confirmed the instrument's reliability and adequacy to measure university personnel's perception of important factors/items impacting on student attrition/retention and how satisfied they were with the university's efforts toward students' academic and personal satisfaction. Thus, the survey was conducted using the instrument that I developed and validated in this study.

The validation process assured that the results of this study can reliably provide administrators of higher education with greater insights on ways to increase student retention by modifying present efforts impacting student persistence. To control for internal and external validity of the instrument contents, I conducted two pilot studies to reduce researcher bias in the inclusion or exclusion of extraneous factors or rival hypotheses. Also, expert judges confirmed the construct validity by assisting in the item selection. The reliability and factor analyses computer programs helped to identify the complex dimensions of the student persistence construct.

Initially, reliability analyses were used to examine the statistical correlations between the items of the instruments. The high Alpha Cronbach coefficient of .95 for the Importance Scale and .91 for the Satisfaction Scale provided the statistical confirmation 
for the two dimensional student retention constructs. The factor analysis for a two-factor rotation also produced statistical support for the judgmental item selection of the two dimensions: institutional efforts (commitment) and students' efforts toward students' academic and personal satisfaction.

In brief, the Melendez Model of Transactional Satisfaction Toward Student Persistence provided an adequate foundation for developing the research instrument and for identifying important institutional factors impacting student attrition/retention and to measure the personnel's perception of how satisfactorily addressed are the institutional factors impacting student persistence. The model posited that as satisfaction with the institution's commitment and efforts to improve student retention increases, student persistence increases.

\section{Research Question 1}

Research Question 1 asked: What university efforts are perceived by personnel as the least and the most important institutional factors impacting student retention/attrition? This question was addressed by calculating and rank ordering the mean scores of each of the 41 items and for the combined total scale scores.

The combined total mean score for the Importance Scale was 4.14. This score indicated that overall the university personnel perceived the instrument items as important institutional factors impacting student retention. The least and the most important factors were items that ranked in the top and bottom $25 \%$ of the range of the mean scores. The six least important factors in descending order are as follows: 
1. Students' campus involvement

2. Students' certainty of major/career

3. Cashier/bursar services

4. Students' loyalty toward the institution

5. Threshold Learning Communities

6. Campus rules and regulations.

The seven most important factors in descending order are as follows:

l. Academic advising

2. Financial aid services

3. Students' commitment to her/his education

4. Instructor effectiveness

5. Students' attitude toward education

6. Adm/fac/staff caring about students' progress

7. Students' class attendance

The six least important items/factors included both institutional and student efforts impacting students' academic and personal satisfaction with the university. These results indicated that personnel tend to perceive both institutional and student efforts as least important factors impacting student attrition while the seven most important factors are only institutional efforts impacting students' academic and personal satisfaction with the university. These results indicate that personnel perceive institutional efforts as influential factors impacting student persistence. In summary, the results indicated that student attrition/retention is an important issue for the university personnel. The most and least 
important factors impacting student persistence are institutional and student efforts influencing students' academic and personal satisfaction from a transactional experience between the institution and the student. Therefore. decision makers need to be aware that personnel are sensitive to student persistence efforts being performed in the university Thus, this provides validity to the Melendez model's premise that once students enter institutions of higher learning their satisfaction level of the transactional experience between the institution and students directly impacts student persistence

\section{Research Question 2}

Research Question 2 asked: What university efforts are perceived by personnel as the least and the most satisfactorily addressed institutional factors impacting student retention/attrition? This question was addressed by calculating and rank ordering the mean scores of each of the 41 items and for the total scale scores.

The total Satisfaction Scale mean was 3.22. This indicated that personnel were not highly satisfied with institutional efforts impacting student persistence/departure. The least and the most satisfactorily addressed factors were items in the bottom and top $25 \%$ of the range of the mean scores, respectively. The five least satisfactory items in descending order are as follows:

1. Students' loyalty toward the institution

2. Social support services for students

3. Campus academic/social climate

4. Students' campus involvement 
5. Students' social integration with institution.

The four top ranking satisfactorily addressed factors in descending order are as follows

1. Library services

2. Registration services

3. Campus safety and security services

4. Instructor effectiveness.

The five least satisfactorily addressed items are a mix of institutional and student efforts impacting students' personal satisfaction. This indicates that personnel perceive items impacting students' personal satisfaction as the least satisfactorily addressed. The top ranking satisfactorily addressed items are institutional efforts impacting students' academic satisfaction. This indicates that personnel perceive items of institutional efforts as most satisfactorily addressed. These findings lend support for the Melendez model by confirming that the responses of personnel on the Satisfaction Scale clearly indicate that institutional and student-centered efforts influence academic and personal satisfaction.

In summary, the results of the Satisfaction Scale indicated that personnel were not highly satisfied with the university's efforts impacting student attrition/retention.

Personnel considered institutional efforts that enhance academic and personal satisfaction as the most important items impacting student persistence. Also, they viewed institutional and student efforts that enhance personal satisfaction as the least important items impacting student persistence. With personnel who are not highly satisfied with the university's student retention efforts and a retention rate that is dropping, administrators may need to consider improving the quality of academic and personal services provided to 
the students.

\section{Null Hypothesis 1}

Null Hypothesis 1 stated: There is no significant difference between the Importance Scale scores and the Satisfaction Scale scores of university personnel. For this hypothesis, a t-test was conducted to identify significant differences between the mean scores of the Importance and Satisfaction Scales.

The t-test between Importance and Satisfaction Scales revealed a significant disparity between the Importance Scale and the Satisfaction Scale. The total mean score for the Importance Scale was 4.14 , and 3.22 for the Satisfaction Scale. t-test results of the total means scores produced a t-value of 20.32 with 124 degrees of freedom and a probability level of .0001 . The total importance mean score was greater than the total satisfaction mean score. University decision makers ought to consider that personnel view institutional factors impacting student retention as important but not very satisfactorily addressed.

The results for the t-test analysis between the Importance Scale and Satisfaction Scale items showed that all but 3 of the 41 items were significantly different at the .05 level. This indicated that personnel perceived the majority of the items with greater importance than their satisfaction with the university's efforts to address the factors impacting student retention/attrition.

The side-by-side item comparison of the most importance/satisfaction ranking indicated that of the seven most important items almost all are institutional and student 
efforts impacting students' academic and personal satisfaction; three items ranked fairly high in both importance and in satisfaction (instructor effectiveness, financial aid services, and $\mathrm{adm} / \mathrm{fac} / \mathrm{staff}$ caring about student program), and four items ranked high in importance but low in satisfaction (students' commitment to her/his education, academic advising, students' attitude toward education, and students' class attendance). The results showed the seven most important items as not highly satisfactorily addressed. Most of the items were institutional and student efforts impacting on academic satisfaction. This indicates that personnel may tend to perceive institutional and student efforts impacting academic satisfaction as important but not satisfactorily addressed by the university.

The satisfactory/important comparison indicated that of the four most satisfactorily addressed items only one item ranked high as satisfactorily addressed and high in importance (instructor effectiveness). One item ranked high in satisfaction but mid-level in importance (registration services). Two items ranked high in satisfaction but low- to midlevel in importance (library services and campus safety and security services). The majority of the four most satisfactorily addressed items were institutional efforts impacting students' academic and personal satisfaction. This indicates that personnel perceive institutional efforts toward students' academic and personal satisfaction as the most satisfactorily addressed. However, these items did not indicate a high level of satisfaction. The only item perceived as satisfactorily addressed and important is instructor effectiveness. This response may be skewed in that faculty provided the highest survey responses rate $(57 \%)$ of all the respondents.

Hence, the results indicated that though personnel viewed some items as somewhat 
satisfactorily addressed, they did not perceive the same item as highly important. The university may be providing satisfactory services in areas that are not as important as others. University administrators may need to focus their resources on satisfactorily addressing factors that are perceived as important while satisfactorily addressing the other factors.

In both the importance/satisfaction and the satisfaction/importance comparative rankings, the results showed that even the most satisfactorily addressed item, library services, did not receive a highly satisfactory rating. This suggests that although personnel consider most of the items as important. the university's efforts to address these factors were rated as not highly satisfactory and thus in need of improvement. University officials need to note that the personnel are not highly satisfied with the institution's efforts impacting student attrition/retention. This may be one of the reasons why the institution has an attrition rate of $45.8 \%$.

\section{Null Hypothesis 2}

Null Hypothesis 2 stated: There are no significant differences among university personnel in their perception of the importance of institutional factors impacting student retention/attrition. This hypothesis was tested with multivariate analyses to identify significant differences of the combined scale mean scores and of the 41 items on the five demographic groups (variables): university status; employment time; gender; divisions, schools, and programs; and teach introductory level course(s). Discriminant analysis was conducted when the divisions, schools, and programs subgroups indicated that there were 
significant differences in the multivariate analysis of variance. One-way analyses of variance were used to test significant differences of the individual items on the university status: employment time; and divisions, schools, and programs demographic subgroups. The Student-Neuman-Keuls--Post Hoc Multiple Comparison Procedure--was used to identify pairwise differences for all significant $\underline{F}$ in the analysis of variance. The $\underline{t}$-tests were used to analyze the difference between gender and teach introductory level course(s) demographic subgroups.

On the multivariate analysis of variance of the combined Importance Scale for the university status subgroups, there were no significant differences between administrators. faculty, professional staff, and clerical/technical staff. This indicated that there was a high degree of congruity among the respondents concerning the importance of the factors impacting on student attrition/retention.

With the individual items, the results revealed that the clerical/technical staff perceived only five items of institutional efforts impacting personal satisfaction (campus rules and regulations, registration services, cashier/bursar services, students' current GPA, and cashier/bursar services) with greater importance than did administrators and faculty. Professional staff perceived one item (cashier/bursar services) with greater importance than did faculty. The results imply that with the individual items, university personnel slightly differ in perception on the importance of institutional efforts impacting students' personal satisfaction.

In the multivariate analysis of variance of employment time subgroups, there were no significant differences among personnel employed less than 1 year, 1 to 5 years, 6 to 10 
years, and 11 or more years. For the individual items, the results showed that those employed 1 to 5 years perceived one item of institutional effort impacting academic satisfaction (library services) with greater importance than did those employed 11 or more years. This indicated that years of employment in the university did not generally influence employees' perception concerning the importance of institutional factors impacting student satisfaction or persistence.

In the multivariate analysis of variance of the total Importance Scale for the gender subgroups, there was no significant difference between the scores of the female and male employees. The results on the individual items showed that females perceived three items of institutional efforts impacting personal satisfaction (campus safety and security services, students' internship/employment, and students' campus involvement) with greater importance than did males. This indicates that, as a whole, gender difference did not alter personnel's perception level of the importance of the factors impacting student persistence. However, on individual items females may perceive some institutional efforts impacting personal satisfaction with greater importance than do males.

On the total Importance Scale for the divisions, schools, and programs subgroups, the results revealed that there were significant differences among personnel from the Division of Arts, Division of Business and Economics, Division of Education, Freshman Division, Division of Liberal Arts and Sciences, School of Nursing, School of Public and Environmental Affairs, and "Other." The "Other" subgroup category consists of the Division of Continuing Education, Division of Labor Studies, General Studies Degree Program, Dental Education, School of Library and Information Science, and School of 
Social Work.

The discriminant analysis results revealed that personnel from the Division of Arts, Division of Business and Economics, and Freshman Division, School of Nursing, Division of Liberal Arts and Sciences perceived mostly items of institutional factors impacting academic and personal satisfaction (academic advising, self-confidence as a student. Threshold Learning Communities, family/child care support services, and registration services) with greater importance than did personnel from the School of Public and Environmental Affairs, Division of Education, and "Other." In contrast, personnel from the Division of Education, School of Public and Environmental Affairs, and "Other" perceived four items of institutional and student factors impacting academic and personal satisfaction (career counseling services, students' current GPA, students' commitment to her/his education, and academic support services) with greater importance than did personnel from the Division of Liberal Arts and Sciences, School of Nursing, Freshman Division, Division of Business and Economics, and the Division of Arts.

The discriminant analysis results indicate that personnel from university departments differ in their perception of the importance between items of institutional efforts impacting students' personal satisfaction and items of institutional and student efforts impacting academic and personal satisfaction. One set of departments considers institutional efforts impacting students' personal satisfaction as most important while another set of departments considers both the institutional and students' efforts impacting both academic and personal satisfaction as most important.

With the individual items for the divisions, schools, and programs subgroups, the 
results revealed that personnel for the Division of Education, Freshman Division, and "Other" departments perceive 5 of the 41 items (campus rules and regulations, admission services, cashier/bursar services, registration services, and Threshold Learning Communities), which are items of institutional efforts impacting personal satisfaction, as greater in importance than did personnel in the Division of Arts and Sciences, Division of Business and Education, and the Division of Arts. The results from the individual items indicate that personnel from university departments slightly differ in perception of which items of institutional efforts impacting students' personal satisfaction are most important.

On the total Importance Scale, there were no significant differences in the teach introductory level course(s) subgroups. This indicated that among personnel who taught or did not teach introductory level course(s) there was congruity in their perception concerning the level of importance of factors impacting student persistence.

With the individual items, personnel who did not teach introductory level course(s) perceived all seven of the items impacting students' personal satisfaction (campus rules and regulations, campus safety and security services, cashier/bursar services, financial aid services, registration services, Threshold Learning Communities, and instructor's effectiveness) as more important than did those who taught introductory level course(s) This indicated that on individual items, personnel who did not teach introductory level course(s) consider items of institutional efforts impacting students' personal satisfaction to be of greater importance than do those who taught introductory level course(s).

Overall, while there were a few differences in perception, there was general congruity on the importance of institutional factors impacting student retention/attrition 
among the five demographic groups with the exception of the divisions, schools, and programs, which differed mainly on the level of importance on items of institutional efforts impacting students' academic and personal satisfaction.

With the individual items, the difference in opinion was on which items of institutional or student efforts impacting students' academic or personal satisfaction were important. There were no instructional institutional academic items (remedial course work services, tutoring services, study skills assessment/development, and academic support services) that produced significant differences in the results. This indicates that personnel exhibited congruity in their opinion that institutional academic efforts are important factors impacting students' satisfaction and retention.

Also, the results indicate that congruity on the importance of institutional factors impacting student persistence exist among personnel regardless of their university status, the difference in years of employment whether they were male or female, and taught or did not teach introductory level course(s). Since a difference in opinion exists among the different divisions, schools, and programs, administrators need to consider the different concerns and needs of each division, school, and program when developing campus-wide strategies impacting student retention. Administrators of institutions of higher learning should target their resources on the most important institutional factors that will produce the greatest student satisfaction and student persistence through the university, within the departments, but especially with the first-year students. 


\section{Null Hypothesis 3}

Null Hypothesis 3 stated: There are no significant differences among university personnel in their satisfaction with the university efforts to address institutional factors impacting student retention/attrition. This hypothesis was tested with multivariate analysis to identify significant differences using the combined total scale score on the five demographic groups (variables): university status; employment time; gender; divisions. schools, and programs; and teach introductory level course(s). Discriminant analyses was conducted when the university status subgroups indicated significant differences in the multivariate analysis of variance. One-way analysis of variance was used to test significant differences of the 41 individual items on the university status; employment time; and divisions, schools, and programs subgroups. The Student-Neuman-Keuis--Post Hoc Multiple Comparison Procedure--was used to identify pairwise differences for all significant Es in the analysis of variance. $t$-tests were used to analyze the difference between the gender and the teach introductory level course(s) subgroups.

On the Satisfaction Scale for the university status subgroups, the results showed significant difference among administrators, faculty, professional staff, and clerical/technical staff. This indicated that personnel differed in their satisfaction with the university's efforts impacting student retention/attrition.

Further analysis showed two of the three discriminant functions as statistically significant. Function 1 showed that those employed as clerical/technical staff and administrators perceived six items of institutional factors impacting students' academic and personal satisfaction (campus safety and security services, instructor academic 
expectation of students, students' sense of self-development, flexible course scheduling, students' current GPA, and adm/fac/staff caring about students' progress) with greater satisfaction than did those employed as professional staff and faculty. In contrast, faculty and professional staff perceived seven items of institutional and student factors impacting students' academic and personal satisfaction (mentoring programs, cashier/bursar services, students' satisfaction with institutional experience, students' academic integration into the institution, self-confidence as a student, students' class attendance, and study skill assessment and development) with greater satisfaction than did administrators and clerical/technical staff. The result of function 1 indicated that personnel differed on how satisfactorily the university addressed factors impacting student persistence particularly on items that are institutional or student efforts and academic or personal satisfaction

Function 2 showed that administrators and faculty perceived eight institutional efforts--6 non-instructional and 2 instructional-impacting students' academic and personal satisfaction (students' academic integration into the institution, students' current GPA, minority retention efforts, study skill assessment and development, tracking students' academic progress, students' class attendance, social support services for students, and registration services) with greater satisfaction than did those employed as clerical/technical staff and professional staff. In contrast, professional staff and clerical/technical staff perceived four institutional efforts--3 non-instructional and 1 instructional-impacting students' academic and personal satisfaction (adm/fac/staff caring about students' progress, remedial course work services, students' campus involvement, and cashier/bursar services) with greater satisfaction than did the faculty and administrators. 
The result of function 2 indicated that personnel differ on some items of how satisfactorily the university addresses factors impacting student persistence.

The results of the individual items showed that in seven items the clerical/technical staffs were more satisfied with the university's efforts impacting student retention than the did other university personnel. The seven items were academic support services, Freshunan Division services, social support services, tutoring services, cashier/bursar services, career counseling services, and students' social integration with institution.

The results of the individual items showed that administrators perceived the following four items as more satisfactorily addressed than did the other personnel: Freshman Division services, academic support services, student satisfaction with institution, and family/child care support services. The clerical/technical staff perceive the following seven items as more satisfactorily addressed than did the other personnel: academic support services, Freshman Division services, social support services, tutoring services, cashier/bursar services, career counseling services, and students' social integration with institution. Faculty and professional staff perceive two items as more satisfactorily addressed than did the other personnel. These results on the individual items indicate that personnel slightly differ on how the university satisfactorily addresses efforts impacting student persistence.

On the total Satisfaction Scale for employment time subgroups, there were no significant differences among personnel employed less than 1 year, 1 to 5 years, 6 to 10 years, and 11 or more years. For the individual items, the results showed that those employed less than 1 year perceived two items as more satisfactorily addressed than did 
those employed 6 to 10 years and 11 or more years. Also, those employed 1 to 5 years and 6 to 10 years perceived one item as more satisfactorily addressed than those employed 11 or more years. The results of these three items indicate that on these few items those employed fewer years may perceive items as more satisfactorily addressed than did those employed more years. However, the collective results indicate that the number of years employed generally does not influence personnel's perception on how satisfactorily addressed are items impacting student retention/attrition.

On the total Satisfaction Scale for gender subgroups, there was no significant difference between female and male employees. With the individual items, male employees perceived one item with greater satisfaction than did females employees. Thus, the results indicate that, as a whole, gender does not influence employees' satisfaction level on how the university addressed factors impacting student retention.

On the total Satisfaction Scale for the eight divisions, schools, and programs subgroups, there were no significant differences among the Division of Arts, Division of Business and Economics, Division of Education, Freshman Division, Division of Liberal Arts and Sciences, School of Nursing, School of Public and Environmental Affairs, and "Other," which included Division of Continuing Education, Division of Labor Studies, General Studies Degree Program, Dental Education, School of Library and Information Science, and School of Social Work. With the individual items, personnel in the "Other" subgroup viewed five institutional and student instructional and non-instructional efforts impacting students' academic and personal satisfaction (students' class attendance, career counseling services, library services, tutoring services, and students' attitude toward 
education) with greater satisfaction than did those in the Division of Arts, Division of Business and Economics, and the Freshman Division. Personnel in the Division of Liberal Arts and Sciences viewed two institutional and student non-instructional efforts impacting students' academic and personal satisfaction (career counseling services, and students' attitude toward education) with greater satisfaction than did those in the Division of Business and Economics, and the Freshman Division.

Personnel in the School of Public and Environmental Affairs viewed instructors' academic expectation of students--instructional institutional efforts impacting students' academic and personal satisfaction--with greater satisfaction than did those in the Division of Arts. The results indicate that personnel in the divisions, schools, and programs are generally congruent in their perception on how satisfactorily the university addresses institutional efforts impacting student persistence, although they may differ slightly on individual items.

On the total Satisfaction Scale for the teach introductory level course(s) subgroups, there were no significant differences between personnel who taught or do not teach introductory level course(s). With the 41 individual items, personnel that taught introductory level course(s) perceived three institutional efforts impacting students' personal satisfaction (campus safety and security services, flexible course scheduling, and $\mathrm{adm} / \mathrm{fac} / \mathrm{staff}$ informal contact with students) with greater satisfaction than did those who did not teach introductory level course(s). In contrast, those who did not teach introductory level course(s) perceived cashier/bursar services as more satisfactorily addressed than did those who taught introductory level course(s). 
This indicated that overall there were few differences among those who taught or did not teach introductory level course(s) in their perception on how satisfactorily the university addresses items impacting student retention. With the individual items, the implication is that they differ slightly in their perception as to what items are satisfactorily addressed.

Also, the results indicated that the demographic groups are generally homogeneous in their satisfactory level with the university's efforts to address factors impacting student retention with the exception of the university status subgroups. The majority of the items with significant differences were institutional efforts.

In summary, the new model provides an alternative prospective to the study of student persistence/departure. It focuses on the need for universities to provide students with academic and personal satisfaction. Student retention/persistence is a transactional relationship between the student and the university. Universities that are committed to providing an environment where the students are satisfied with their academic and personal experience in the university will enhance their student retentions rates.

My dual-scale student persistence instrument provides the means to simultaneously identify the important institutional efforts that most influence student retention and measure how satisfactorily addressed those areas are that most impact student attrition. This information allows leadership to focus their resources on activities that scratch where students "itch".

The study confirms the value of including research data from university personnel when studying student retention. I found that though personnel where generally 
congruent on the importance of the items, there were nuances of differences among personnel from the divisions, schools, and programs. Also, personnel from different employment status subgroups differed in their perception as to which items were being satisfactorily addressed by the university. This may infer the need for administrators to be cognizant that employees from divisions, schools, and programs may differ as to what items are perceived as important student persistence efforts. Personnel from employment status subgroups differ on how satisfactorily the university is addressing the areas impacting student attrition.

\section{Conclusions}

Based on the results of this study, the following conclusions were drawn:

1. The university personnel are generally in harmony in their attitude toward the importance of institutional factors impacting student retention'attrition.

2. Personnel are aware of the importance of the institutional factors impacting student attrition.

3. The university personnel are generally congruent in their satisfaction level with the university's efforts to address factors impacting student persistence although some differences exist among demographic subgroups.

4. Personnel are aware that the university efforts to address student persistence are not entirely satisfactory and need improvement.

5. There is general congruity among personnel groups concerning the importance of institutional factors impacting student persistence. Employees from a few of the 
divisions, schools, and programs slightly differed in their opinion as to which factors were more important.

6. There is general congruity among the personnel concerning their perception of how satisfactorily addressed are institutional and student factors impacting student persistence. There are slight differences of perception with a few items among administrators, faculty, professional staff, and clerical/technical staff as to which items are satisfactorily addressed by the university.

7. Some significant disparities exist between how personnel perceived the importance of the institutional factors impacting student persistence and how satisfied personnel are with the university's efforts to address the student attrition issue.

8. The Melendez model provided adequate guidance for the development of the survey instrument and interpretation of the results.

\section{Recommendations}

Recommendations for Administrative Practice

The following administrative recommendations are from the statistical findings and from the literature review of the literature:

1. The results of this study point out a challenge to university administrators in that personnel perceived the factors impacting student retention as important, but they are not entirely satisfied which the university's efforts to address the student attrition problem.

2. Since the literature on student attrition reported that a larger percentage of first-year students dropped out during the first 8 weeks, the bulk of student retention 
efforts and resources should pivot around this crucial time.

3. Academic advising was selected as the most important factor impacting student attrition but was perceived as not highly satisfactorily addressed; administrators may consider increasing the quality of this service.

4. Before finalizing any strategic plans on student retention, university officials should identify which retention factors are important to the individual divisions, schools, and programs

5. The entire personnel groups should be approached when attempting to identify retention factors that need to be satisfactorily addressed.

6. University officials should identify what factors or resources are needed to provide quality customer service to the students (Peters, 1987, p. 70; Spanbauer, 1996).

7. After developing an effective student retention plan, administrators can launch an intensive internal public relations campaign to improve the university's image concerning student retention among the personnel and enlist personnel to improve the least satisfactory services.

8. The results of this study can help administrators focus on ways to empower and equip personnel with effective methods of enhancing student persistence and providing quality education to every student, not just those who would naturally persist.

9. The results can help administrators target their resources to the most important factors that will produce the greatest improvement.

10. Administrators ought to identify the best strategy and university factors impacting student satisfaction. 


\section{Recommendations for Further Research}

Based on the review of literature and the findings of this study, the following research recommendations are made:

1. A similar study should be conducted to further refine my instrument by merging similar items and grouping them on the instrument by subfactors. This would simplify the administration of the survey and the analysis of data.

2. Further research should be conducted to examine student retention from the prospective of a transactional relationship of customer/service (student/institution) satisfaction using the Melendez Model of Transactional Satisfaction Toward Students Persistence.

3. Further study is needed to investigate student persistence in relationship to the institution's and the students' efforts toward academic and personal satisfaction comparing both students and university personnel as research subjects.

4. Further study should be conducted to investigate if a student's academic and personal satisfaction within an institution of higher learning has a direct impact on student persistence.

5. A study should be conducted to determine if student attrition is directly or indirectly correlated with personnel believing institutional factors impacting student persistence are important and with personnel not being highly satisfied with the quality of the university's efforts to address student attrition. 
APPENDIX

Reproduced with permission of the copyright owner. Further reproduction prohibited without permission. 
APPENDIX A

LETTERS 
January 29. 1997

Mr. Jose Melendez

$314 \mathrm{~N}$. Blutf Street

Berrien Springs MI $\$ 9103$

Dear Mr. Melendez:

As Assistant Vice Chancellor of Student Affairs and Director of the Freshman Division I hereby grant you administrative authority to conduct the Institutional Student Persistence Survey at This instrument will be administered to the faculty. professional and support staff members during the month of February 1997.

In addition. permission has been given for you to use the research data for your Ph.D. studies at Andrews University. All respondents of the study should be kept anonymous and their individual responses should be held in the strictest confidence.

I look forward to working with you on this very important project.

Sincerely.

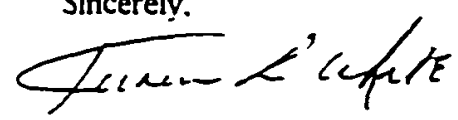

Karen L. White

Assistant Vice-Chancellor Student Affairs

Director Freshman Division 
March 24, 1997

Dear Colleagues:

Attached you will find a survey whose purpose is to identify current programs at which directly impact student persistence. Information gathered in this way will be one source of data available as we develop a coordinated program to improve student success and persistence to completion of clear academic goals

The instrument has been created and the survey is being conducted by Joe Melendez a doctoral student at Andrews University who is a research associate on our campus this year.

On behalf of Assistant Vice Chancellor Karen White and those members of our faculty and staff who are working on this important project. I urge you to take a few minutes and complete this survey. We need your help.

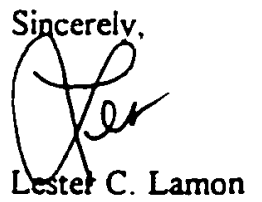

Acting Chancellor 


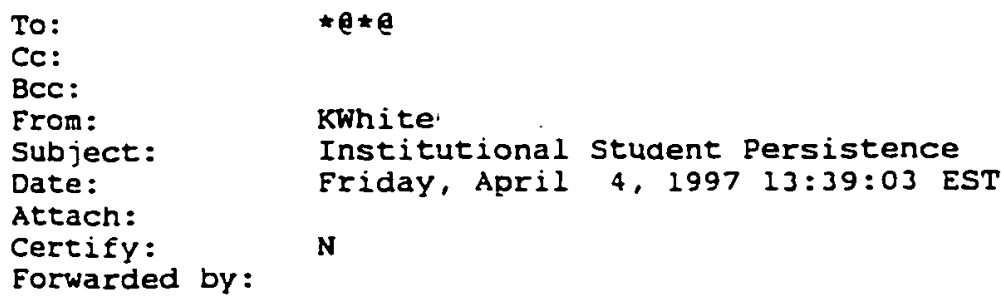

Thank you for completing and returning the IUSB Institutional student Persistence Surrey. If you have not yet completed the survey, we hope you do so soon. Thus far, we have received 102 of the 703 surveys. That's great for the first week! However, 9 percent of the returns have many items not marked in Part I. It is important that Part I is completely filled-out for statistical reasons.

We are getting an exceptional response to Part II. Keep it up. If you are an administrator, faculty, or professional staff and have not received your copy of the yellow Institutional student Persistence Survey form, please call or e-mail Karen White - . or Joe Melendz - Your participation is most important as we try to identify ways to better serve our students.

Thanks.

Karen white 
Mail Codes: I and II

To: All Faculty and Staff

This brief note will serve two purposes: 1) to thank everyone who has turned-in the yellow Institutional Student Persistence Survey and 2) to encourage those who have not yet done so. We have received only 152 of 703 mailed surveys. Arrangements are presently being made to set up focus panel sessions to discuss the surveys.

Please consider that Part I should be completely filled-out to maximize its statistical value. The survey may be returned with only Part I completed. If any item is unclear, contact the following persons for clarification: Karen White kwhite@. or Joe Melendez - , jmelende@.

Mail Codes: I and II

To: All Faculty and Staff

This brief note will serve two purposes: 1) to thank everyone who has turned-in the yellow institutional Student Persistence Survey and 2) to encourage those who have not yet done so. We have received only 152 of 703 mailed surveys. Arrangements are presently being made to set up focus panel sessions to discuss the surveys.

Please consider that Part I should be completely filled-out to maximize its statistical value. The survey may be returned with only Part I completed. If any item is unclear, contact the following persons for clarification: Karen White kwhite@ or Joe Melendez - .jmelende@ 


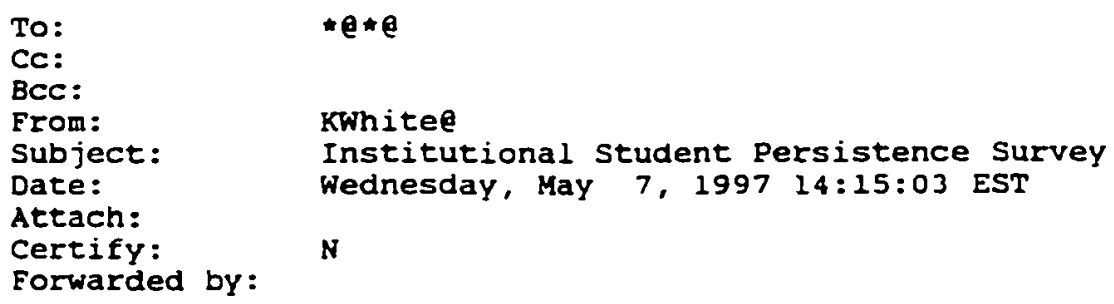

N

FINAL REQUEST FOR THE PERSISTENCE SURVEY:

This is the final request for the return of the completed Institutional student Persistence Surveys. To date, we have received 185 usable surveys. Could you help make it 200?

Again, thank you for your tremendous cooperation. We believe that the results will provide useful insight into the student retention issue. For more information, contact Karen White - or Joe Melendez - 


\section{APPENDIX B}

SURVEY 


\section{SURVEY INSTRUCTIONS}

Though participation in this survey is voluntary, your thoughtful responses are very important. This survey will reflect how you perceive is addressing student attrition/retention issues. No attempts will be made to identify any individual. DO NOT write your name anvwhere on this material! When you are finished, seal the questionnaire in the enclosed red confidential Campus Mail envelope and return via intercampus mail to the Freshman Division. The survey responses will be recorded and computer analyzed by an independent researcher. If you have questions regarding the study, contact Researcher: Joe Melendez at

or Karen White,

IRB approved - 2/4/97

\section{SURVEY INSTRUCTIONS}

Though participation in this survey is voluntary, your thoughtful responses are very important. This survey will reflect how you perceive is addressing student attrition/retention issues. No attempts will be made to identify any individual. DO NOT write your name anywhere on this material! When you are finished, seal the questionnaire in the enclosed red confidential Campus Mail envelope and return via intercampus mail to the Freshman Division. The survey responses will be recorded and computer analyzed by an independent researcher. If you have questions regarding the study, contact Researcher: Joe Melendez at or Karen White.

: [RB approved - 2/4/97.

\section{SUR VEY INSTRUCTIONS}

Though participation in this survey is voluntary, your thoughtful responses are very important. This survey will reflect how you perceive ' is addressing student attrition/retention issues. No attempts will be made to identify any individual. DO NOT write your name anywhere on this material! When you are finished, seal the questionnaire in the enclosed red confidential Campus Mail envelope and return via intercampus mail to the Freshman Division. The survey responses will be recorded and computer analyzed by an independent researcher. If you have questions regarding the study, contact Researcher. Joe Melendez at $\cdot . \cdot . \cdot$ or Karen White, $\cdot$ : $\mathbb{R B}$ approved - 2/4/97. 


\section{INSTITUTIONAL STLDENT PERSISTENCE SURVEY PART I}

The ttems below impact student attrition'persistence. The left side requires you to circle the number indicating how important you feel that particular item is to student retention at The right side requires you to circle a number indicatung how satisfactorily you feel addresses the item as it relates to students remaining in an educational program until completion. Please respond to EVERY itern on both sides of Par 1 .

INSTITLTIONAL ACADEMIC/SOCIAL INFLLENCES ON RETENTION

1. Academic Advising

2. Admissions Services

3. Campus Rules and Regulations

4 Campus Safety and Security Services

5. Career Counseling Services

6. Cashier/Bursar's Services

7 Financial Aid Services

8. Freshman Division Services

9. Library Services

10. Registration Services

11. Transfer Options

12. Academic Support Services

13. Family/Child Care Support Services

14. Flexible Course Scheduling

15. Mentoring Programs

16. Minority Retention Efforts

17. Remedial Course Work Services

18. Social Support Services for Students

19. Studem Internship/Employment

20. Study Skills Assessment/Development

IMPORTANCE

1 - Very Unimportant

2 - Unimportant

3 - Neutral

4 - Important

5 - Very Important

12345

12345

12345

12345

12345

12345

12345

12345

12345

12345

12345

12345

12345

12345

12345

12345

12345

12345

12345

12345
SATISFACTION

1 - Very Unsatisfactory

2 - Unsatisfactory

3 - Neutral

4 - Satisfactory

5 - Very Satisfactory

12345

12345

12345

12345

12345

12345

12345

12345

12345

12345

12345

12345

12345

12345

12345

12345

12345

12345

12345

12345

12345

12345

12345 
STLDENT ACADEMIC'SOCIAL INFLLENCES ON RETE.NTION

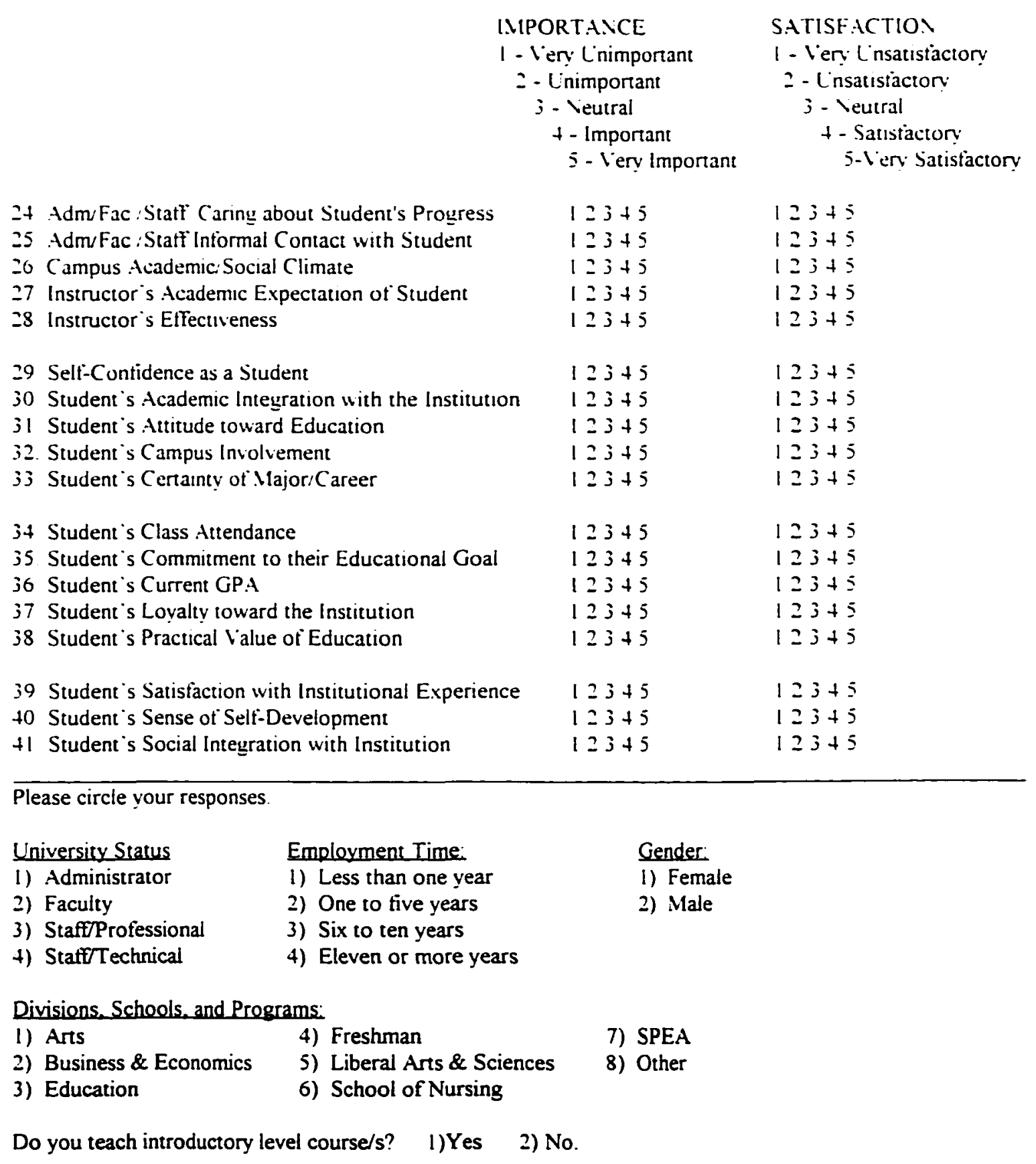


INSTITUTIONAL STUDENT PERSISTENCE SURVEY

PART II

In this section of the survey. please write your response to the question. If you need more space. write your responses on the back. Respectively number each response

I What services are being̣ performed in your department/division to enhance freshman retention '

2. What resources/information/tools are available to you to enhance student persistence?

3. What activities are you involved in to reduce student attrition?

4. What information/activity/program do you believe may significantly enhance student retention?

5. What do you believe will assist you to enhance student retention?

6. What kind of activity would you rather have to obtain information on student persistence: workshop. seminar, individual training or other?

7. (Please respond to this question if you are in an upper division.) How are you assessing/monitoring the upper division students' academic progress?

8. From your perception. what three institutional factors most impact student attrition at IUSB? Rank your responses - number one ( 1 ) being the most significant.

Thank you for participating. Again, retum the questionnaire in the confidential intercampus envelope. 
APPENDIX C

COMPUTER PRINTOUTS 


$$
\begin{aligned}
& = \\
& 3
\end{aligned}
$$

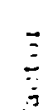




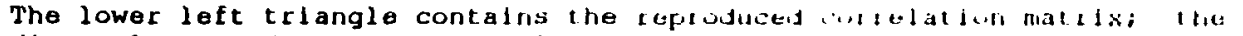

diagonal, reproduced communalitles; and the upper fight il tangle residuals

between the observed correlations and the reprodusid ciltelationis.

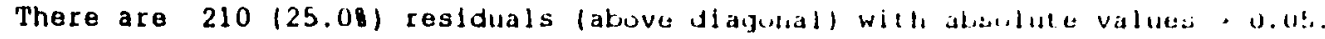

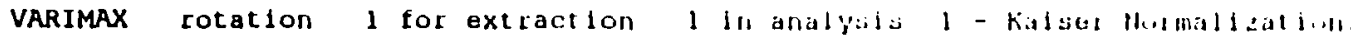
VARIMAX converged in 14 iterations.

Rotated Eactor Matrix:

\begin{tabular}{|c|c|c|c|c|c|c|c|c|}
\hline & Factor 1 & Factor & Eactor & fractor & factor & $f a \cdot 1,1$ & fustu & fas:t,.t \\
\hline I 35ST & .78856 & .23511 & $.09 / 42$ & $.130 j 5$ & $.1008011)$ & צו1, & .114011 & $.11 \mathrm{HA}$ \\
\hline I $31 S T$ & .76871 & .09395 & .13385 & .11706 & .04648 & .1798 & .12501 & - (i) \\
\hline I 34ST & .74396 & .27907 & .13357 & .108 .38 & .1 .8990 & . W6. & .0 .3534 & (1แ,!) \\
\hline I28ST & .70247 & .09952 & .35040 & .01252 & .19061 & $-.11 . \% 1.8$ & .011949 & -.1 .1150 \\
\hline I 29ST & .67211 & .22455 & .12110 & .18154 & .03270 & $\therefore \therefore 1023$ & $\therefore 1845$ & .05184 \\
\hline I $40 S T$ & .62255 & .35985 & -.005.45 & .10559 & .10915 & .197011 & -.11825 & . (unoly! \\
\hline I 27ST & .61506 & .16777 & $.3911 \%$ & .08011 & $.120(10)$ & $-\therefore m, 1$ & -.21300 & $-\ldots 1+91$ \\
\hline I 39ST & .61091 & .24702 & $\therefore 4 / 001$ & .11112 & - onotsol & -.11 .961100 & $.1+1910$ & .191111 \\
\hline I $30 S T$ & .55966 & .25683 & .166 .28 & .50043 & $.0=8(2)$ & .10400 & .0356. & gonds \\
\hline I $38 \mathrm{ST}$ & .52494 & .01487 & -.01889 & .28029 & .10511 & (164) & .411211 & sulog \\
\hline I17IN & .14740 & $.00640^{\circ}$ & .Uמצ' & . ususol & .01293 & $.401 \div 1$ & 1043. & .1140 .4 \\
\hline I 23 IN & .14431 & .65272 & .32451 & .01230 & $.094011)$ & .130 .4 &.$-(187.19$ & .29214 \\
\hline IIBIN & .16797 & .64119 & $.180 \sin$ & .31192 & $.038 \div 4$ &. $\mid 01101$ & .1897 & $-0 ! 301$ \\
\hline I16IN & .16203 & .63063 & .01353 & .28000 & .18594 & $-.10,4500$ & .12119 & .01549 \\
\hline I15IN & .19134 & .62593 & .04 .308 & .34261 & .123100 & .11113 & .019937 & -1.91 .3 \\
\hline I $201 \mathrm{~N}$ & .28627 & .59625 & $20 \div 415$ & .04804 & $.035 \%$ & . तilut & -.0700 .4 & -.114002 \\
\hline I 13 IN & .25902 & .59511 & .22932 & .12004 & 1.247 & -1900 & -.005 .11 & $-155,9.3$ \\
\hline I 14 IN & .43928 & .53137 & .13091 & .05510 & .31292 & $-.61 \ldots \ldots$ & 24194 & .11!0111 \\
\hline I 22 IN & .27981 & .50088 & .90012 & .11148 & $.058 \mid 7$ & $\ldots 11111$ & -.12610 & . Ins5u \\
\hline I 12 IN & .25729 & .48906 & .30111 & .11901 & $.023 \mathrm{~s}$ & .110.11 & (i) ubs & -20.118 \\
\hline I $24 \mathrm{ST}$ & .46085 & .46983 & $\therefore 844$ & .30010 & -.111011 & .11) +ut & .119941 & .24111 \\
\hline I BIN & .13501 & .20119 & .00113 & . $1590 .$. & $.01 .3+1113$ & $\ldots 21 ; n d$ & $.110 \times 44$ & 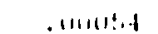 \\
\hline I 2 IN & .27634 & .11011 & .03804 & $-115 \%$ & $.1 \% 1.2$ & - .6in!s. & (1) told & .103 .910 \\
\hline IIIN & .52305 & .16599 & s971) & 119.90 & , & -1141 & 114 & .uttest. \\
\hline I IOIN & .15503 & .18527 & $.501 \therefore 1$ & .10050 & Ju7nd & .1 lows & . URisto & . $11 . .1518$ \\
\hline I $6 \mathrm{IN}$ & -.07461 & .10305 & .5635 .1 & - (1) 201 & .40210 & i. How & anglt & .10601013 \\
\hline I 9 IN & .24371 & .03059 & .53441 & .13975 & $.40 \% 30$ & $-.116,1113\}$ & $.130 \%$ & $-.111019 \mathrm{~s}$ \\
\hline I $5 \mathrm{IN}$ & .15399 & .30368 & $.490 / 5$ & .11014 & .0 .1799 & $.1+41.3$ & ivs: & -.31709 \\
\hline I IIN & .39762 & .31798 & .39912 & .17943 & .04167 & -.116 .61 & atlos & .141104 \\
\hline I $41 \mathrm{ST}$ & .20406 & .34098 & $.0 / 0+10$ & .1 .5465 & .11919.4 &., $111 . \therefore$ & -1.111 & . $161, \therefore 1$ \\
\hline
\end{tabular}




\begin{tabular}{|c|c|c|c|c|c|c|c|}
\hline I $37 \mathrm{ST}$ & .22471 & -.02601 & -.019 .909 & .04971 & $\therefore 2810$ & $\ldots 111$ & [14s \\
\hline I $32 \mathrm{ST}$ & .17603 & .24315 & .03470 & .60581 & .0010 .44 & . 1,11, & .01 .28010 \\
\hline $126 \mathrm{ST}$ & .29782 & .35584 & .28001 & $.0+131$ & $-.118+84$ & $-.111,11$ & . (112.1.1 \\
\hline
\end{tabular}

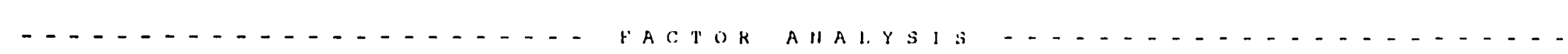

\begin{tabular}{|c|c|c|c|c|c|c|c|c|}
\hline & Factor & Factor & Factut & Factur & Fiactos bs & $f=1.1,1$ & facter & $f a: 1, \ldots$ \\
\hline I 25ST & .29021 & .28154 & .2118. & . 40032 & -11.3 .1 & $-\ldots 1,111$ & & מים \\
\hline $\begin{array}{l}\text { I } 3 \text { IN } \\
\text { I } 4 \text { IN }\end{array}$ & $\begin{array}{l}.12732 \\
.14151\end{array}$ & $\begin{array}{l}.18182 \\
.10903\end{array}$ & $\begin{array}{l}120.14 \\
.24111\end{array}$ & $\begin{array}{r}-.111000 \\
.12305\end{array}$ & $\begin{array}{l}.711 \text { e. } \\
.75135\end{array}$ & $\begin{array}{r}-.141 \ldots 0 \\
\ldots .2410 .8\end{array}$ & $\begin{array}{r}-.165+11 \\
.000500\end{array}$ & $\begin{array}{r}.136110 \\
-.12079\end{array}$ \\
\hline $\begin{array}{l}\text { I 33ST } \\
\text { I } 21 \mathrm{IN}\end{array}$ & $\begin{array}{l}.30969 \\
.00324\end{array}$ & $\begin{array}{l}.08004 \\
.38233\end{array}$ & $\begin{array}{l}.11191 \\
.31011\end{array}$ & $\begin{array}{l}.25141 \\
.28124\end{array}$ & $\begin{array}{l}.10015 \\
.0536 \%\end{array}$ & $\begin{array}{l}.53014 \\
.5 .52406\end{array}$ & $\begin{array}{l}.11910 \\
.044001\end{array}$ & $\begin{array}{r}.1 \leq 481 \\
-0.5081\end{array}$ \\
\hline $\begin{array}{l}\text { I11 IN } \\
\text { I19IN }\end{array}$ & $\begin{array}{l}.11366 \\
.30917\end{array}$ & $\begin{array}{l}.07721 \\
.36312\end{array}$ & $\begin{array}{l}.04291 \\
.05537\end{array}$ & $\begin{array}{r}-.051041 \\
.04014\end{array}$ & $\begin{array}{r}.01961 \\
-.05205\end{array}$ & 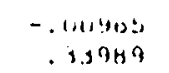 & $\begin{array}{l}11.81 .8 \\
.97707\end{array}$ & $\begin{array}{l}-.1164 .8 \\
-.07362\end{array}$ \\
\hline I $36 \mathrm{ST}$ & .35276 & .08129 & $.211 \% 0$ & .231002 & $\ldots 44: 11$ & s.:. & $-.11<20$ & . soust. \\
\hline
\end{tabular}

Factor Transformat ion Matrix:

\begin{tabular}{|c|c|c|c|c|c|c|c|c|c|}
\hline & & Factor & Factor & factos & factor & ractur & fat $t \ldots l$ & ract,ol & ractor \\
\hline Factor & 1 & .588996 & .52381 & Alsous & .34037 & . 1801 & .1019 & 1.0011 & .111 .21 \\
\hline Factor & 2 & -.18710 & -.17460 & .01390 & -.48356 & .55561 & - . (11).:11:? & .10703 & - \\
\hline Factor & 3 & -.70579 & .64435 & . orouges & .10300 & - (1):1:1 & $\therefore 1509$ & -.0 .27 .00 & -.15701 \\
\hline Factor & 4 & -.18996 & -.34610 & -.109 .11 & .52990 & .51001 .1 & .41 .46 & -.117 uts 1 & $\therefore 5+15$ \\
\hline Factor & 5 & -.19844 & -.36888 & .99817 & $.472 \% ?$ & $-.11+11$. & $-.11 / 114$ & .15,1) & $-\because \ldots, 0$ \\
\hline Factor & 6 & .11812 & -.00192 & $-30 t 501$ & $-1040:$ & III. W.:. & 15. 1, & .1109011 & $-.919 .4 \mathrm{~s}$ \\
\hline Factor & 7 & -.07587 & .00937 & .09945 & $-\therefore 0845$ & $-3+110$. & (3) 1111 & .3 .199 & .1110 .1 \\
\hline Factor & 8 & -.15749 & .15496 & -.11161 & $.1791 \mathrm{~A}$ & . & $-(1)+11 . \therefore$ & fous.: I & (1918) \\
\hline
\end{tabular}


FACTOR ANALYSIS

Measures of Sampling Adequasy (MSA) are printed on the diagonal.

1-tailed Significance of Correlation Matrix:

- Is printed for diagonal elements.

Extraction 1 for analysis 1, Principal Components Analysis (PC)

Hi-Res Chart 2: Factor scree plot

PC extracted 8 factors.

Factor Matrix:

\begin{tabular}{|c|c|c|c|c|c|c|c|}
\hline Factor 1 & Factor 2 & Factúl 9 & factor 4 & factor & Far:t... & fiactot & Fartot \\
\hline .67307 & -.19835 & -.03204 & -.01724 & -.18 .29 & צ & . vdouou & $.18139 .:$ \\
\hline .65453 & -.09159 & -.31257 & -.00113 & -.15021 & -.12840 & -.15580 & -.18720 \\
\hline .64968 & -.23733 & -.069 .9 & -.25588 & -.04410 & 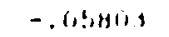 & .10789 & $-\therefore 1.141$ \\
\hline .64199 & -.24616 & .0470 .3 & -.11750 & .11199 & $-\therefore \cos 44$ & -.11285 & -.07981 \\
\hline .62062 & .17835 & -.23819 & .01934 & -.146 .31 & $.11: 114$ & .24035 & .01806 \\
\hline .61960 & .16890 & -.18019 & -.04039 & -.37971 & .61 .26 .1 & . & $.117: 9$ \\
\hline .57978 & .24021 & -.097500 & .00333 & .24394 & $.1091 \mathrm{H}$ & -.12795 & -19300 \\
\hline $.57 \theta 13$ & -.17350 & .13375 & -.30239 & .03323 & $-\ldots 5 \times 9$ & 19452 & -.00487 \\
\hline .57028 & .10098 & -.21207 & .01082 & $-.02+2 B$ & $.15 \Delta B 7$ & -.40163 & $-.1+190$ \\
\hline .53839 & .03829 & -.21079 & -.10297 & $-.05+10 .:$ & $-\ldots \ldots+111$ & $-.104+1$ & $-.30 .8+1$ \\
\hline .52806 & -.38549 & .247 .97 & -.14849 & $-.2141 !$ & . $1 \therefore \cup B: 2$ & -.18384 & .12491 \\
\hline .51775 & -.40156 & -.04530 & -.23499 & -.01475 & . (1015.4t) & $-.25 .32 \mathrm{~B}$ & . 3011 ! \\
\hline .50874 & -.38027 & $-.104 \%$ & .32508 & .26919 & .10010 & .04456 & .0041. \\
\hline .50586 & -.05405 & .45913 & .09911 & -.3053 .1 & . $(105) 7$ & .29155 & $22+44$ \\
\hline .48759 & .22439 & -.15091 & .19700 & -.35870 &.- .91100 & .093215 & .1000. \\
\hline .48078 & -.35505 & .0 .5258 & .47573 & .154 .11 & . A.181 & .00510 & $.00 \% 44$ \\
\hline .47669 & -.16863 & .30105 & -.20067 & $.1018 !$ & $-\ldots 8 \div 010$ & -.112496 & -.13810 \\
\hline .47375 & .08031 & .08592 & .17007 & .20041 & נון & -.05202 & $.4+312$ \\
\hline .46810 & .08370 & -.14165 & $-.05,407$ & -.10280 & . ingl &.$\because 58.17$ & -.25 .114 \\
\hline .45614 & .07341 & $-.0,90: 09$ & .40959 & $-\ldots 10.47$ & . & $.(11) ! n)$ & $-.2(19) 10$ \\
\hline .44006 & -.00847 & -.20894 & .0 .0924 & -11091 & .111101 & -.301 .34 & . \\
\hline .44029 & -.10717 & -.22811 & $21+13$ & .33391 & $-\operatorname{surdu}$ & $-\ldots 20.4$ & $-.11 \ldots 1$. \\
\hline .42817 & .07256 & $-.0044: 2$ & -.13909 & .01891 & $\therefore 4034$ & $-\ldots 40+1$ & -16915 \\
\hline .42460 & .36846 & .0 .31978 & .06 .303 & $-.11101 !$ & . (16)1, & - & $-.0961: 1$ \\
\hline .41235 & .11093 & $-.100 / 13$ & .30495 & .10831 & $-. .110 \div 1$ & ... & - . s..uL \\
\hline .40159 & -.32170 & -.289 .25 & -.19495 & .20 .395 & . 1. & $.14 \div 0 ! 5$ & -.112114 \\
\hline .39833 & .23741 & .18193 & -.17133 & .17914 & $-\ldots 1 / 10$. & בSמציolo. & .00149 \\
\hline .37463 & .20973 & .00819 & -.12748 & $.33: 232$ & $-1: 011$ & .11499 & . \\
\hline
\end{tabular}




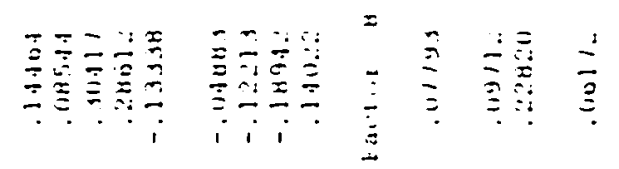

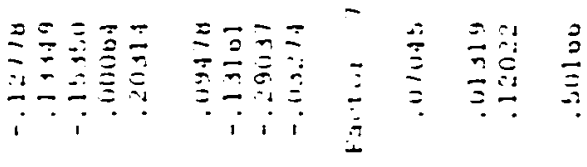

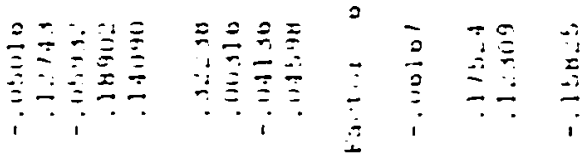

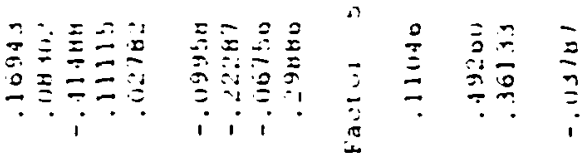

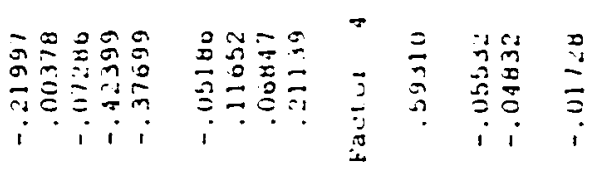

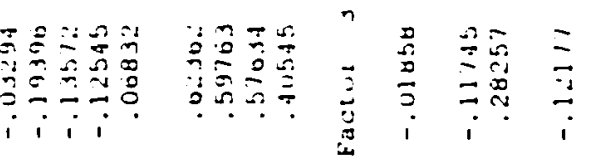

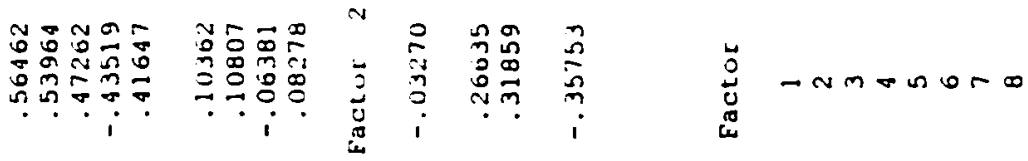

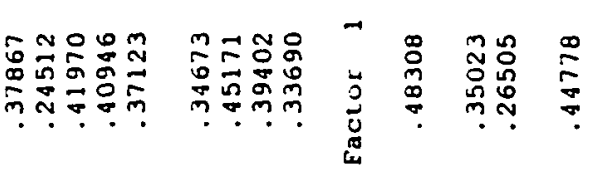

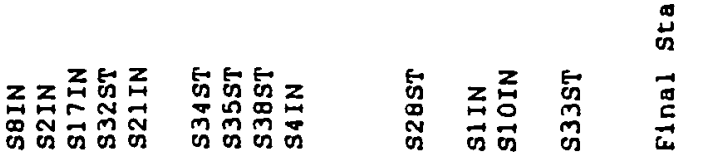
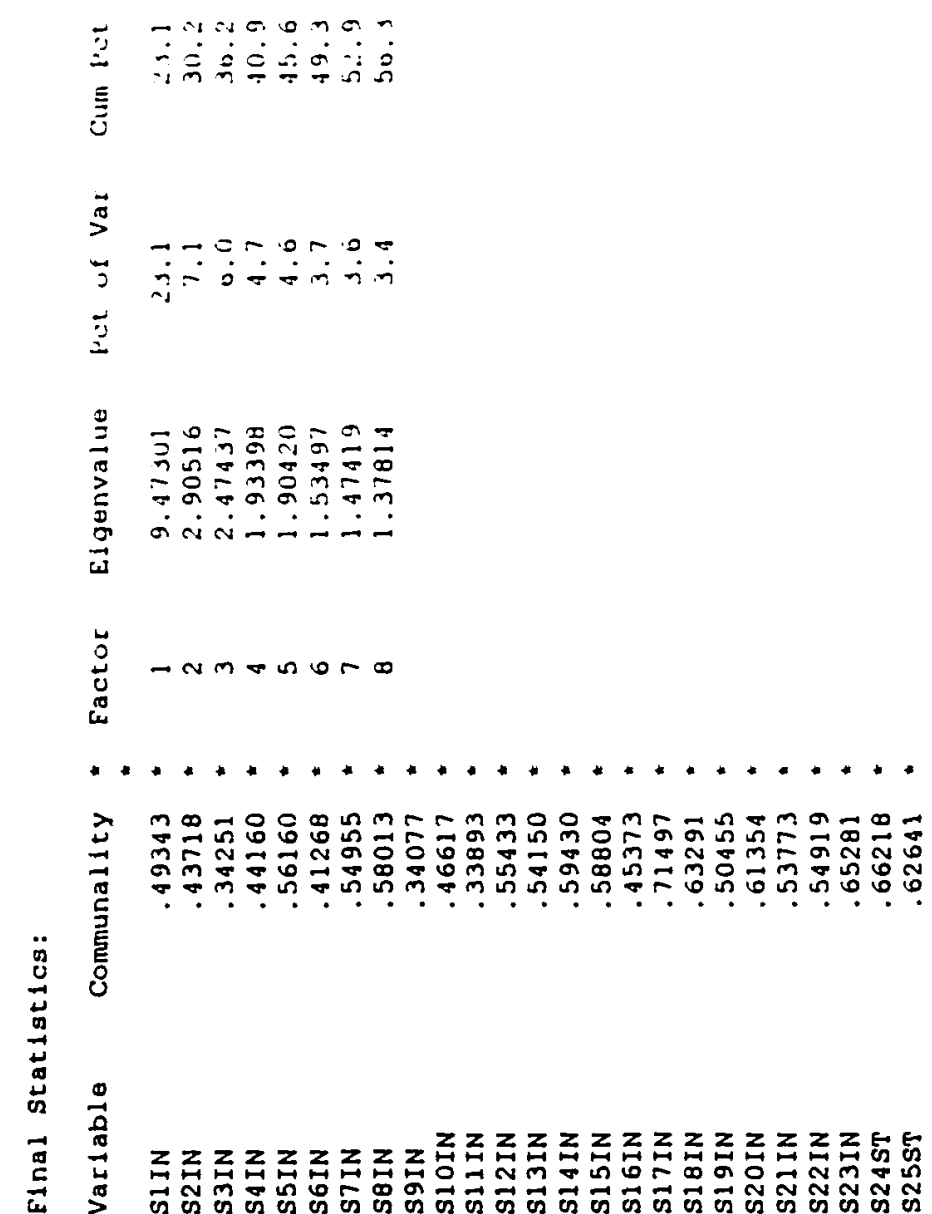


S33ST
S35ST
S34ST
S3EST
S36ST
S4IN
SBIN
S1IN
S1OIN
S2IN
S9IN
S2IIN
S7IN
SIIN
S24ST
S2BST
S25ST
S5IN
S15IN
S16IN
S2IIN
S11IN
S13IN
S14IN

\begin{tabular}{|c|c|}
\hline .37710 & 2020 \\
\hline & .17404 \\
\hline .10109 & -.01213 \\
\hline .02178 & -.03489 \\
\hline .21695 & .40119 \\
\hline .02595 & -.05390 \\
\hline-.02166 & .28528 \\
\hline .12102 & -.06517 \\
\hline .04937 & -.01592 \\
\hline-.14028 & .28697 \\
\hline .06639 & .05045 \\
\hline .05049 & .14198 \\
\hline .18962 & .31751 \\
\hline-.10853 & .24164 \\
\hline .20036 & - - outs \\
\hline .05737 & .24194 \\
\hline .35882 & -.04549 \\
\hline .08122 & .06656 \\
\hline .17147 & .19941 \\
\hline .26947 & .37344 \\
\hline .03947 & \\
\hline .21842 & .04259 \\
\hline $\begin{array}{r}.10054 \\
-07063\end{array}$ & .12591 \\
\hline
\end{tabular}

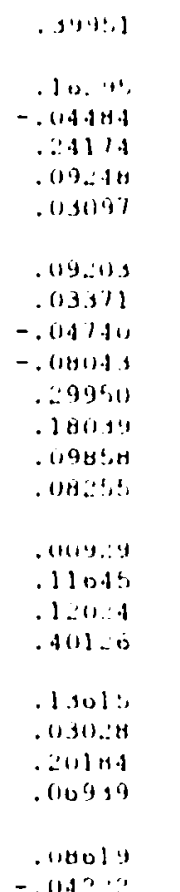

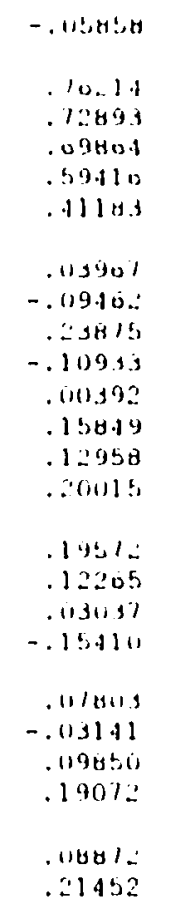

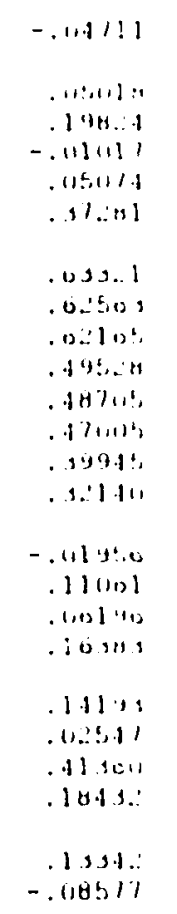

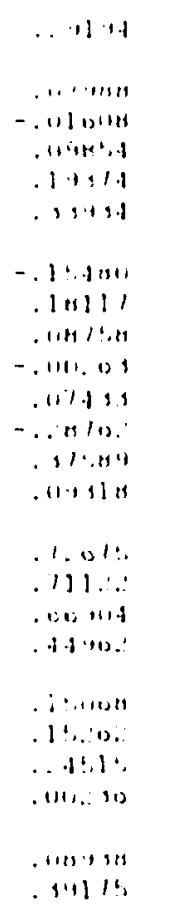

\begin{tabular}{|c|c|}
\hline$-.111 \therefore$ &.$\therefore 111$ \\
\hline $.1,1 . .1$ & מומיו \\
\hline$-(1.1914$ & . \\
\hline . $9311 .:$ & -.149301 \\
\hline$-\ldots 941 .: 1$ & .13 .2112 \\
\hline - . $1111 \cdot 641 .:$ & $-.11+14 n$ \\
\hline$\therefore 4,13 H$ & $-.11 . .113$ \\
\hline $.10 \% 119$ & .109000 \\
\hline$-1611, \ldots . .2$ & $-.111, \therefore 1.4$ \\
\hline .111111 & $\therefore 4 / 11$ \\
\hline .6119 .27 & .1114 .111 \\
\hline ."150... & $.941 \% 1$ \\
\hline.$-(104,411)$ & $-\ldots+\ldots 1$ \\
\hline$\therefore 0141$ &. .1244 \\
\hline $.1 .+18.21$ & $.1 \ldots t, 1 \mathrm{~s}$ \\
\hline r & 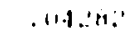 \\
\hline | 1116,1009 & 4..1806 \\
\hline $.314,1=$ & -...urn! \\
\hline $.6 \div 1104$ & $.19 \therefore \ldots 1$ \\
\hline .459913 & - - \\
\hline.$+100 ! 2$ & $\therefore 0(1,1)$ \\
\hline .12 .8001 & .141 .4 \\
\hline .1 .15 .4 & . coul! 1.1 \\
\hline
\end{tabular}

Factor Transformation Matrix:

\begin{tabular}{lrrr} 
& & Factor 1 & \multicolumn{1}{c}{ Factus 2} \\
Factor 1 & .39289 & .41080 \\
Factor 2 & -.59610 & .33718 \\
Eactor 3 & -.09246 & -.23514 \\
Factor 4 & -.48319 & .11079 \\
Factor 5 & .03579 & -.63472 \\
Factor 6 & .26636 & -.27490 \\
Factor 7 & -.02771 & .04536 \\
Factor 8 & .41867 & .40530
\end{tabular}

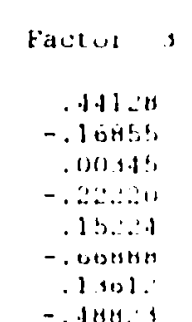

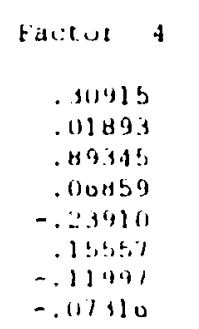

faxtert:

fis:1:1,

Fis:lw *

\begin{tabular}{|c|c|}
\hline 3...(11.813 & . \\
\hline .01!11 & $-\ldots(1+1)$ \\
\hline . & - . wettiot \\
\hline$-.19 \div 11$ & .111 \\
\hline .0191 .1 & $.31,1,1$ \\
\hline $.10 H+1$ &.$(1.4 \cdot 1,19$ \\
\hline .11110 & .10n and \\
\hline
\end{tabular}

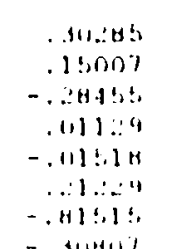

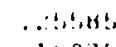

.10975
-.048
$-.1699+1$

$-.11 \times 9+1$

$-.19+119$

$\therefore 1109$

- . I 1 111 
REFERENCE LIST

Reproduced with permission of the copyright owner. Further reproduction prohibited without permission. 


\section{REFERENCE LIST}

Astin. A. W. (1975). Preventing students from dropping out: A longitudinal multiinstitutional study of college dropouts. San Francisco: Jossey-Bass.

Astin, A. W. (1984). Student involvement: A developmental theory for higher education. Journal of College Student Personnel, 25, 297-308.

Astin, A. W. (1985). Achieving educational excellence: A critical assessment of priorities and practices in higher education. San Francisco: Jossey-Bass.

Astin, A. W. (1993). What matters in college? Four critical years revisited. San Francisco: Jossey-Bass.

Astin, A. W., \& Others. (1980). The impact of student financial aid programs on student college choice. Washington, DC: Office of Planning, Washington Division of Postsecondary Planning.

Bailey, R. D. N. (1993). A revisitation of the WISC-R factor structure with adequate sample size, systematic control of both $I Q$ and age ranges, and the use of procedures to limit overfactorization. Unpublished doctoral dissertation, Andrews University, Berrien Springs.

Balian, E. S. (1988). How to design, analyze, and write doctoral or master's research. Lanham, MD: University Press of America.

Bangura, A. K. (1992). The limitations of survey research methods in assessing the problem of minority student retention in higher education. San Francisco: Mellen Research University Press.

Beal, P. E., \& Noel, L. (1980). What works in student retention. Iowa City, IA: American College Testing Program and the National Center for Higher Education Management Systems.

Bean, J. P. (1980). Dropouts and turnover: The synthesis and test of a causal model of student attrition. Besearch in Higher Education. 12, 155-187. 
Bean, J. P. (1982a). Conceptual models of student attrition: How theory can help the institutional researcher. In E. T. Pascarella (Ed.), Studying student attrition: New directions for institutional research (pp. 17-32). San Francisco: Jossey-Bass.

Bean, J. P. (1982b, March). The interaction effects of GPA on other determinants of student attrition in a homogeneous population. Paper presented at the annual meeting of the American Educational Research Association, New York.

Bean, J. P. (1983). The application of a model of turnover in work organizations to the student attrition process. Review of Higher Education, 6, 129-148

Bean, J. P. (1985). Interaction effects based on class level in an explanatory model of college student dropout syndrome. American Educational Research Journal, 22, 35-64.

Bean, J. P., \& Metzner, B. S. (1985). A conceptual model of non-traditional student attrition. Review of Educational Research. 55 (4), 485-540.

Bentler, P. M., \& Speckart, G. (1979). Models of attitude-behavior relations. Psychological Review, 86(452), 464.

Berry, M. D. (1993). Perceptions of educational administration professors about factors which affect doctoral attrition (Doctoral dissertation, Mexico State University, 1993). Dissertation Abstracts International, 54(08), 2810.

Biddle, B., \& Thomas, E. J. (Eds.). (1966). Role theory Concepts and research. New York: Wiley.

Boyle, (1988). A naturalistic examination of influential variables, especially faculty mentoring and modeling, affecting university student attrition (Tinto) (Doctoral dissertation, Brigham Young University, 1988). Dissertation Abstracts International, 50 (01), 82 .

Butler, E. R., \& Markley, H. D. (1993, March). Developmental characteristics of nontraditional aged students. Paper presented at the annual meeting of the American College Professional Association, Kansas City, MO.

Cabrera, A. F. (1992). The convergence between two theories of college persistence. Joumal of Higher Education 63(2), 143-164.

Cantrell, B. J. (1986). Proposal of the Alabama task force on retention: An appraisal (Doctoral dissertation, Alabama University, 1986). Dissertation Abstracts International, 48(03), 546. 
Chickering, A. W. (1974). Commuting versus resident students. San Francisco: Jossey-Bass.

Collis, J. (1991). Correlates of behaviors of "pre-business" students denied admission to the school of business in a research university. Unpublished doctoral dissertation, University of Connecticut.

Coplen, M. (1994, July). Student success and development at Hutchinson Community College: Future plans. Paper presented at the Annual International Conference of the League for Innovation in the Community College and the Community College Leadership Program, San Diego, CA.

DeVaugh, E. L. (1995). Effects of academic support and student services on freshmen in community colleges (Doctoral dissertation, Connecticut University, 1995). Dissertation Abstracts International, 57(02), 561.

Durkheim, E. (1961). Suicide (J. A. Spaulding \& G. Simpson, Trans.). Glencoe: The Free Press. (Original work published 1897.)

Festinger, L. (1962). A theory of cognitive dissonance. Stanford: Stanford University Press.

Fishbein, M., \& Ajzen, I. (1975). Belief, attitude intention, and behavior: An introduction to theory and research. Reading, MA: Addison-Wesley.

Friedlander, J., \& MacDougall, P. (1991). Achieving student success through student involvement. Community College Review, 20(2), 20-28

Gable, R. K., \& Wolf, M. B. (1993). Instrument development in the affective domain. Boston: Klwer Academic.

Hinkle, D.E., Wiersma, W., \& Jurs, S. G. (1994). Applied statistics for the behavioral sciences ( 3 rd ed.). Boston: Houghton Miffin Company.

Hossler, D., Bean, J. P., \& Associates. (1990). The strategic management of college enrollments. San Francisco: Jossey-Bass.

Jose, J. R. (1978). Some plain talk on retention by a college dean. In L. Noel (Ed.), Reducing the dropout rate (pp. 57-63). San Francisco: Jossey-Bass.

Joseph, L. K. (1995). Institutional persistence of first-generation college students: A test of Tinto model attrition, retention (Doctoral dissertation, West Virginia University, 1995). Dissertation Abstracts International, 57(06), 2384. 
Keller, M. J., \& McKeown, M. P. (1984, March). Factors contributing to postsecondary enrollment decisions of Maryland national merit scholarship semifinalists. Paper presented at annual meeting of the Association for the Study of Higher Education, Chicago.

Kerlinger, F. (1973). Foundations of behavioral research (2nd ed.). New York: Holt, Rinehart \& Winston.

Klimovich, D. E. (1994). Effect of academic support services on retention of college freshmen: A study of persisters and nonpersisters (Doctoral dissertation, Fordham University, 1994). Dissertation Abstracts International. 55(11), 3426.

Lagowski, J. J. (1973). Foundations of behavioral research (2nd ed.). New York: Holt, Rinehart \& Winston.

Lagowski, J. J. (1992). Faculty attitudes and student retention. Journal of Chemical Education. 69 (3), 173.

Lall, B.M., \& Lall, G. R. (1994). New dynamic leadership. Berrien Springs, MI: Geetanjali Publishers.

Lenning, O. T., Beal, P. E., \& Sauer, K. (1980). Retention and attrition: Evidence fer action and research. Boulder, CO: National Center for Higher Education Management Systems.

Levitz, R. S., \& Noel, L. (1980). Attracting and retaining adult leamers--summary report of a nationwide survey. Iowa City, IA: American College Testing Program. Group.

Lomax, R.G. (1992). Statiscal concepts. White Plains, NY: Longman Publishing

Matthew, C.L. (1993). Teacher preferred student behavior and persistence into the second year of college (Doctoral dissertation, Columbia University, 1993). Dissertation Abstracts International. 57(02), 2736.

McJamerson, E. M. (1991). Undergraduate academic major \& minority student persistence: Individual choices, national consequences. Equity \& Excellence, 25(2), 35-48.

McMillan, J., \& Schumacher, S. (1993). Research in education: A conceptual introduction (3rd ed.). New York: Harper Collins College.

Nanus, B. (1992). Visionary leadership. San Francisco: Jossey-Bass. 
Napoli, A.R. (1996). Psychosocial factors related to retention and early departure of two-year community college students (Doctoral dissertation, New York University, 1996). Dissertation Abstracts International, 57(06), 4093.

Nehila, R. S. (1996). Attrition at a private, urban university: A longitudinal cohort study, retention (Doctoral dissertation, Boston University, 1996). Dissertation Abstracts International. 56(12), 4676.

Noel, L. (1978). Reducing the dropout rate. San Francisco: Jossey-Bass.

Noel, L., \& Levitz, R. (Eds.). (1996). A compendium of successful innovative retention programs and practices. Iowa City, IA: USA Group Noel-Levitz.

Noel, L., Levitz, R., Saluri, D., \& Associates (1985). Increasing student retention: Effective programs and practices for reducing the dropout rate. San Francisco: JosseyBass.

Norusis, M. (1990). SPSS introductory statistic student guide. Chicago, IL: SPSS

Parker, H. L. (1995). How do institutional attitudes of community colleges faculty and administrators affect and influence economically disadvantaged minority students? (Doctoral dissertation, North Carolina State University, 1995). Dissertation Abstracts International. 56(07), 2540.

Pascarella, E. T. (1980). Student-faculty informal contact and college outcomes. Review of Educational Research. 50(4), 545-595.

Pascarella, E. T. (Ed.). (1982a). Studying student attrition: New directions for institutional research. San Francisco: Jossey-Bass.

Pascarella, E. T. (1982b). Validation of a theoretical model of college dropouts (NIE-G-81 0057). Washington, DC: National Institute of Education. (ERIC Document Reproduction Service No. ED 221 130)

Pascarella, E. T., \& Terenzini, P.T. (1980). Predicting freshman persistence and voluntary dropout decisions from a theorical model. Joumal of Higher Education, 51(1), 60-75.

Pascarella, E. T., \& Terenzini, P. T. (1983). A path analytic validation of Tinto's model. Loumal of Educational Psychology . 75, 215-226.

Pascarella, E. T., \& Terenzini, P. T. (1983). How college affects students: Findines and insights from twenty years of research. San Francisco: Jossey-Bass. 
Perone, L. S. (1994). The persistence of first-year college students at the two-year college level (Doctoral dissertation, Hofstra University, 1994). Dissertation Abstracts International 55(04), 880 .

Pervin, L. A., Reik, L. E., \& Dalrymple, W. (Eds.). (1966). The dropout and the utilization of talent Princeton: Princeton University.

Peters, T. (1987). Thriving on chaos. New York: Alfred A. Knopf.

Peterson, S. L. (1992). The relationship between career decision-making selfefficacy and dimensions of institutional integration among underprepared college students (Doctoral dissertation, Minnesota University, 1992). Dissertation Abstracts International. $\underline{53}(10), 3446$.

Pietropaolo, P. A. (1994). The effects of an academic intervention on persistence of science/technology majors at a community college (Doctoral dissertation, Syracuse University, 1994). Dissertation Abstracts Intemational. 56(03), 787.

Price, J. L. (1977). The study of tumover. Ann Arbor, MI: Reed Elsevier.

Price, J. L., \& Mueller, C. W. (1981). A causal model of turnover for nurses. Academy of Management Joumal_ 24, 543-565.

Rivero Y Hornos, C. M. (1993). The relationship of selected institutional factors to retention at a state college (Doctoral dissertation, Vanderbilt University, 1995). Dissertation Abstracts International.53(12), 4229.

Rootman, I. (1972). Voluntary withdrawal from a total adult socializing organization: A model. Sociology of Education. 45(3), 258-270.

Roueche, J., \& Baker, G. (1987). Access and excellence. Washington, DC: The Community College Press.

Schein, E. H. (1985). Organizational culture and leadership: A dynamic view. San Francisco: Jossey-Bass.

Spady, W. (1970). Dropouts from higher education: An interdisciplinary review and synthesis. Interchange, $1,64-85$.

Spanbauer, S. J. (1996). Reengineering education with quality. Indianapolis: USA Group Research Institute. 
Stiefelmeyer, L. M. (1993). Perception of retention efforts in practice among Alabama's 2-year colleges (Doctoral dissertation, Alabama University, 1993). Dissertation Abstracts International. 55(02), 209.

Stodt, M. M., \& Klepper, W. M. (1987). Increasing retention: Academic and student affairs administrators in partnership. San Francisco: Jossey-Bass.

Summerskill, J. (1961). Dropouts from college. In N. Sanford (Ed.), The American college (pp. 627-657). New York: John Wiley and Sons.

Tabachnick, B. G., \& Fidell, L.S. (1996). Using multivariate statistics (3rd ed.). New York: Harper Collins.

Terenzini, P. T. (1982). Designing attrition studies. In E. T. Pascarella (Ed.), Studying student attrition. San Francisco: Jossey-Bass.

Terenzini, P.T., Lorang, W. G., \& Pascarella, E. T., (1981). Predicting freshman persistence and voluntary dropout decisions: A replication. Research in Higher Education. 15(2), 109-127.

Thiede, W. S. (1994). Developmental change in freshman students: Validating Chickering's theory of student development. Paper presented at the annual meeting of the Association for the Study of Higher Education, Tucson, AZ.

Tinto, V. (1975). Dropout from higher education: A theoretical synthesis of recent research. Review of Educational Research. 45(1), 89-125.

Tinto, V. (1987). Leaving college: Rethinking the causes and cures of student attrition. Chicago: University of Chicago.

Tinto, V. (1993). A lengitudinal study of the coordinated studies program at Seattle Central Community College. Syracuse, NY: National Center for Postsecondary Teaching, Learning, and Assessment, Syracuse University. Press.

Van Gennep, A. (1960). The rites of passage. Chicago: University of Chicago

Wade, M. B. (1995). Factors associated with persistence of adult students attending a community college (retention) (Doctoral dissertation, Texas Tech University, 1995). Dissertation Abstracts Intemational. 56(06), 2091. 
Waggoner, R. G. (1994). Selected institutional persistence predictors of NCAA division I-A football student-athletes (Doctoral dissertation, Northern Colorado University, 1994). Dissertation Abstracts International_54(11), 3958.

White, T. J. (1993). Student services and instructional services in partnership to enhance student persistence (Doctoral dissertation, University of Texas at Austin, 1993). Dissertation Abstracts International, 54(04), 1261.

White, W.F., \& Mosely, D. (1995). Twelve-year pattern of retention and attrition in commuter-type university. Education, 115(3), 400-403.

Wood, D. L. (1994). The influence of perceived social support and social skills on undergraduate retention: An extension of the Tinto (Doctoral dissertation, Vanderbilt University, 1994). Dissertation Abstracts International, 55(11), 5053.

Wyatt, S. K. (1987). The effect of values congruence with peers on institutional integration and peer-group interaction among college freshman attrition (Doctoral dissertation, Vanderbilt University, 1987). Dissertation Abstracts International, 48(10), 2556. 
VITA

Reproduced with permission of the copyright owner. Further reproduction prohibited without permission. 
Jose Melendez

314 N. Bluff Street

Berrien Springs, MI 49103

Date of Birth:

July 7, 1949

Place of Birth:

Santurce, Puerto Rico

Schools and Degrees:

Andrews University

Rowan University

Ph.D. Educational Administration

1997

Walla Walla College

M.A. Corporate Public Relations

1989

B.A. Theology

1973

Bronx Community College

Pre-engineering

1970

Aviation $\mathrm{H}$. S

Diploma

1968

Professional Experiences:

1997 Institutional Researcher, Indiana University, South Bend, IN

1995-1996 Research Assistantship, Andrews University, MI

1981-1994 Clergy-Ordination 1986, Allegheny East SDA Conference, Pine Forge, PA

1978-1980 Director, Early Childhood Center, Wilmington, DE

1973-1977 Principal/Teacher SDA Junior Academies, Chesapeake SDA Conference, Columbia, MD/Texaco SDA Conference, Amarillo, TX

Publication:

Lall, B. M., Davis, H. F., Gaban, B. T., \& Melendez, J. (Eds.) (1996). A Primer on Public Relations for All Institutions, Especially Financial. Manuscript submitted for publication.

Melendez, J. (1989). Handbook on How to Become a More Dynamic LayPreacher. Bridgeton, NJ.

Honor Society:

1995

\author{
Member, Phi Delta Kappa
}



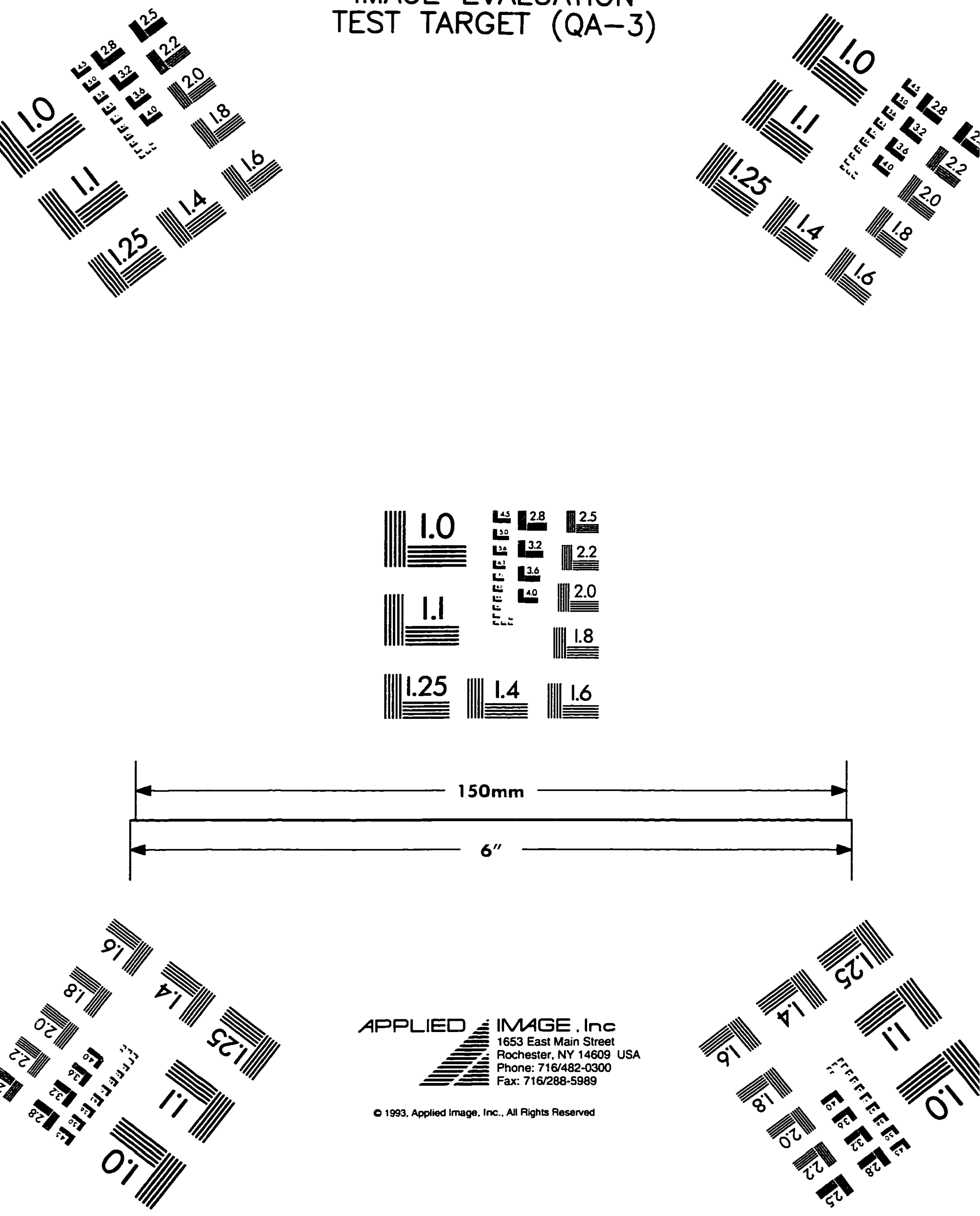